New-onset diabetes after renal transplantation

Diagnosis, incidence, and long-term effect on patient survival

Tone Gretland Valderhaug

Institute of Clinical Medicine

University of Oslo

2012 


\section{(C) Tone Gretland Valderhaug, 2012}

\section{Series of dissertations submitted to the}

Faculty of Medicine, University of Oslo No. 1327

\section{ISBN 978-82-8264-386-3}

All rights reserved. No part of this publication may be reproduced or transmitted, in any form or by any means, without permission.

Cover: Inger Sandved Anfinsen.

Printed in Norway: AIT Oslo AS.

Produced in co-operation with Unipub.

The thesis is produced by Unipub merely in connection with the thesis defence. Kindly direct all inquiries regarding the thesis to the copyright holder or the unit which grants the doctorate. 



\section{TABLE OF CONTENTS}

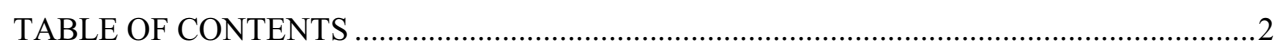

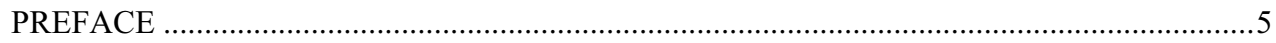

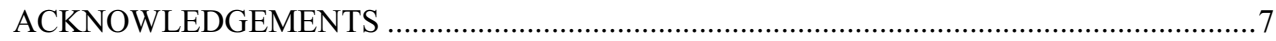

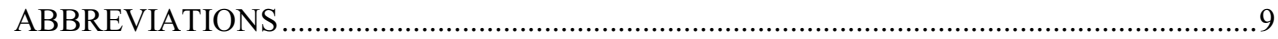

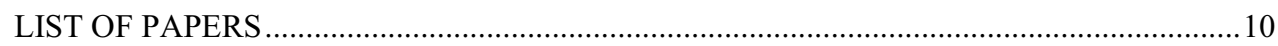

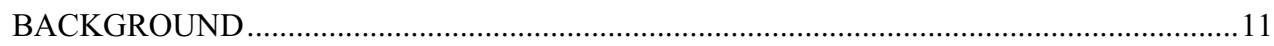

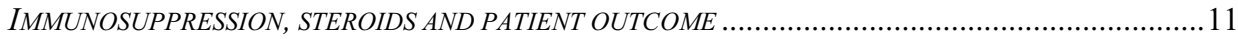

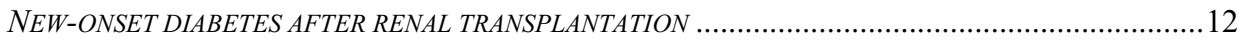

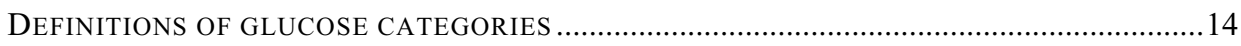

DIAGNOSTIC CONSIDERATIONS OF NEW-ONSET DIABETES AFTER RENAL

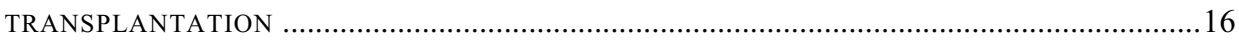

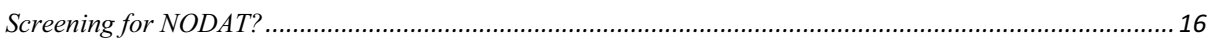

Stepwise screening approach: based on risk factors and laboratory analysis .......................................... 17

The optimal method for diagnosing new-onset diabetes after transplantation: $f P G, 2 h P G$ or HbAlc?.......... 18

RISK OF NEW-ONSET DIABETES AFTER RENAL TRANSPLANTATION .................................19

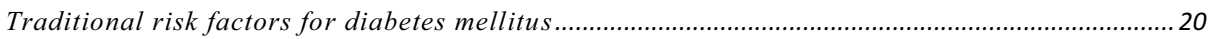

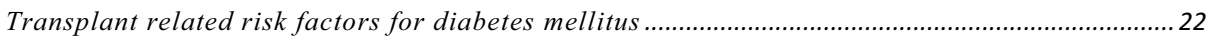

IMPACT OF EARLY POST-TRANSPLANT GLYCEMIA ON LONG-TERM OUTCOMES ...............26

THE MAIN RESEARCH QUESTIONS ADDRESSED IN THIS THESIS .....................................28

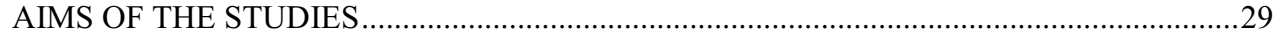

PAPER 1 - SCREENING FOR NEW-ONSET DIABETES AFTER RENAL TRANSPLANTATION ...29

PAPER 2- REDUCED INCIDENCE OF NEW-ONSET DIABETES AFTER RENAL

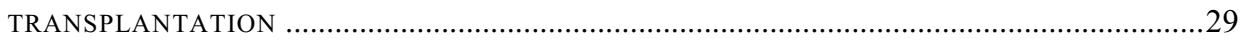

PAPER 3 - ASSOCIATION OF POST-TRANSPLANT GLYCEMIA WITH MORTALITY ..................29

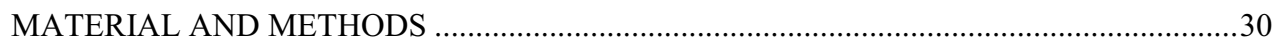

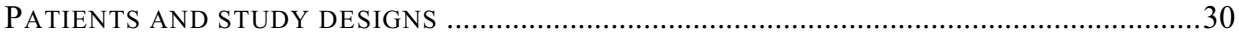

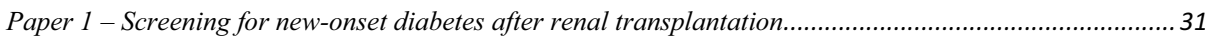

Paper 2 - Reduced incidence of new-onset diabetes after renal transplantation ............................................. 32

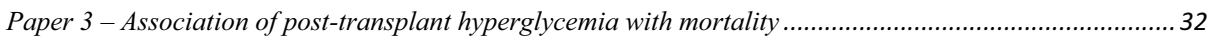

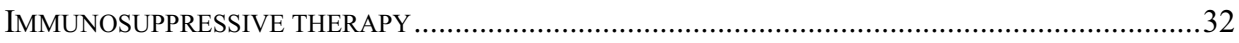

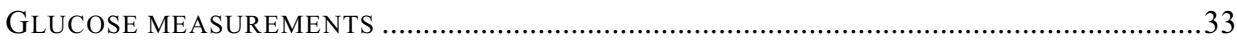

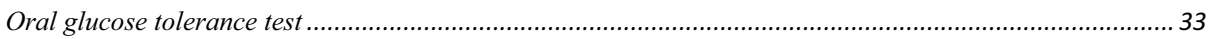

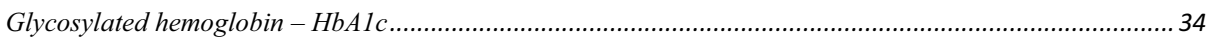

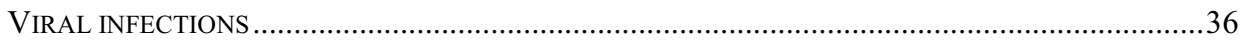




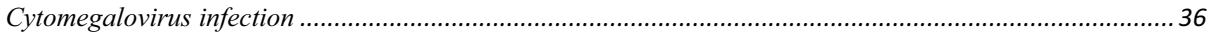

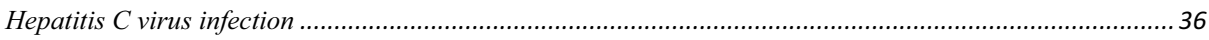

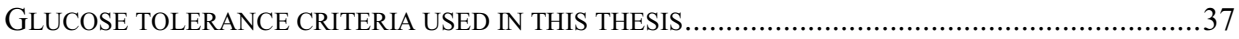

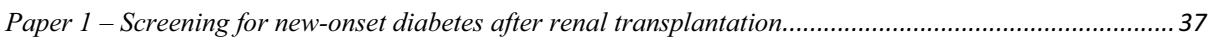

Paper 2 - Reduced incidence of new-onset diabetes after renal transplantation ...........................................37

Paper 3 - Association of post-transplant hyperglycemia with mortality ....................................................... 37

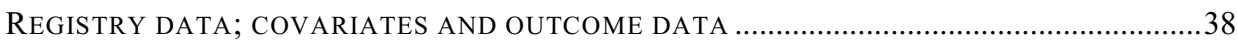

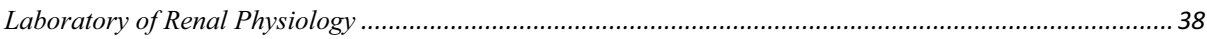

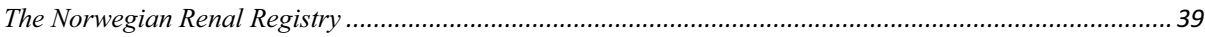

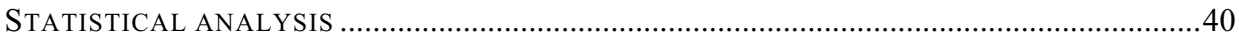

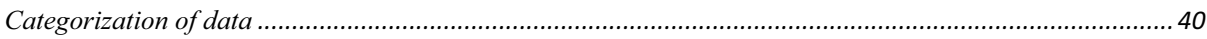

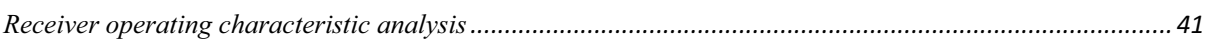

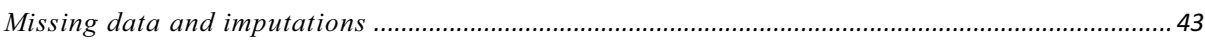

Paper 1 - Screening and diagnostic considerations for new-onset diabetes after renal transplantation, receiver operating characteristic analysis......................................................................................... 45

Paper 2 - Reduced incidence of new-onset diabetes after renal transplantation, logistic regression analysis 45

Paper 3 - Association of post-transplant glycemia with mortality, Kaplan Meyer and Cox regression analysis

PAPER 1 - SCREENING AND DIAGNOSTIC CONSIDERATIONS FOR NEW-ONSET DiABETES

AFTER RENAL TRANSPLANTATION ........................................................................4 47

PAPER 2 - REDUCED INCIDENCE OF NEW-ONSET DIABETES AFTER RENAL

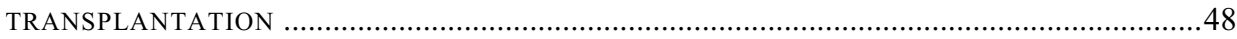

PAPER 3 - ASSOCIATION OF POST-TRANSPLANT GLYCAEMIA WITH MORTALITY .............49

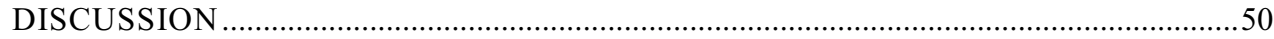

RECOMMENDATIONS FOR DIAGNOSING NEW-ONSET DIABETES AFTER RENAL

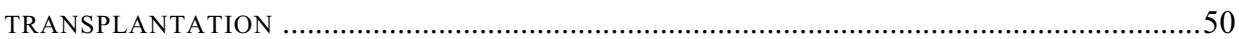

The preferred diagnostic test for new-onset diabetes after renal transplantation .........................................50

The optimal time to diagnose new-onset diabetes after renal transplantation ..........................................50

PAPER 1 - SCREENING AND DIAGNOSTIC CONSIDERATIONS FOR NEW-ONSET DIABETES

AFTER RENAL TRANSPLANTATION .......................................................................52

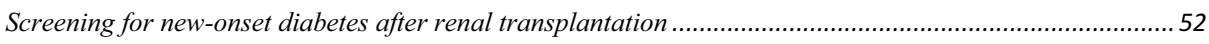

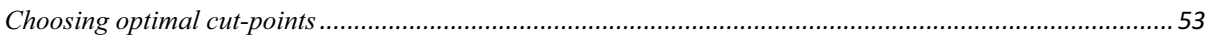

Pre-transplant risk assessment of new-onset diabetes after renal transplantation......................................5 54

Validation of HbA1c $\geq 6.5 \%$ for the diagnosis of new-onset diabetes after renal transplantation..................55

PAPER 2 - REDUCED INCIDENCE OF NEW-ONSET DIABETES AFTER RENAL

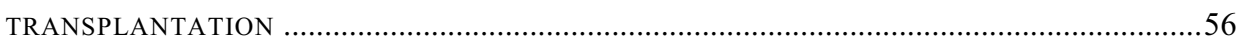

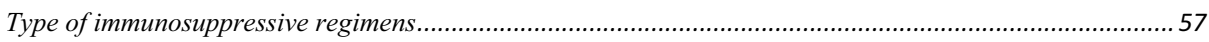

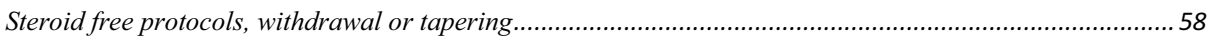

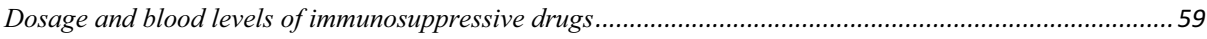

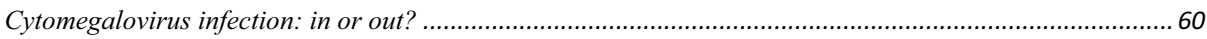


PAPER 3 - ASSOCIATION OF POST-TRANSPLANT GLYCEMIA WITH MORTALITY ..................61

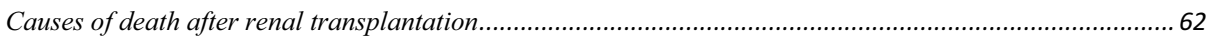

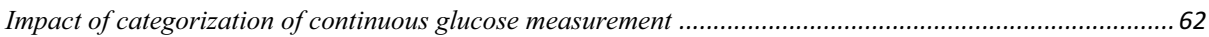

The risk of cardiovascular disease with transient diabetes after renal transplantation ................................... 63

Is pre-diabetes after renal transplantation a predictor for mortality? ............................................................63

Isolated non-diabetic hyperglycemia: a predictor for mortality after renal transplantation?........................... 64

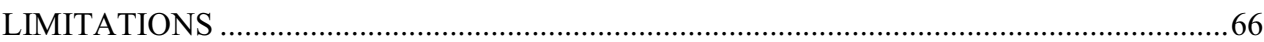

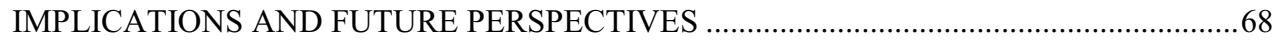

THE OPTIMAL TEST AND TIME FOR DIAGNOSING OF NEW-ONSET DIABETES AFTER RENAL

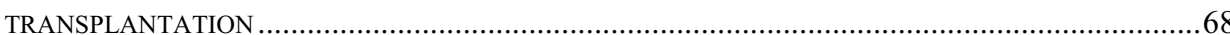

IMMUNOSUPPRESSIVE THERAPY: IMPACT ON INCIDENT DIABETES AND LONG-TERM POST-

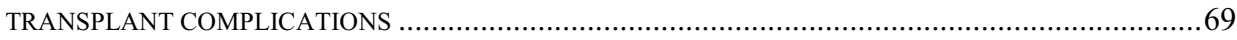

THE ROLE OF ISOLATED POST-TRANSPLANTATION HYPERGLYCEMIA IN LONG-TERM MORBIDITY

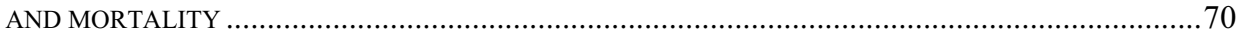

MANAGEMENT OF NEW-ONSET DIABETES AFTER RENAL TRANSPLANTATION ...........................71

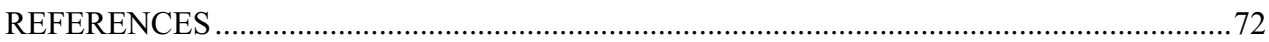

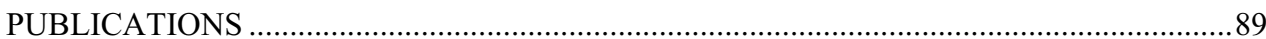




\section{PREFACE}

Renal transplantation is the treatment of choice for patients with end-stage renal disease and renal transplant recipients have lower rates of morbidity and mortality compared to patients remaining on dialysis. Nevertheless, renal transplant patients are considered a high risk population and the development of new-onset diabetes after renal transplantation (NODAT) may potentiate the risk of reduced patient and graft survival. The main focus of this thesis has been to identify renal transplant recipients with NODAT as diagnosed by the current guidelines and to explore the association of post-transplant hyperglycemia with long-term mortality in a renal transplant population. The thesis includes a large cohort of renal transplant recipients who undertook an oral glucose tolerance test (OGTT) performed in the early post-transplant period and were observed either until the end of the study or until the occurrence of the primary endpoint (death from any cause).

The lack of medical consensus surrounding the diagnosis of NODAT has resulted in large variations in the published incidence figures (5-50\%). Although guidelines for the diagnosis and management of NODAT have existed since 2003, most studies have not applied the diagnostic criteria for diabetes mellitus as suggested by the guidelines. The guidelines for NODAT recommend that fasting glucose is the preferred test for diabetes whereas two hour glucose after an OGTT may be a more sensitive test. An OGTT is both time-consuming and difficult to implement in a clinical practice. Thus a selective screening strategy to identify a subgroup of high risk patients to undergo an OGTT could be beneficial.

In the early days of renal transplantation steroid doses were high and the incidence of NODAT was as high as $50 \%$. New immunosuppressive therapy has evolved during the last few decades resulting in reduced total and daily steroid doses. Accordingly, one might expect the incidence of NODAT also to have reduced. However, no study has yet verified this hypothesis.

It is commonly acknowledged that diabetes is associated with increased mortality and morbidity after renal transplantation. However, since two hour glucose after an OGTT is more 
sensitive than fasting glucose in diagnosing NODAT, we hypothesized that post-challenge hyperglycemia might be a stronger predictor of mortality than fasting hyperglycemia. Also, no threshold for accelerated mortality risk is known for continuous glucose measurements and we examined whether the risk of mortality might be increased even in cases of pre-diabetic levels of hyperglycemia.

Although we have assessed various aspects of early measured glucose variables in the early post-transplant period, the studies in this thesis have been of observational design and do not explore the possible causal relationship between early post-transplant hyperglycemia and longterm mortality after renal transplantation. Our goal has rather been to achieve the best possible data set and to examine predictors of NODAT and all-cause mortality reflecting the associations in a large renal transplant population. 


\section{ACKNOWLEDGEMENTS}

The present work has been performed in affiliation with Medical Department, Section for Nephrology, Department for Organ Transplantation, Gastroenterology and Nephrology Division for Specialized Medicine and Surgery, Oslo University Hospital, Rikshospitalet between January 2007 and December 2011. The work was funded by Oslo University Hospital, Rikshospitalet and the University of Oslo.

After completing the specialty of internal medicine, I became interested in research within the field of diabetes. I first approached the department of Nephrology while I was still in maternity leave with my youngest son, and was fortunate to be meet by great enthusiasm by Professor Anders Hartmann. I was invited to participate in a research group studying various aspects of renal transplantation, including new-onset diabetes after renal transplantation. Further, I was given the opportunity to combine clinical research with a teaching position at the University of Oslo, Division of Thoracic Surgical Department.

I especially would like to express my gratitude towards my principal supervisor Jøran Hjelmesæth, who challenged me during the whole period, gradually improving my skills as an independent scientist. He always found time to thoroughly comment on even the minor questions I might have had. His extensive knowledge of our common field of epidemiological research and clinical statistics always was a great inspiration. Also, I wish to express gratitude toward my co-supervisors Professor Anders Hartmann and Professor Trond Geir Jenssen for their continuous support and valuable comments in numerous manuscript revisions. I further wish to thank Jo Røislien at the Institute of Biostatistics for his statistical support, to Torbjørn Leivestad at the Institute of Immunology for his valuable assistance in data collection and to the staff at the Laboratory of Renal Physiology for their laboratory assistance. Without their help, the present work would not have been possible.

Also, I wish to thank the head of Thoracic Surgical Department Professor Odd Geiran, for the opportunity to withstand a teaching position throughout my research period which enabled me to improve my academic skills as a clinical teacher. I was able to combine my clinical 
experience as an internist with new knowledge acquired with the help of my colleagues at the Division of Surgery.

Finally, I wish to thank my dear husband Stig and my two wonderful sons, Ole and Jens, for their everlasting patience at times when five minutes turned into five hours whenever a statistical analysis or a reviewer process did not turn out as expected. Also, I wish to thank my parents for their support in helping me taking care of my boys and giving me the opportunity to combine a career as a medical researcher with motherhood.

Oslo, April 2012

Tone Gretland Valderhaug 


\section{ABBREVIATIONS}

2hPG; $\quad$ Two hour plasma glucose after an oral glucose tolerance test

ADA; American Diabetes Association

$\mathrm{CV} ; \quad$ Cardiovascular

CVD; $\quad$ Cardiovascular disease

CMV; $\quad$ Cytomegalovirus

CNI; $\quad$ Calcineurin inhibitor

DM; $\quad$ Diabetes mellitus

ESRD; $\quad$ End stage renal disease

fPG; $\quad$ Plasma glucose after an overnight fast

GFR; Glomerular filtration rate

$\mathrm{HCV}$; $\quad$ Hepatitis $\mathrm{C}$ virus

IFG; $\quad$ Impaired fasting glucose

IGT; Impaired glucose tolerance

MMF; $\quad$ Mycophenolate mofetil

NGT; $\quad$ Normal glucose tolerance

NODAT; New-onset diabetes after renal transplantation

USRDS; United States Renal Data System 


\section{LIST OF PAPERS}

1. Valderhaug TG, Jenssen T, Hartmann A, Midtvedt K, Holdaas H, Reisaeter AV, Hjelmesæth J. Fasting plasma glucose and glycosylated hemoglobin in the screening for diabetes mellitus after renal transplantation. Transplantation 2009 Aug 15;88(3):429-34.

2. Valderhaug TG, Hjelmesaeth J, Rollag H, Leivestad T, Roislien J, Jenssen T, Hartmann A. Reduced incidence of new-onset post-transplantation diabetes mellitus during the last decade. Transplantation 2007 Nov 15;84(9):1125-30.

3. Valderhaug TG, Hjelmesaeth J, Hartmann A, Roislien J, Bergrem HA, Leivestad T, Line PD, Jenssen T. The association of early post-transplant glucose levels with longterm mortality. Diabetologia 2011 Jun;54(6):1341-9. 


\section{BACKGROUND}

The first successful kidney transplantation (between monozygotic twins) was performed by Joseph Edward Murray in Boston, December 24, 1954 (Figure 1) (1;2).

Only two years later the surgeon Leif Efskind performed the first allograft renal transplantation at Rikshospitalet (3). In 1963, the first renal transplantation with a family kidney donor was performed using steroid and azathioprine as immunosuppressive therapy. The recipient lived for another 22 years and the donor lived to be 92 years of age (4).

\section{Immunosuppression, steroids and patient outcome}

Whereas the surgical techniques were available, acute rejections were the main obstacle for successful renal transplantation in the early era. Advances in immunosuppression were of paramount importance for further progress. The discovery of the immunosuppressive effects of the soil fungus cyclosporine A (CsA) in 1969 led to a dramatic turning point in the history of organ transplantation. In parallel with the development of new immunosuppressive therapy, the improvements in short-term complications after renal transplantation have been substantial, possibly due to lower rejection rates and infection control. The current survival rate at one year is $95 \%$ and around $90 \%$ at 3-5 years (5). Renal transplant recipients have increased risk of morbibidy and mortality compared to patients with end stage renal disease (ESRD) $(6 ; 7)$, with the major causes of mortality being cardiovascular disease (CVD), infectious disease and 
malignancy $(5 ; 8)$. Although the amount of short-term complications after renal transplantation has improved, the long-term results have remained largely unchanged $(5 ; 9)$.

Over the last decades, kidney transplantation has developed from an experimental procedure to the preferred treatment of patients with ESRD (6). The main obstacles to allograft success have been the occurrence of acute rejection episodes which in the earliest decades were treated with large and repeated doses of corticoidsteroids (10). With the introduction of steroid sparing immunosuppressive treatment, such as calcineurin inhibitors, short-term complications associated with renal transplantation have improved dramatically (10). However, the immunosuppressive therapy has serious adverse effects and may affect risk factors for CVD and chronic allograft nephropathy $(11 ; 12)$.

New-onset diabetes after renal transplantation

Most patients with uremia have abnormal glucose metabolism by mechanism of increased insulin resistance (13). Successful renal transplantation is expected to improve glucose tolerance by the reduction of uremic toxins. However, subsequent immunosuppression therapy after transplantation is associated with glucose intolerance and eventually new-onset diabetes after renal transplantation (NODAT) (14). Diabetes mellitus (DM) was described as a complication of kidney transplantation over 40 years ago (15). Since the 1980's the incidence of NODAT has ranged between 2 and $53 \%$ across various studies predominantly due to differences in diagnostic strategies for diabetes (16-21). In acknowledgement of the need for uniformity, international consensus guidelines were established and the diagnostic criteria of NODAT have been aligned with the recommendations of the guidelines of The American Diabetes Association (ADA) since 2003 (22). Although expert consensus statements for the diagnosis of diabetes do not account for the occurrence of diabetes among recipients of organ allograft $(23 ; 24)$, non-compliance to the established diagnostic criteria has been criticized for introducing new diagnostic criteria that do not reflect the evidence for developing complications of diabetes (25). The NODAT guidelines recommend that fasting plasma glucose 
(fPG) is the preferred test for diagnosing NODAT, but studies have indicated that a two hour glucose (2hPG) after an oral glucose tolerance test OGTT may be more sensitive for the identification of NODAT $(26 ; 27)$.

Since 1995, Rikshospitalet has routinely performed an OGTT ten weeks after renal transplantation on recipients without diabetes over 18 years of age. In 1995-96, we observed that many of the renal transplant recipients had undiagnosed DM in the early post-transplant period. A cross-sectional study confirmed that half the recipients had dysglycemia; either prediabetes (preDM) or DM (28). Although the majority of NODAT cases develop during the first three months post-transplant, large epidemiological studies have showed that the number of patients developing NODAT increases progressively thereafter $(19 ; 29)$. Notably, in these studies NODAT was defined by Medicare claims or by the requirement of hypoglycemic agents past 30 days post-transplant. Recent studies report an incidence of NODAT between 7 and $40 \%$ across various populations and time post-transplant (19;30-36).

The development of NODAT is classified as a "drug or chemical induced" or "infectious induced" type of diabetes and sorts under the category "other specific types" according to the definition and classification of DM of the World Health Organization (WHO) or the American Diabetes Organization (ADA) (24;37) (Table 1). There are several similarities between NODAT and type 2 DM with both sharing traditional risk factors such as age, ethnicity, family history of diabetes, obesity, hyperlipidaemia, hypertension and reduced kidney function. Additionally, renal transplant patients are exposed to extensive lifelong immunosuppressive medications that are in themselves diabetogenic and put the patients at extra risk of developing abnormal glucose metabolism (30;38). Furthermore, renal transplant recipients have compromised immune systems and are consequently at risk of opportunistic infections (39). Viral infections such as cytomegalovirus (CMV) infections and hepatitis $\mathrm{C}$ infections are common in transplant patients and have been associated with post-transplant hyperglycemia $(40 ; 41)$. 
Table 1. Etiologic classification of diabetes mellitus

\begin{tabular}{|c|c|}
\hline Classification & Etiology \\
\hline \multirow[t]{2}{*}{ I. Type 1 diabetes } & Immune mediated \\
\hline & Idiopathic \\
\hline \multirow[t]{2}{*}{ II. Type 2 diabetes } & Increased insulin resistance \\
\hline & Impaired insulin secretion \\
\hline \multirow[t]{9}{*}{ III. Other specific types } & Genetic defects in beta-cell function \\
\hline & Genetic defects in insulin action \\
\hline & Diseases of exocrine pancreas \\
\hline & Endocrinopathies \\
\hline & Drug or chemical induced \\
\hline & Infections \\
\hline & Uncommon forms of immune mediated diabetes \\
\hline & Other genetic syndromes associated with \\
\hline & diabetes \\
\hline IV. Gestational diabetes & During pregnancy \\
\hline
\end{tabular}

\section{Definitions of glucose categories}

According to the New-onset diabetes after transplantation 2003 International consensus guidelines, NODAT should be defined based upon the current definitions of the ADA, WHO, and IDF (Table 2) (22). The NODAT guidelines further recommend that an fPG is the preferred test for diagnosing NODAT, whereas a $2 \mathrm{hPG}$ after an OGTT may identify more NODAT cases. 


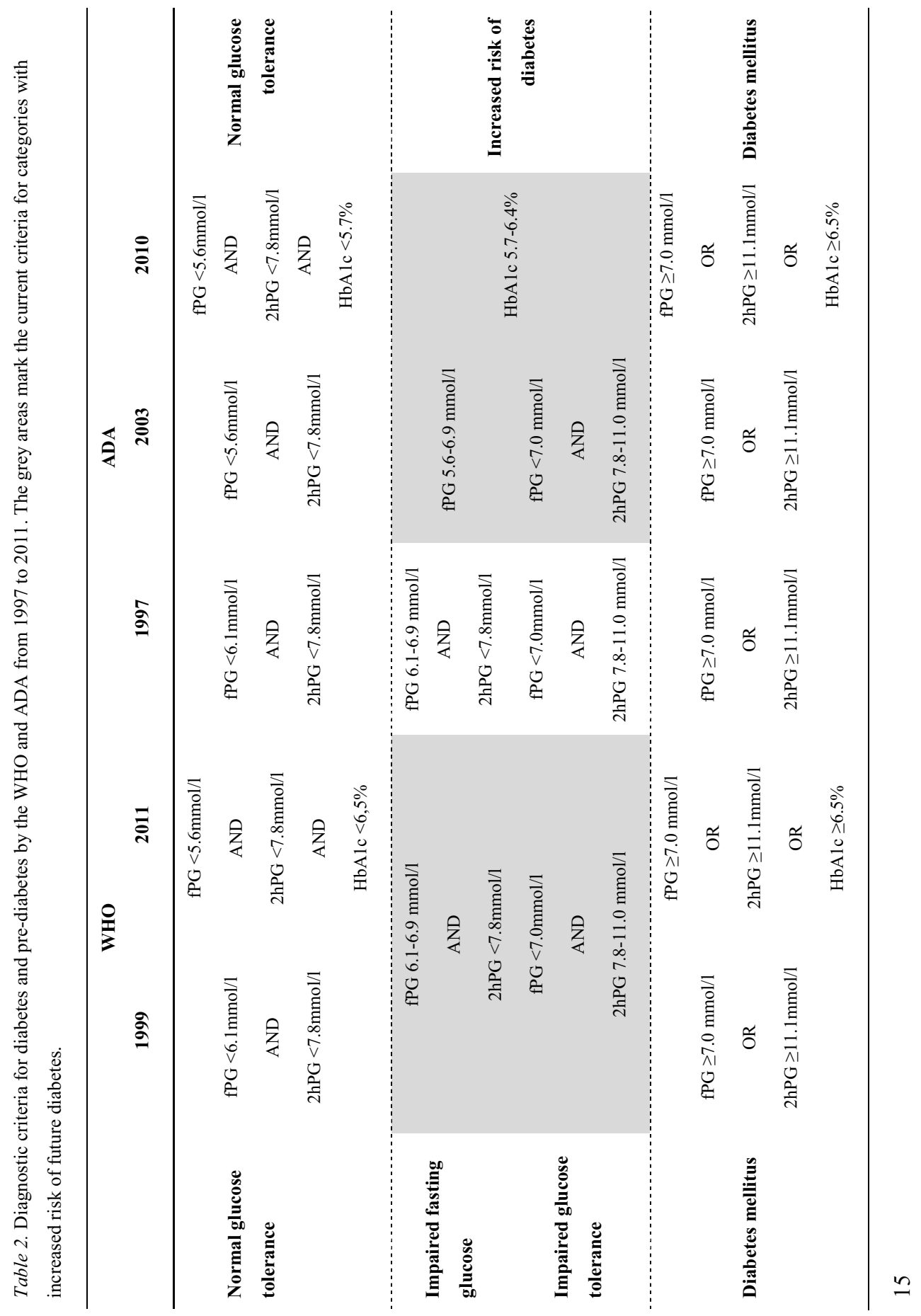




\section{Diagnostic considerations of new-onset diabetes after renal transplantation}

Screening for NODAT?

The early stages of DM are often asymptomatic and many persons with undetected diabetes are thus unaware of their increased risk of morbidity and mortality. Considering the large impact of NODAT on patient morbidity and mortality among renal transplant recipients, early identification of persons at risk is necessary to implement risk reducing strategies $(18 ; 19)$. Consequently, one might consider screening the entire transplant population. In 1968, Wilson and Jungner attempted to define generally applicable criteria for medical conditions or diseases that would be suitable for screening based upon ethical, social, and economic considerations as well as the capacity to detect the condition at an early stage and the availability of an acceptable treatment (42). The classical screening criteria as defined by Wilson and Jungner is summarized in Table 3 (43).

The development of NODAT is certainly an important health problem and the natural history of the disease is adequately understood. Furthermore, the condition is recognizable at a latent or early stage and the facilities of both PPG and 2hPG for the diagnosis are available to a renal transplant population. While most renal transplant patients may be positive towards glucose testing with an PPG, widespread usage of an OGTT may not be considered an acceptable test to the population. One study of more than 6,000 individuals from the general population reported that the most important but uncertain variable of screening is the effect of treatment (44). Whether or not screening for NODAT is cost-effective is unknown. Although $2 \mathrm{hPG}$ identifies more NODAT cases, it must be acknowledged that an OGTT may not be feasible to perform in all renal transplant recipients. 
Table 3. Classical screening criteria as defined by Wilson and Jungner $(47,48)$.

\section{Criteria}

1. The criterion sought should be an important health problem.

2. There should be an accepted treatment for patients with recognized disease.

3. Facilities for diagnosis and treatment should be available.

4. There should be a recognizable latent or early symptomatic stage.

5. There should be a suitable test or examination.

6. The test should be acceptable to the population.

7. The natural history of the condition should be adequately understood.

8. There should be an agreed policy on whom to treat as patients.

9. The cost of case-finding should be economically balanced to expenditure on medical care as a whole.

10. Case finding should be a continuous process.

Stepwise screening approach: based on risk factors and laboratory analysis

It has been suggested that high-risk group, selected by risk factors such as age, sex, and BMI, rather than entire populations should be screened for diabetes $(45 ; 46)$. However, a random plasma glucose is reported to be superior to age and BMI alone, and comparable to a screening model containing age, BMI, ethnicity, sex, and family history of diabetes in a general population (47). Alternatively, a stepwise screening algorithm based on laboratory analysis alone may be explored. There are three accepted laboratory variables describing a person's glucose metabolism; fPG, 2hPG and glycosylated hemoglobin (HbA1c). Both fPG and HbA1c have been included in screening algorithms to detect undiagnosed diabetes in a general population $(48 ; 49)$. In a large European epidemiological study, an fPG alone would fail to detect $31 \%$ of the subjects with a $2 \mathrm{hPG} \geq 11.1 \mathrm{mmol} / 1$. Using a strategy of maximized sensitivity and specificity, this study 17 
identified an optimal threshold for predicting a $2 \mathrm{hPG} \geq 11.1 \mathrm{mmol} / 1$ of $5.8 \mathrm{mmol} / \mathrm{l}$ for women and $6.4 \mathrm{mmol} / 1$ for men with a sensitivity of $76 \%$ and $70 \%$, respectively (48). One study found that $\mathrm{HbA} 1 \mathrm{c}$ of $5.8 \%$ or greater yielded the highest sum of sensitivity ( $86 \%)$ and specificity $(92 \%)$ and concluded that an $\mathrm{HbA} 1 \mathrm{c}$ of $5.8 \%$ would be an appropriate cut-point above which to proceed to further evaluation (49). The latter study did not, however, use an OGTT to diagnose diabetes. Among patients with ESRD one study found that $8 \%$ of the candidates had unknown diabetes before transplantation (50). In this study, pre-transplant fPG identified only 16 out of $72(22 \%)$ of the cases with undetected diabetes whereas $2 \mathrm{hPG}$ after an OGTT revealed another 56 (78\%) patients with undetected diabetes. The authors suggested a case-finding strategy in which patients with an $\mathrm{fPG}$ equal to or above $5.1 \mathrm{mmol} / \mathrm{l}$ should be referred to a subsequent OGTT for verification of the diagnosis of diabetes. This two-step strategy would require half the population to undergo an OGTT and identified $90 \%$ of the patients with undetected diabetes (50).

The optimal method for diagnosing new-onset diabetes after transplantation: $f P G, 2 h P G$ or HbAlc?

According to the current NODAT guidelines, $\mathrm{fPG}$ is the preferred diagnostic test for NODAT after renal transplantation (22). Renal transplant patients with hyperglycemia often have normal fasting glucose and elevated postprandial glucose (26;51). In a study of 200 renal transplant recipients, a $2 \mathrm{hPG}$ after an OGTT was more sensitive in detecting NODAT and an PPG failed to identify $65 \%$ of the patients with NODAT beyond 5 months post-transplant (26). Although there is a paucity of data in the usage of $\mathrm{HbAlc}$ in patients with renal disease, it is logical to assume that the validity of $\mathrm{HbA} 1 \mathrm{c}$ will decrease with advancing renal failure. The original NODAT guidelines of 2003 do not recommend the use of HbA1c for diagnosing NODAT, partly because of changes in red cell turnover, anemia, acidosis (22;52). Accordingly, the diagnostic criterion of HbA1c $\geq 6.5 \%$ as introduced by the ADA and the WHO may not apply in a renal transplant population. A study of renal transplant recipients found that $10 \%$ of all patients had an $\mathrm{HbA} 1 \mathrm{c}$ $\geq 6.1 \%$ beyond 3 months post-transplant and the authors suggested that HbA1c should be 
considered as a screening test for NODAT (53). This study did not, however, include an OGTT for diagnosing NODAT.

\section{Risk of new-onset diabetes after renal transplantation}

Most cases of NODAT develop within the first three months post-transplant, but incidences increase progressively thereafter (19;29). The pathophysiological mechanisms for NODAT are considered to be a combination of insulin resistance and deficient insulin production $(54 ; 55)$. One small study comparing the one-year cumulative incidence of NODAT in renal transplant recipients with ESRD patients recently showed that 14\% and 5\% developed NODAT, respectively. In this study, only four out of eight recipients with NODAT one year post-transplant had pre-diabetes before transplantation, indicating that other transplant associated factors may be involved in the development of NODAT (56).

Risk factors for a disease are important because they help identify asymptomatic individuals who have a greater chance of developing the disease in question and may be defined as preceding the outcome of disease (i.e. NODAT, a myocardial infarction or death), predicting the outcome and being in the biological causal pathway of the disease (57). A biomarker is considered an indicator of a biological process that may or may not have a causal relationship with the disease $(57 ; 58)$. The difference between a risk factor and a biomarker is subtle; a biomarker may be considered a form of risk factor when it is causal. Risk factors and biomarkers for NODAT, which may or may not be modifiable, are summarized in Table 4. Increasing age, non-white ethnicity, and immunosuppressive medication are the strongest risk factors $\operatorname{NODAT}(19 ; 21 ; 29 ; 30)$. Components of the metabolic syndrome, physical inactivity, post-transplant viral infections, immunosuppressive agents and rejection episodes constitute the target points for reducing the risk of progression of post-transplant hyperglycemia into NODAT in the early post-transplant period (Table 4). 
Table 4. Risk factors and biomarkers for new-onset diabetes after transplantation (NODAT) after renal transplantation

\begin{tabular}{lll}
\hline Non-modifiable & Modifiable \\
\hline Age & Metabolic syndrome \\
& Ethnicity & Pre-transplant hyperglycemia \\
& Family history of diabetes & Physical inactivity \\
Genetics & Post-transplant hyperglycemia \\
Cause of ESRD & Social status \\
& HLA-mismatch & Viral infections \\
& Donor characteristics & Rejection episodes \\
\hline
\end{tabular}

ESRD; end stage renal disease.

\section{Traditional risk factors for diabetes mellitus}

Increasing recipient's age is consistently reported to correlate with the incidence of NODAT $(19 ; 21 ; 28 ; 29)$. Kasiske et al showed that recipients over 60 years of age had the greatest risk of NODAT compared to the reference group of 18-44 years (19). Furthermore, Cosio et al found that recipients over 45 years of age were 2.2 times as likely to develop NODAT than recipients of a younger age (29). Age is, however, a continuous variable and re-categorizing it may introduce unfavorable effects $(59 ; 60)$. In a study of 173 consecutively included renal transplant recipients, the risk of NODAT increased by $4 \%$ per increased year of age (28). The risk of NODAT is higher in non-whites than among white individuals $(19 ; 29 ; 30)$. Also, family history of diabetes is reported to increase the risk of developing NODAT by a fourfold if present (28). Furthermore, a genetic susceptibility for NODAT has also been demonstrated $(61 ; 62)$ with various genotypes 
involved. Epidemiological studies have not reported any differences between the genders in the development of NODAT (28-30).

The associations between modifiable traditional risk factors for NODAT are inconsistently reported within the literature $(18 ; 19 ; 21 ; 28 ; 30 ; 31 ; 33 ; 54 ; 63-67)$. Pre-diabetes after renal transplantation may predict future NODAT; Cosio et al. found that the odds of developing diabetes increased by $50 \%$ in patients with a fPG 5.6-6.1 mmol/1 compared to those with a $\mathrm{PPG}<$ $5.0 \mathrm{mmol} / 1$. Furthermore, $70 \%$ of the patients with an $\mathrm{PPG} 6.1-6.9 \mathrm{mmol} / 1$ progressed into NODAT within the first post-transplant year (31). Some recipients develop transient abnormal hyperglycemia $(31 ; 32 ; 68)$. Indeed, the normalization of glucose intolerance has been associated with improved insulin sensitivity (69). On the other hand, an early $\mathrm{fPG} \geq 7.0 \mathrm{mmol} / \mathrm{l}$ five days post-transplant was associated with a fivefold increased risk of subsequent NODAT in a study of 282 renal transplant recipients $(70)$.

Compared to recipients without NODAT, hypertriglyceridemia was particularly pronounced in recipients with NODAT in a large single center study of 1,811 renal transplant recipients (18). The study also showed that elevated levels of both triglycerides and total cholesterol preceded the development of NODAT (18). Hypertriglyceridemia is furthermore associated with insulin resistance, a central pathophysiological mechanism in the development of NODAT $(71 ; 72)$.

Physical inactivity were effective in the prevention and treatment of individuals with insulin resistance in a general population and intensive lifestyle modifications improved glucose metabolism in a study of 111 renal transplant recipients with impaired glucose tolerance (IGT) or NODAT $(73 ; 74)$. Kasiske et al. reported a lower risk of NODAT in recipients with a college degree as compared to recipients without a college degree and although not shown within a renal transplantation population, it is logical that social status and work related elements such as employment and income are associated with increased risk of NODAT $(19 ; 75 ; 76)$. 
Transplant related risk factors for diabetes mellitus

Immunosuppressive therapy is a well known modifiable risk factor for NODAT (21). An acute rejection episode also strongly predicts the onset of early NODAT and is closely correlated to the usage of corticoids $(21 ; 29)$. Furthermore, some studies report that post-transplant viral infections might be involved in the pathological mechanisms of developing NODAT, but a causal relationship between viral infections and NODAT is not established (77;78). The role of donor vital status for the development of NODAT is inconsistently reported in studies $(19 ; 79)$. The relationship between ESRD, immunological components and the development of NODAT is unclear $(21 ; 80 ; 81)$.

\section{The role of immunosuppressive therapy}

During the early decades of renal transplantation's history irradiation and high-dose glucocorticoid immunosuppressive regimens were used as immunosuppressive therapy to prevent acute rejection episode, with steroid induced diabetes reported in up to $50 \%$ of renal transplant recipients (16;82). Although corticosteroids are important components of immunosuppressive regimens and effectively reduce the incidence of acute rejection, they are also associated with numerous adverse effects including hypertension, hyperglycaemia and hyperlipidaemia, cataracts, osteoporosis, and CVD $(83 ; 84)$. The type of immunosuppressive drugs is reported to account for $74 \%$ of the variability of NODAT incidence with prednisolone use considered a predominant determinant of insulin resistance after renal transplantation $(21 ; 55 ; 85)$. However, beta cell function also seems to be impaired (86). The pathogenesis of NODAT therefore accords with the general accepted understanding of the pathogenesis of type 2 diabetes $(87 ; 88)$. Some studies suggest that the effects of corticosteroids are dose related $(54 ; 69)$. In a study of 173 renal transplant recipients, each increased $0.01 \mathrm{mg} / \mathrm{kg} /$ day dose of prednisolone was associated with a $5 \%$ increased risk of developing NODAT (28). In addition, other adverse effects of corticosteroids such as changes in weight and redistribution of abdominal fat may also contribute to the increased insulin resistance seen after renal transplantation $(89 ; 90)$. 
In coherence with an increasing focus on steroid minimization during the past decades and steroid withdrawal and lower frequencies of steroid related side effects have been reported in recipients receiving steroid-free immunosuppressive therapy (91-93). Improved glucose metabolism by way of decreased insulin resistance was seen after corticoid withdrawal at six months post-transplant (94). On the other hand, a small study showed that a dosage reduction below $5 \mathrm{mg}$ /day was not related to improvements in glucose metabolism (95). Furthermore, results of a meta-analysis suggested that steroid avoidance or early withdrawal increased the risk of acute allograft rejection (96;97). Although an increasing number of patients are discharged with corticosteroids free regimens, a significant proportion of renal transplant recipients return to corticosteroids at 6-12 months post-transplant (93). Nonetheless, steroid sparing protocols remain controversial and may increase the risk of acute and chronic rejection that in turn may jeopardize transplant outcome.

In addition to corticosteroids, common standard maintenance immunosuppressive protocols include calcineurin inhibitors (CNIs) (cyclosporine A and tacrolimus) or mammalian target of rapamycin (mTOR) inhibitors which may also contribute to the development of NODAT $(35 ; 98-$ 101). The diabetogenic effects of the commonly used immunosuppressive agents are summarized in Table 5 .

CNIs allow lower doses of steroids, but are themselves associated with increased risk of NODAT by mechanisms of both impaired insulin secretion and insulin sensitivity $(35 ; 54 ; 56 ; 98)$. Tacrolimus is reported to be more diabetogenic than CsA $(100 ; 102 ; 103)$. However, the increased diabetogenic effect associated with tacrolimus might be explained by a high whole blood trough concentration ( $\mathrm{C} 0)$ of tacrolimus in the early post-transplant period $(35 ; 104)$. A prospective randomized study comparing renal transplant recipients treated with either CsA or tacrolimus found a higher incidence in the tacrolimus group than in the CsA group at six months posttransplant (35). In this study the target C0 level of tacrolimus was high (10-15 $\mu \mathrm{g} / \mathrm{l})$ during the first three months post-transplant. Another meta-analysis of 4,102 patients included in randomized trials comparing patients receiving CsA with tacrolimus indicated that a cut-off point for tacrolimus $\leq 10 \mu \mathrm{g} / \mathrm{l}$ would minimize the risk of NODAT (104). Furthermore, a small study of 15 renal transplant recipients showed an improved beta-cell secretion capacity after tacrolimus 23 
trough level reduction six months post-transplant indicating a possible reversible toxic effect (94).

Table 5. Diabetogenic effects and suspected mechanisms of various immunosuppressive regimens

\begin{tabular}{|c|c|c|}
\hline Immunosuppressant & Diabetogenic effect & Mechanism \\
\hline Prednisolone & +++ & 个 Insulin resistance \\
\hline Cyclosporine A & + & $\begin{array}{l}\downarrow \text { Insulin secretion, } \\
\uparrow \text { Insulin resistance }\end{array}$ \\
\hline Tacrolimus & ++ & $\begin{array}{l}\downarrow \text { Insulin secretion, } \\
\uparrow \text { Insulin resistance }\end{array}$ \\
\hline Sirolimus & + & $\begin{array}{l}\uparrow \text { Insulin resistance } \\
\downarrow \text { Insulin secretion }\end{array}$ \\
\hline Basiliximab & $(+)$ & $\downarrow$ Insulin secretion (?) \\
\hline Azathioprine & - & - \\
\hline Mycophenolate & - & - \\
\hline \multicolumn{3}{|c|}{$\begin{array}{l}+ \text { Denotes graded association with diabetes. - Denotes no association with diabetes. Arrows indicate } \\
\text { impact on the diabetogenic mechanism }\end{array}$} \\
\hline
\end{tabular}

The mTOR inhibitor sirolimus is reported to be an independent predictor of NODAT $(99 ; 105)$. A small study of CNI withdrawal and conversion to sirolimus was associated with a $30 \%$ increased incidence of impaired glucose tolerance and a significant fall in insulin sensitivity (101). Impaired glucose metabolism correlates to an increase in serum triglyceride levels $(99 ; 101)$. Hypertriglyceridemia is a known side effect of sirolimus (106;107). 
Recently, one study reported impaired glucose homeostasis in renal transplant recipients receiving induction with basiliximab. The authors speculated that basiliximab might interfere with the immunologic balance of beta cells in a post-transplant setting and interfere with the beta cell function; however the mechanism for this effect remains unknown (108). Other components of standard immunosuppressive regimens are azathioprine and MMF which are considered nondiabetogenic drugs. Data from the USRDS showed that renal transplant recipients who used MMF had an 18\% lower risk of developing NODAT compared to recipients who did not (19). Furthermore, the absence of an antiproliferative agent was associated with a higher risk of developing NODAT (20).

$\underline{\text { The link between viral infection and new-onset diabetes after renal transplantation }}$

Renal transplant recipients use extensive doses of lifelong immunosuppressive medication and are thus at risk of serious and opportunistic infectious diseases. The CMV is a beta-herpes virus that is transmitted through infected body secretions and may affect several organs. Infections with CMV are highly prevalent early after renal transplantation and correlate with post-transplant morbidity and mortality $(109 ; 110)$. Some studies have hypothesized a linkage between early onset CMV infection and NODAT $(40 ; 111)$. A study of 160 non-diabetic renal transplant recipients showed an association between NODAT and both CMV disease and asymptomatic CMV infection (40). In this study, insulin sensitivity was not affected by CMV infection, indicating that impaired insulin secretion might be involved in the impaired glucose metabolism seen in recipients with CMV infection (40). Conversely, a retrospective analysis of 1,023 Indians transplanted between 1989 and 2000 showed no association between CMV and NODAT (112). The mechanisms of a correlation between virus infections and diabetes progression are poorly understood. One in vitro study of the general population showed a direct deleterious effect of coxachie virus on beta cell survival resulting from a virus induced activation of proinflammatory cytokines (113). The following explanations for beta cell damage by concurrent CMV infection have been proposed: 1) a direct toxic effect by the CMV with subsequent apoptosis, 2) indirect effect by a inflammatory response of cytokine production either by the beta cell itself (autocrine 25 
effect) or by other islet cells such as endothelial cells or fibroblasts (paracrine effect) ultimately leading to apoptosis of the beta cells, or immunological mechanisms involving either a cytokine response by circulating macrophages or granulocytes or a specific T-cell response reacting with the beta cells (77). However, no causality between CMV infection and NODAT has been established.

Hepatitis C virus (HCV) has been associated with DM in the general population (114). The relationship between HCV and NODAT is inconsistently reported in studies. Some studies have shown a positive correlation between HCV and NODAT $(19 ; 115 ; 116)$, whilst others have not (117). Two studies hypothesized that the diabetogenic effect of tacrolimus might be enhanced by an underlying hepatitis $\mathrm{C}$ infection $(41 ; 78)$. The current guidelines for NODAT recommend that management of $\mathrm{HCV}$ should be coupled with monitoring and prevention of diabetes after renal transplantation, particularly in $\mathrm{HCV}$-infected patients (22).

\section{Impact of early post-transplant glycemia on long-term outcomes}

The development of NODAT is well recognized as a complication of organ transplantation. Large epidemiological studies have shown that NODAT adversely affects long-term patient survival $(18 ; 19 ; 118)$. Data from the USRDS showed that renal transplant recipients with NODAT had a two-fold increased risk of all-cause mortality compared to recipients with normal glucose tolerance (NGT) (19). Cosio and et al. analyzed data from 1,811 renal transplant recipients in a single centre study between 1983 and 1998 and found that from the time of the NODAT diagnosis, the mortality risk of recipients with NODAT was comparable to the risk of pretransplant DM (18). On the other hand other studies have shown no association between NODAT and reduced patient survival $(119 ; 120)$. In a large study including 37,448 renal transplant recipients, pre-transplant DM, but not NODAT, was the major predictor for all-cause and CV mortality one year after transplantation (120). However, since this study had a relatively short observational time, it may have been subject to a statistical type II error. One study reported that pre-transplant diabetes was the major predictor of all-cause and cardiovascular (CV) mortality 
whereas NODAT alone was not associated with patient survival (120). Importantly, none of these epidemiological studies used glucose testing to diagnose NODAT as is recommended by the current guidelines. The different methods by which NODAT is diagnosed may contribute to the diversity in long-term outcome reported in these studies (22).

Whether diabetes duration is associated with long-term mortality outcome is unclear. One study, however, showed that recipients with NODAT had similar patient survival estimates as those with preexisting DM from the time of the NODAT diagnosis, suggesting that patients with NODAT may have an accelerated progression of diabetes related complications (18). In this subanalysis, the authors did not adjust for known confounders for mortality. Although the recipients with pre-existing DM and NODAT were of comparable age (47.5 vs. 48 , respectively), the proportion of males and African Americans was higher among recipients with NODAT than preexisting DM (63\% vs. $60 \%$ and $28 \%$ vs. $24 \%$, respectively) (18).

Renal transplant recipients with NODAT have also been linked to increased rates of CVD as compared to recipients with NGT $(18 ; 31 ; 119)$. Conversely, the influence of NODAT on graft survival is unclear. Data from a large US database found a 63\% (46-84\%) increased risk for overall graft failure and a $46 \%(25-70 \%)$ increased risk of death-censored graft failure as compared to recipients without NODAT (19). This study did not, however, adjust for acute rejections as a confounding variable in the multivariable analysis. Furthermore, another study using the same database found an association between NODAT and overall graft failure (HR 1.24 [95\% CI 1.14-1.35]) but not after censoring for death with a functioning graft (1.12 [0.991.26]) (121). Renal transplant recipients who experienced an acute rejection episode and developed NODAT had the greatest risk of transplant failure (121). One study also reported that acute rejection had greater impact on 15-year graft survival and death censored graft survival than NODAT (122). Thus, although NODAT probably has a detrimental effect on patient survival after renal transplantation, the influence of NODAT on graft survival after censoring for death with a functioning graft needs further clarification.

Although 2hPG after an OGTT is shown to be superior to an PPG in the detection of NODAT, the long-term implications of abnormal post-prandial glucose measurement in renal transplant 27 
recipients are unknown. In the general population, epidemiological studies suggest a close link between post-prandial hyperglycemia and CVD (123;124). Underlying mechanisms for this relationship includes oxidative stress and glycosylation of proteins leading to endothelial dysfunction (125). Recent studies have further suggested that fPG correlates non-linearly, whereas both 2hPG and HbA1c correlates linearly with CVD and mortality (126-129). The relationship between non-diabetic hyperglycemia and mortality is not well studied among renal transplant recipients. However, Cosio et al. reported a strong association between fasting hyperglycemia and CV risk post-transplant suggesting that there is a continuous relationship between increasing levels of fasting plasma glucose and CV-risk (31).

In the general population both prediabetic glucose categories (impaired fasting glucose [IFG] and especially IGT) are associated with CVD and mortality (123;130-132). In a renal transplant population, similar data on pre-diabetic categories are limited. In a sub-study of 490 adult renal transplant recipients, a total of 351 renal transplant recipients with post-transplant fasting hyperglycemia were followed for an average period of $40 \pm 14$ months (31). Compared to having an $\mathrm{fPG}<5.0 \mathrm{mmol} / \mathrm{l}$, an $\mathrm{PPG}$ between 5.6 and $6.0 \mathrm{mmol} / \mathrm{l}$ was not correlated with increased $\mathrm{CV}$ risk, but recipients with an fPG between 6.1 and $6.9 \mathrm{mmol} / 1$ had a 2.4 times increased risk of any $\mathrm{CV}$ events compared to recipients with $\mathrm{fPG}<5.0 \mathrm{mmol} / \mathrm{l}(31)$.

\section{The main research questions addressed in this thesis}

In this thesis, the validity of $\mathrm{fPG}$ and $\mathrm{HbA} 1 \mathrm{c}$, using a $2 \mathrm{hPG} \geq 11.1 \mathrm{mmol} / 1$ as the reference, for diagnosing NODAT was assessed in a renal transplant population. Furthermore, we examined whether the incidence of NODAT was reduced in line with changes in the immunosuppressive therapy. Finally, the impact of hyperglycemia on long-term mortality outcome after renal transplantation was examined. 


\section{AIMS OF THE STUDIES}

\section{Paper 1 - Screening for new-onset diabetes after renal transplantation}

The aim of this study was both to validate $\mathrm{PPG}$ and HbA1c for the diagnosis of NODAT defined by a $2 \mathrm{hPG} \geq 11.1 \mathrm{mmol} / \mathrm{l}$ and to evaluate a two step screening algorithm to select patients for an OGTT based on laboratory values for either fPG or HbAlc.

\section{Paper 2- Reduced incidence of new-onset diabetes after renal transplantation}

The aim of this study was to examine whether glucose tolerance measured early post-transplant had improved in parallel with changes in immunosuppressive therapy introduced in 2001.

\section{Paper 3 - Association of post-transplant glycemia with mortality}

The aim of this study was to assess the long-term effects of early post-transplant glycemia on long-term mortality after renal transplantation. 


\section{MATERIAL AND METHODS}

\section{Patients and study designs}

Since May 1995, The Laboratory of Renal Physiology, Rikshospitalet has routinely examined the majority of non-diabetic renal transplant recipients over 18 years of age with an OGTT ten weeks after renal transplantation, thus providing a large cohort of renal transplant recipients available for follow-up studies. A mandatory OGTT was performed during the pre-transplant work-up in the majority of study patients to exclude recipients with pre-existing DM before transplantation. In a sub-group of 301 patients transplanted between October 2003 and October 2005 (new cohort, paper 2), 79\% reported a complete OGTT before transplantation at a median of 50 (range 32-82) weeks before transplantation in the period 2003-2005 (64).

The studies included in this thesis had a prospective observational design starting at the time of transplantation. A total of 2,458 renal transplantations were performed between February $2^{\text {nd }}$ 1995 and October $19^{\text {th }} 2006$ (Figure 2). Recipients under 18 years of age $(n=102)$, recipients who had preexisting diabetes at the time of transplantation $(n=366)$, recipients who experienced either graft loss $(n=63)$ or died $(n=49)$ before the scheduled OGTT were not included in the study. A total of $241(10 \%)$ recipients were unable to perform an OGTT at ten weeks post-transplant. The main reason was early transfer of these patients to local hospitals due to comorbidity. The recipients who were unable to perform an OGTT ten weeks after transplantation were on average older (50 [SD 15] and 55 [16] years, $\mathrm{P}<0.001$ ) and more likely to receive a kidney from a deceased donor $(75 \%$ vs. $58 \%, \mathrm{P}<0.001)$ compared to recipients included in the studies. Consequently, by exclusion of these patients the mortality risk might have been underestimated in the transplant population examined in this thesis. The proportion of males was similar in both groups (no OGTT: $65 \%$ and study population: $66 \%, \mathrm{P}=0.885$ ).

The participants were predominantly Caucasians and the majority of the recipients were hepatitis C negative. 
All patients gave informed consent to participate and the studies were approved by the regional ethics committee (S-07485a).

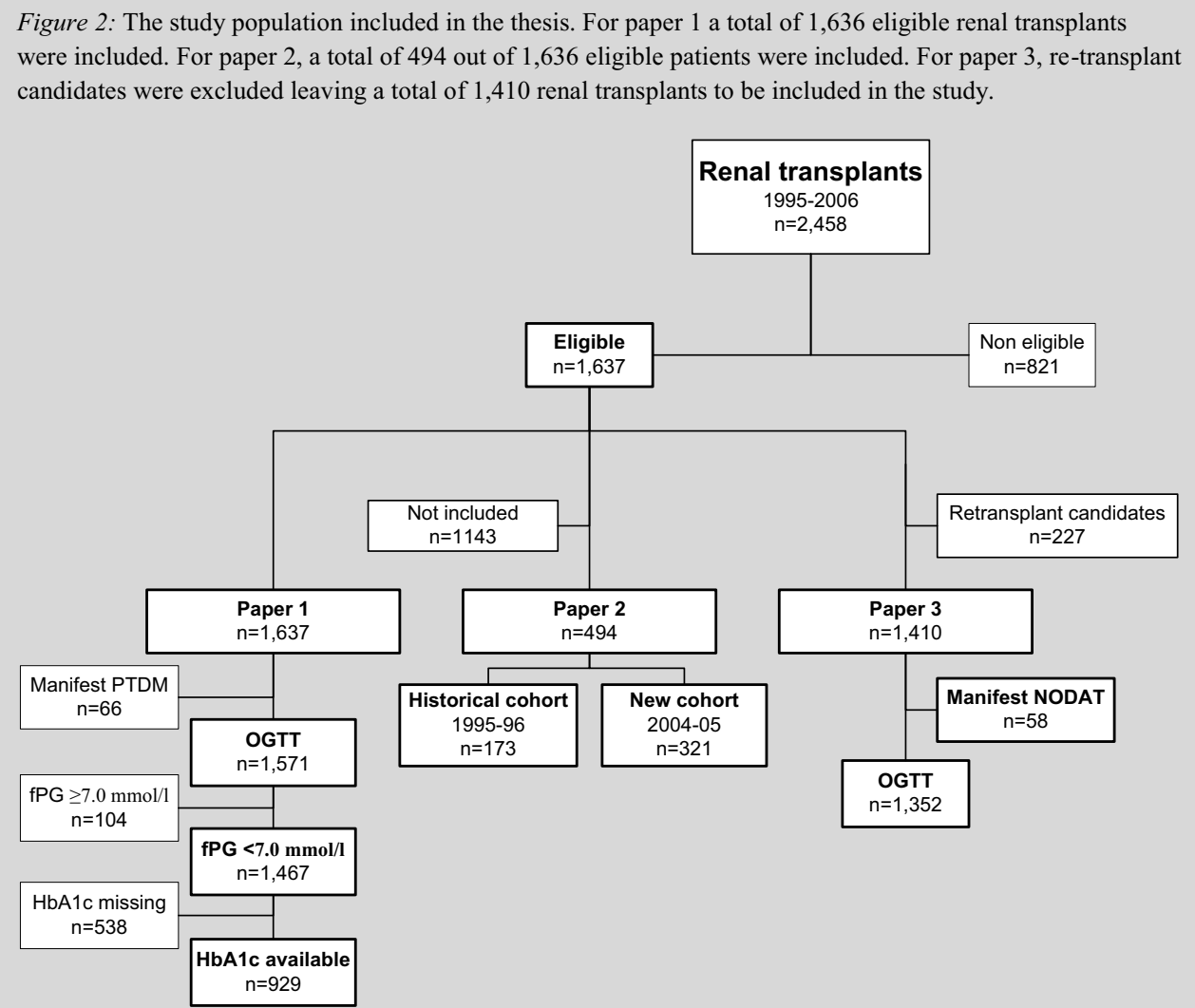

\section{Paper 1 -Screening for new-onset diabetes after renal transplantation}

For the study of screening for NODAT the outcome data was collected at ten weeks posttransplant. Patients receiving their first renal allograft and patients who were re-transplanted were included $(n=1,571)$ whereas patients who developed NODAT during the first ten weeks after transplantation were excluded $(\mathrm{n}=66)$ (Figure 2). 
Paper 2 - Reduced incidence of new-onset diabetes after renal transplantation

For the study of NODAT incidence, outcome data were collected prospectively ten weeks posttransplant. We compared a new cohort of recipients transplanted in 2004-05 with a historical cohort transplanted in 1995-96 which introduced retrospective elements in the study design. We included both patients who received their first renal allograft and those who were re-transplanted (Historical cohort: $n=173$ and New cohort: $n=321$ ) (Figure 2).

Paper 3 - Association of post-transplant hyperglycemia with mortality

In the study of the association of post-transplant glycemia on long-term survival, only first time renal transplant recipients were included $(n=1,410)$. Data collected at the ten week visit was used as baseline data for the prospective survival analysis observing the recipients until either the primary endpoint (death) was reached or until December 2008 (Figure 2).

\section{Immunosuppressive therapy}

From February 1995 to January 2000, the standard immunosuppressive protocol consisted of prednisolone, cyclosporine (CsA) and azathioprine. Induction therapy with basiliximab in combination with CsA and prednisolone was used in 2000, and from January 2001, the standard immunosuppressive protocol included prednisolone, CsA and mycophenolate, without induction therapy. Tacrolimus was given mainly if CsA was withdrawn due to rejection, toxicity or side effects. Steroids were given in doses of $500 \mathrm{mg}$ methylprednisolone i.v. during surgery followed by a dose of $80 \mathrm{mg}$ i.v. the following day. Oral prednisolone was given in a daily dose of $80 \mathrm{mg}$ from day 2, tapered to $15 \mathrm{mg}$ after one month and ten $\mathrm{mg}$ after two months. CsA was given orally in doses of $5 \mathrm{mg} / \mathrm{kg}$ on the day of transplantation and another $5 \mathrm{mg} / \mathrm{kg}$ i.v post-operatively. CsA was subsequently given orally ten $\mathrm{mg} / \mathrm{kg}$ in two daily doses and titrated according to blood CsA concentration levels. The CsA monitoring was initially titrated according to C0 of 300-400 $\mu \mathrm{g} / \mathrm{l}$, tapering to $100-150 \mu \mathrm{g} / 1$ at ten weeks post-transplant from 1995 thru 2002 and according to two 
hour post-dose concentration (C2) initially targeting 1600-2000 $\mu \mathrm{g} / 1$, tapering to $1200-1700 \mu \mathrm{g} / 1$ at ten weeks post-transplant from 2003 thru 2006. Tacrolimus was titrated according to $\mathrm{C} 0$ during the entire study period: initially targeting $10-12 \mu \mathrm{g} / 1$, tapering to $5-10 \mu \mathrm{g} / 1$ at ten weeks posttransplant. The patients received azathioprine in an average dose of $1 \mathrm{mg} / \mathrm{kg} / \mathrm{day}$. Mycophenolate was used twice daily in standard doses of $1,000 \mathrm{mg}$.

Acute rejection episodes were diagnosed clinically and biopsies were as a rule performed for verification. Rejection episodes were treated with intravenous methyl prednisolone boluses (500$125 \mathrm{mg} /$ day) for 4-5 days. The oral daily dose of prednisolone was subsequently increased to 30 $\mathrm{mg}$ and then tapered by $5 \mathrm{mg}$ every 2 weeks. Biopsy-verified steroid resistant rejections were treated with antilymphocyte antibodies (ATG/OKT3).

\section{Glucose measurements}

\section{Oral glucose tolerance test}

The OGTT was performed after an overnight fast with patients instructed not to eat or drink, to refrain from smoking and to not take any medication less than eight hours before the test. Each patient drank75 $\mathrm{g}$ of anhydrous glucose dissolved in $250 \mathrm{ml}$ of water. Blood samples were drawn after 0 and 120 minutes. From May 1995 to August 1996, glucose was measured in serum using a glucose dehydrogenase method (Cobas Mira, Roche, Basel, Switzerland). Theoretically, a longer pre-analytic time lapse from blood sampling till processing may permit a continued intracellular glucose metabolism and thus lower glucose concentrations in serum. However, the differences in glucose values in plasma and serum are shown to be small and we have presented the glucose in serum and plasma as equivalent values (133). From September 1996 until December 2006 venous whole blood glucose was measured immediately after sampling using the Hemocue AB B-glucose Analyzer, Angelholm, Sweden. Because glucose permeates the erythrocytes quickly, the glucose concentration is higher in plasma than in blood. A conversion factor between venous blood and plasma is approved in normally hydrated individuals (134). Thus, we multiplied blood 
glucose with the conversion factor of 1.11 to calculate the plasma glucose (134). Internal quality assessment was based on daily management of precision at the lowest $(2.5[0.8] \mathrm{mmol} / \mathrm{l})$ and highest levels $(10.0[1.2] \mathrm{mmol} / \mathrm{l})$ of venous blood glucose. External quality assessment applied every 6 months resulted in an interassay coefficient of variance of $5 \%$.

The OGTT was performed once without a confirmatory test on a subsequent day as recommended by the current guidelines. For clinical usage a repeated diagnostic test is recommended (37). However, the WHO acknowledge that for epidemiological purposes, the diagnosis of diabetes may be based on a single OGTT or fPG (135). Furthermore, fPG and 2hPG are reported to have intraindividual coefficients of variance of $13 \%$ and $7 \%$, respectively in Caucasian subjects with newly diagnosed DM (136). Although the OGTT test is more time consuming and has a higher intra-individual coefficient of variance compared to fPG, a $2 \mathrm{hPG}$ is more sensitive for the detection of NODAT and necessary for the identification of IGT after renal transplantation $(26 ; 27)$.

Glycosylated hemoglobin - HbAlc

HbAlc (normal range 3.5-6.5\%) was measured by a Diabetes Control and Complication Trial (DCCT)-aligned turbidimetric immunoinhibition (Tina-Quant II HbA1c Assay, Roche, Basel, Switzerland), using an auto-analyzer Hitachi 917 or Modular P. Precisions of the lowest and highest levels of HbA1c were $6.3 \%$ (coefficient of variance $2.8 \%$ ) and 10.7\% (coefficient of variance $2.3 \%$ ), respectively. External quality assessment showed less than $3 \%$ deviation from the target.

In Norway, High Performance Liquid Chromatography (HPLC) assay and immunological methods are commonly used for HbAlc measurements (137). The immunological method used for the analysis of $\mathrm{HbA} 1 \mathrm{c}$ is less affected by variant hemoglobin than chromatographic methods $(138 ; 139)$. The Tina-quant II HbA1c antibody recognizes the glycosylated $\mathrm{N}$-terminal part of betaglobin. Most variant hemoglobin has mutations located either in other parts of betaglobin 
than recognized by this antibody or in alpha globin. Variant hemoglobin is rare in our renal transplant population, which consists of 95\% Caucasians (140). Because of the low prevalence of variant hemoglobin and the immunological method's ability to withstand interference from variant hemoglobin, the number of possible variant hemoglobin is minimal and should not have influenced the results in this thesis. Chemically modified derivates, such as carbamylated hemoglobin (cHb), are increased in uremic patients and may falsely overestimate HbAlc (139). However, in our study, however, HbAlc was measured by enzyme immunoassay which is not influenced by hemoglobin carbamylation $(139 ; 141)$. Nevertheless, ten weeks after renal transplantation the renal function of the study participants was stabilized (mean urea 9.7 [SD 4.2] $\mathrm{mmol} / 1)$.

Pathophysiological conditions affecting red cell turnover limit the utility of $\mathrm{HbA} 1 \mathrm{c}$ in the management of glucose metabolism (139). Most patients scheduled for renal transplantation are treated with erythropoietin which increases erythrocyte turnover and consequently reduces $\mathrm{HbA1c}$. The widespread use of erythropoietin for dialysis patients and patients with chronic renal disease has minimized the degree of anemia in patients who are scheduled for renal transplantation (142). Accelerated red cell turnover probably contributes to a lower HbAlc at the time of transplantation. Early after transplantation, blood loss related to the surgical procedure and subsequent inflammation may lead to anemia. Furthermore high doses of immunosuppressive therapy causing bone marrow suppression, and the subsequent cessation of erythropoietin substitution may delay the normalization of erythrocyte turnover (142). Thus, given the short diabetes duration and a lower $\mathrm{HbAlc}$ at the time of transplantation, HbA1c cut-off for identifying diabetes might be lower in a transplant population compared to the general population. On the other hand, normalized levels of erythropoietin and hematocrit have been reported as early as two months post-transplant (142). 


\section{Viral infections}

Data on CMV infection and HCV infection were retrieved from the patients' records in the microbiology department during the first ten weeks after transplantation.

\section{Cytomegalovirus infection}

All renal transplant recipients undergo weekly testing for CMV infection during the first ten weeks. From May 1995 to 2002 CMV was assessed by virus isolation in blood by measuring CMV pp65 antigen lower matrix protein in EDTA blood samples. The results was given as the number of CMV pp65 antigen-positive cells per 100000 leukocytes. Patients with CMV pp65 antigenaemia of 1 or more per 100,000 leucocytes were classified as having CMV infection (143). Separated leucocytes (cytospins) of EDTA blood were strained for CMV pp65 by an immunocytochemical method and used for quantification. From 2002, assessment of CMV DNA in plasma was performed by a quantitative CMV DNA PCR (Cobas Amplicor CMV Monitor ${ }^{\circledR}$, Roche Diagnostics, Basel, Switzerland). The CMV PCR has been shown to be highly predictive of future CMV disease (144).

\section{Hepatitis $C$ virus infection}

The presence of antibodies to HCV was assessed by a third-generation enzyme immunoassay (Axzym HCV 3.0; Chiron, Emeryville, California, USA). The majority (99\%) of the renal transplant recipients at our centre were hepatitis $\mathrm{C}$ negative. Consequently, we have not included hepatitis $\mathrm{C}$ as a potential confounder for NODAT in the studies in this thesis. 


\section{Glucose tolerance criteria used in this thesis}

Paper 1 - Screening for new-onset diabetes after renal transplantation

The 2003 ADA criteria for the diagnosis of diabetes, which coheres with the WHOs criteria of 1999 , were employed in paper $1(24 ; 145)$. We defined a $2 \mathrm{hPG} \geq 11.1 \mathrm{mmol} / 1$ as the "golden standard" for the detection of diabetes and the diagnostic criteria of $\mathrm{fPG} \geq 7.0 \mathrm{mmol} / \mathrm{l}$ was validated using $2 \mathrm{hPG} \geq 11.1 \mathrm{mmol} / \mathrm{l}$ as the reference. In 2010 , the $\mathrm{ADA}$ introduced $\mathrm{HbA} 1 \mathrm{c} \geq 6.5 \%$ as an additional diagnostic criterion for diabetes in the general population; some six months after the publication of paper 1 (37). The newly introduced criteria were validated against the reference $(2 \mathrm{hPG} \geq 11.1 \mathrm{mmol} / \mathrm{l})$ in a posthoc analysis of data of a subgroup of 976 consecutive renal transplant recipients who underwent an OGTT ten weeks after renal transplantation.

Paper 2 - Reduced incidence of new-onset diabetes after renal transplantation

In paper 2, the WHOs 1999 criteria for the diagnosis and classification of diabetes and preDM was used to classify glucose measurement into glucose categories (24). Since the historical cohort was categorized according to the WHO criteria, we used the WHO criteria for the assessment of glucose intolerance in the new cohort. The glucose measurements from the historical cohort of 1995-96 were re-categorized according to the WHO criteria of 1999 (24).

\section{Paper 3 - Association of post-transplant hyperglycemia with mortality}

In paper 3, we explored the association of diabetes and pre-diabetic categories with long-term mortality using continuous glucose measurements and the current ADA criteria for glucose categories (Table 2) (145). In order to explore potential differences between the ADA and WHO guidelines, the analysis was additionally performed with glucose measurements categorized according to the WHO-criteria (24). Furthermore, the patients were categorized as either postchallenge hyperglycemic defined as a $2 \mathrm{hPG} \geq 7.8 \mathrm{mmol} / 1$ or normoglycemic defined as a $2 \mathrm{hPG}<7.8 \mathrm{mmol} / \mathrm{l}$. 


\section{Registry data; covariates and outcome data}

There is only one center which performs renal transplantations in Norway. Pre-transplant workup, as well as post-transplant follow-up beyond 3 months, is handled by local centres, whereas the national transplant center handles the renal transplant recipients from the time of transplantation until transferral to local units approximately three months after transplantation.

\section{Laboratory of Renal Physiology}

Since 1995, the majority of renal transplant recipients have undergone a routine laboratory examination ten weeks after transplantation, including an OGTT, before being transferred to local units, at the Laboratory of Renal Physiology. Ten weeks post-transplant, the majority of renal transplant recipients is clinically stable and immunosuppressive therapy has been reduced to maintenance levels. The following data was retrieved from the database of the Laboratory of Renal Physiology:

Paper 1: Explanatory variables: fPG, HbA1c, age, gender, height, weight, Cr-EDTA measured glomerular filtration rate (GFR), donor vital status. Outcome variables: NODAT defined by 2hPG.

Paper 2:, Explanatory variables: age, gender, height, weight, donor vital status, CNI usage (CsA and tacrolimus), doses and trough levels of CsA, prednisolone dose. Outcome variable: NODAT defined by fPG and $2 \mathrm{hPG}$.

Paper 3: Explanatory variables: fPG, 2hPG, NODAT, IGT, IFG, age, gender, height, weight, serum creatinine, Cr-EDTA GFR, donor vital status, serum lipid levels (total cholesterol, high density cholesterol, triglycerides), CNI usage (CsA and tacrolimus), doses and trough levels of CNI (CsA and tacrolimus), prednisolone dose. 
Furthermore, to obtain the best possible baseline dataset for paper 3, we searched the patient records for missing data on serum lipid levels, creatinine and $\mathrm{HbAlc}$.

\section{The Norwegian Renal Registry}

The Norwegian Renal Registry was formally constituted in 1994 as a collaboration between The Norwegian Renal Association and Oslo University Hospital, Rikshospitalet (146). Further, Norwegian renal units have reported to the ERA-EDTA-registry since the late sixties. Of the 19 counties in Norway, all but one has a central renal unit and some have two units reporting data to the Norwegian Renal Registry. Nephrologists at 24 centres annually report data on all Norwegian patients undergoing renal replacement therapy to the registry which contains data on all cardiovascular events such as cardiovascular procedures (cardiovascular surgery or percutaneous coronary intervention), myocardial infarction, strokes, graft failure and death. The numbers of death were cross-checked with the official National Census and the causes of deaths were encoded by experienced local nephrologists. Additional variables such as HLA-B27, rejection episodes, methylprednisolone doses, causes of ESRD, blood pressure, antihypertensive medication, smoking habit, pre-transplant dialysis (months on dialysis) are registered in the database. The following data was extracted from the Norwegian Renal Registry:

Paper 2: Explanatory variables: HLA-B27, total methylprednisolone dose, polycystic kidney disease,

Paper 3: Explanatory variables: pretransplant CVD, blood pressure, usage of antihypertensive medication, smoking habit (never, active, former), pre-emptive transplantation, months on dialysis before transplantation, early rejection episodes (during the first ten weeks posttransplant). Outcome variables: mortality figures and causes of death.

The results of this thesis were partly based on register analysis, and the validity of our data is therefore a reflection of the quality of the registers involved. Each register may only be used to 
describe the occurrence of the events in the studies, and not to provide any causal relationships between the explanatory variables and the events.

\section{Statistical analysis}

Descriptive data are presented as mean (standard deviation [SD]), median (range) or frequencies (\%). Differences between groups were analyzed using independent samples t-test or one way analysis of variance (ANOVA) for continuous data and chi-square test or Fishers's exact test for categorical data. Correlations were calculated with Pearson's correlations coefficient for parametric variables and Spearman's Rho for non-parametric variables. Risk estimates were presented as Odds Ratio (OR) or Hazard Ratio (HR) with 95\% CI as appropriate. For all analyses a two tailed $\mathrm{P}<0.05$ was considered significant. The analyses were performed using SPSS (Chicago IL, USA) (version 12 and 15), PASW 18 (Chicago, IL, USA) and STATA11.0 (StataCorp, College Station, TX, USA).

\section{Categorization of data}

Observational epidemiology aims to assess relationships between predictors and disease outcomes using appropriate statistical methods. Categorization of continuous data into ordinal variables (i.e. per ten years of age) or dichotome variables (i.e. above v.s. under 60 years of age) are common, but may result in several problems (147). First, valuable information and statistical power may be lost and categorization of data may bias the final results. $(59 ; 60)$. Second, arbitrary cut-offs may result in an overestimation of outcome variation between categories. Thus, individuals close to each other but on opposite sides of the cut-point (i.e. 39 years of age vs. 41 years of age with a cut-point of 40 years) are characterized as being very different rather than being very similar (60). Third, a non-linear relationship between a predictor and the outcome may be concealed $(59 ; 60)$. In view of this, we included glucose measurements three different types of 
variables: 1) continuous variables, 2) categorized variables according to the ADA (PTDM, IGT, IFG, and NGT), and 3) dichotomized variables according to the level of 2hPG (post-challenge hyperglycemia $[2 \mathrm{hPG} \geq 7.8 \mathrm{mmol} / \mathrm{l}]$ ) and normoglycemia $[2 \mathrm{hPG}<7.8 \mathrm{mmol} / \mathrm{l}]$ )

\section{Receiver operating characteristic analysis}

Receiver operating characteristic analysis was originally developed during World War II to analyze classification accuracy in differentiating signals from noise in radar detection (148). The ROC plots are commonly used to select a cut-off point to distinguish "normal" from "abnormal", and to investigate to what extent the test results differ among people who do or do not have the diagnosis of interest (149). The diagnostic accuracy of the test is given by the area under the curve (AUC). An AUC of 1 equals a perfect prediction of the diagnosis (line A) whilst an AUC of 0.5 (equals the 45 degree reference line) indicates that the test randomly predicts the

Figure 3. Hypothetical receiver operating characteristic (ROC) curves representing different levels of diagnostic accuracy by areas under the curve (AUCs).

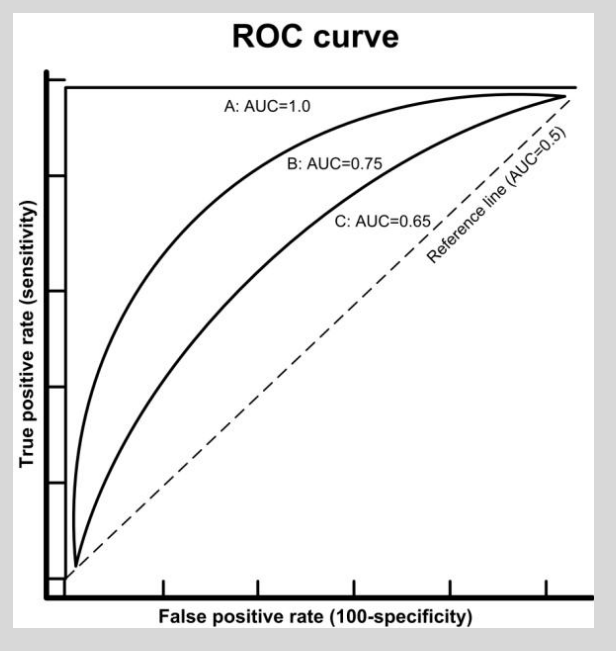
diagnosis of interest (Figure 3). As the diagnostic test accuracy improves, the ROC curve moves towards A (Figure 3). It has been suggested that an AUC greater than 0.9 has high diagnostic accuracy, levels between 0.7-0.9 indicate moderate accuracy, 0.5-0.7 low accuracy

and 0.5 indicates a chance result (150). Figure 3 demonstrates schematically different levels of diagnostic accuracy by various AUCs. 
The properties of a diagnostic or screening test are often described using sensitivity and specificity or predictive values $(151 ; 152)$. Likelihood ratios are ratios of probabilities and may be used as alternative statistics for summarizing diagnostic accuracy (153). Each test has its own likelihood ratio which summarizes how many times more likely patients with the disease are to have that test-result than patients without the disease. A likelihood ratio greater than 1 indicates that the test result is associated with the presence of the disease (positive likelihood ratio) whereas a likelihood ratio less than 1 indicates that the test result is associated with absence of the disease (negative likelihood ratio). The further the likelihood ratio is from 1, the stronger the evidence for the presence or absence of the disease. A likelihood ratio higher than ten or lower than 0.1 is considered strong evidence upon which to confirm or rule out a diagnosis of interest (153). Statistical measures descriptive of diagnostic accuracy are explained in Table 6.

There are different approaches to choosing a cut-point which determines whether a disease is present or not. If both sensitivity and specificity are equally important for the binary outcome, the optimal cut-point is identified by the point on the curve closest to the upper left hand corner (maximized sensitivity and specificity) $(149 ; 154)$. Another statistical approach is to choose the point on the curve with the maximum vertical distance from the 45-degree reference line (Youden index) (155). The choice of the cut-point that optimizes the utility of the test is often an expert opinion taking factors such as the sensitivity, specificity, cost and purpose of the test into account (154). Sensitivity and specificity are both measures of a test's performance, but provide distinct and equally important information. Sensitivity provides information on how often the test is positive in diseased persons, whereas specificity provides information on how often the test is negative in non-diseased persons (156).

A single test, such as fPG, may be used for both screening and diagnostic purposes, but different cut-points may be involved. In a highly sensitive test, a positive test result may be used to identify patients with increased risk of the disease. On the other hand, when an fPG is used for diagnostic purposes, the aim of the test would be to exclude subjects without the disease $(154 ; 156)$. In our study, we argue that for screening purposes in the early post-transplant period, a cut-point with a maximized sensitivity should be chosen and that a minimum of $80 \%$ sensitivity for diagnosing NODAT would apply for a screening test in a renal transplant population. 


\begin{tabular}{|c|c|}
\hline Term & Explanation \\
\hline Sensitivity & The proportion of true positives that are correctly identified by the test (151). \\
\hline Specificity & The proportion of true negatives that are correctly identified by the test (151). \\
\hline Positive predictive value & $\begin{array}{l}\text { The proportion of patients with positive results who are correctly diagnosed } \\
\text { (152). }\end{array}$ \\
\hline Negative predictive value & $\begin{array}{l}\text { The proportion of patients with negative test results who are correctly } \\
\text { diagnosed (152). }\end{array}$ \\
\hline Positive likelihood ratio & $\begin{array}{l}\text { The ratio of the probability of a positive test in people who do have the disease } \\
\text { to the probability of the same result in people who do not (153). }\end{array}$ \\
\hline Negative likelihood ratio & $\begin{array}{l}\text { The ratio of the probability of a negative test in people who do have the } \\
\text { disease to the probability of the same result in people who do not (153). }\end{array}$ \\
\hline
\end{tabular}

\section{Missing data and imputations}

Missing data represent a persistent problem in epidemiology. Missing data may arise from a patients' refusal or non-eligibility to participate in the study, or from single values missing in the data set. The data registries used in this thesis have evolved during the past decades and new data has been included in the database. Missing laboratory values may be due to failure in the procedure producing the value or may simply not be included in the database during the first years of registration. Consequently, although we searched the patients' records for missing values, data may not be included in the medical records and thus not available for retrospective data collection.

One approach to deal with missing values is to exclude all cases with missing values and to perform a complete case analysis (157). If the data are missing completely at random (MCAR) 43 
the analysis remains unbiased. On the other hand, since whole data sets of each subject with missing values are excluded, statistical power may be lost. Data missing at random (MAR) is the more common and non-ignorable form of missing data and may constitute a major statistical concern. However, data MAR follows a recognizable pattern and missing values may be estimated from these patterns (158). Different types of missing values are explained in Table 7. If data are not MAR or MCAR they are classified as missing not at random (MNAR) (157). By examining data sets it is not possible to distinguish between data MAR and data MNAR, but data MNAR may be processed as data MAR if additional variables that correlates to the missing data are included (157;159). Nonetheless, the statistical software for creating multiple imputations assumes that the data are MAR and even if the assumption of MAR is incorrect, the multiple imputation will provide improved estimates (159).

Table 7. Types of missing data

\begin{tabular}{ll}
\hline Term & Explanation \\
\hline Missing completely at random & Data are distributed across all observations and are independent of other data. \\
Missing at random & Data are distributed by identifiable patterns \\
Missing not at random & Data are not related to neither observed nor missing values \\
\hline
\end{tabular}

The values used to replace missing data are generated by regression models taking all other variables in the data set into consideration. For example, blood pressure may be systematically related to age, gender and BMI. Consequently a missing value for blood pressure may be predicted from a combination of these values. The number of variables in the imputation model correlates to the accuracy of the imputed data (159). Accordingly, multiple imputations creating multiple data sets rather than a single one is preferred with 3-5 iterations of imputations recommended (160). If the proportion of missing data is high, a higher number of iterations are needed. To reduce the risk of systematic bias it is recommended to perform multiple imputations on variables with more than $10 \%$ missing data. On the other hand, imputation of data is not recommended if the proportion of missing data exceeds $60 \%$ (161). 
Paper 1 - Screening and diagnostic considerations for new-onset diabetes after renal transplantation, receiver operating characteristic analysis

NODAT was diagnosed by a $2 \mathrm{hPG} \geq 11.1 \mathrm{mmol} / 1$. Renal transplant recipients with an $\mathrm{PPG} \geq 7.0$ $\mathrm{mmol} / \mathrm{l}$ were excluded from the final analysis as these patients would not require an OGTT in clinical practice. We used ROC analysis to evaluate the diagnostic accuracy of fPG and HbAlc and to define the optimal cut-off values to predict NODAT. Our choice of cut-off value for fPG and $\mathrm{HbA} 1 \mathrm{c}$ to prompt a subsequent OGTT was based upon a clinical evaluation that a minimum of $80 \%$ of the recipients with undetected NODAT should be diagnosed from the screening algorithm.

Paper 2 - Reduced incidence of new-onset diabetes after renal transplantation, logistic regression analysis

Sample size was calculated based on an assumption of 50\% reduction in the NODAT incidence found in the historical cohort of 1995-96 (28). More than 300 recipients were needed to secure a statistical power of $80 \%(\alpha=0.05)$. Thus all patients transplanted during a period of two years were evaluated for inclusion. We used univariate and multivariate logistic regression to compare the binary outcome data of NODAT incidence (yes/no) of the new cohort of renal transplanted patients with a historical cohort of patients who received a renal transplant a decade earlier. Possible predictors of NODAT were selected a priori based on analysis of the historical cohort (28). The results were presented as Odds Ratios (ORs) with 95\% confidence intervals (CIs).

Paper 3 - Association of post-transplant glycemia with mortality, Kaplan Meyer and Cox regression analysis

Kaplan-Meier plots and log-rank test were used to analyze cumulative survival for the various glucose categories. For the mortality assessment we used Cox proportional regression analysis with $2 \mathrm{hPG}$ as the time dependent variable. The analysis was adjusted for well established confounders in the multivariable analysis. We adjusted for a total of 14 confounders in the final models. Adjustments for ten events per confounding variable are generally accepted as a rule of 45 
thumb (162-164). In our models for all-cause mortality a total of 282 events occurred, but the cause-specific analysis was based on fewer events (CVD 120, malignancy 65, infectious disease 67, and other causes 17). Nonetheless, findings of a large study showed that acceptable results were achieved from multivariable regression analysis even with less than ten events per predictor variable (165). The results were presented as Hazard Ratios (HRs) with 95\% CIs. Cox regression analysis assumes proportionality between the covariates. Model discrimination was assessed by Harrell's concordance index (c-statistic). The relationship between the dependent and independent variables was assessed using multiple fractional polynomials (166), which allows for linear and non-linear relationships between a continuous independent variable and the outcome data. Multiple fractional polynomials present the relationship with the best fit for all the covariates included in the model.

Since the aim of this study was to assess the relationship between hyperglycemia and mortality, we chose not to perform multiple imputations on glucose measurements obtained by the OGTT ten weeks post-transplant. Patients who were not able to perform the OGTT were not included in the study. The following confounding variables with missing data were imputed: hypertension (32\%), smoking status (27\%), total cholesterol (10\%), height (3\%), weight (3\%), and CMV (1\%). During the imputation process both complete and incomplete data sets were used as predictors and10 iterations were generated to compensate for the number of missing data, each containing a complete data set. Subsequently, each data set was analyzed and thereafter pooled to achieve a single variable estimate. 


\section{RESULTS}

\section{Paper 1 - Screening and diagnostic considerations for new-onset diabetes after renal transplantation}

Screening for new-onset diabetes after renal transplantation

Using a large cohort of renal transplant recipient who underwent an OGTT at10 weeks posttransplant, we found that the majority of transplant patients who developed NODAT were identified by a $2 \mathrm{hPG} \geq 11.1 \mathrm{mmol} / \mathrm{l}$ after an OGTT. Of the recipients with NODAT, $80 \%$ were identified from a $2 \mathrm{hPG} \geq 11.1 \mathrm{mmol} / 1$, whereas only $50 \%$ whereas identified from an $\mathrm{PPG} \geq 7.0$ $\mathrm{mmol} / \mathrm{l}$.

After excluding recipients who had an $\mathrm{fPG}<7.0 \mathrm{mmol} / 1$, we identified three two step screening algorithms, all reaching an $80 \%$ sensitivity level: 1) $\mathrm{fPG} \geq 5.3 \mathrm{mmol} / \mathrm{l}, 2) \mathrm{HbA} 1 \mathrm{c} \geq 5.8 \%$ and 3 ) $\mathrm{fPG} \geq 5.0$ and $\mathrm{HbA} 1 \mathrm{c} \geq 5.7$ combined. The screening algorithms reduced the number of renal recipients needed to undergo an OGTT to $49 \%, 40 \%$ and $29 \%$, respectively (Table 8 ).

Table 8. Screening algorithms for NODAT based on fasting plasma glucose or HbAlc, using two hour plasma glucose as the "gold standard".

\begin{tabular}{lcccc}
\hline Cut-off value & OGTT needed (\%) & Sensitivity (\%) & $\begin{array}{c}\text { Positive } \\
\text { likelihood ratio }\end{array}$ & $\begin{array}{c}\text { Negative } \\
\text { likelihood ratio }\end{array}$ \\
\hline Fasting glucose $5.3 \mathrm{mmol} / 1$ & $49 \%$ & $81 \%$ & 1.7 & 0.4 \\
HbA1c 5.8\% & $40 \%$ & $83 \%$ & 2.2 & 0.3 \\
Fasting glucose $5.0 \mathrm{mmol} / 1$ & $29 \%$ & $79 \%$ & 2.9 & 0.3 \\
AND HbA1c 5.7\% & & & & \\
\hline
\end{tabular}




\section{Paper 2 - Reduced incidence of new-onset diabetes after renal transplantation}

In a comparative observational cohort study we compared data from a new cohort transplanted in 2004-2005 with a historical cohort transplanted in 199596. We found that the incidences of NODAT and preDM ten weeks after renal transplantation were reduced from $20 \%$ and $32 \%$ in the historical cohort to $13 \%$ and $18 \%$ in the new cohort (both $\mathrm{P}<0.001)$. The incidence of NGT had increased from $48 \%$ in the historical cohort to $69 \%$ in the new cohort $(\mathrm{P}<0.001)$ (Figure 4). The recipients in the new cohort were older (mean 47 [SD 16] vs. 50 [15] years. $\mathrm{P}=0.038)$ and had a higher $\mathrm{BMI}\left(23.5[3.8]\right.$ vs. $\left.24.5[3.6] \mathrm{kg} / \mathrm{m}^{2}, \mathrm{P}=0.003\right)$ than the historical cohort. The majority of the study participants received prednisolone and CNIs as part of their standard immunosuppressive therapy. The CsA doses and trough levels were significantly lower in the new cohort compared to the historical cohort (216 [86] vs. 242 [60] $\mu \mathrm{g} / 1, \mathrm{P}<0.001)$ and more recipients used tacrolimus ( $21 \%$ vs. $2 \%, \mathrm{P}<0.001)$.

The odds of having NODAT were reduced by more than half in the new cohort compared to NC (OR 0.44 [95\% CI 0.26-0.74]). The results were largely unchanged after multivariable adjustments for recipient age, prednisolone dose, early CMV infection and HLA-B27 (0.42 [0.23$0.77])$.
Figure 4. Incidence of new-onset diabetes after renal transplantation (NODAT), pre-diabetes (PreDM) and normal glucose tolerance (NGT) at ten weeks after transplantation in the historical (HC) and the new cohort (NC).

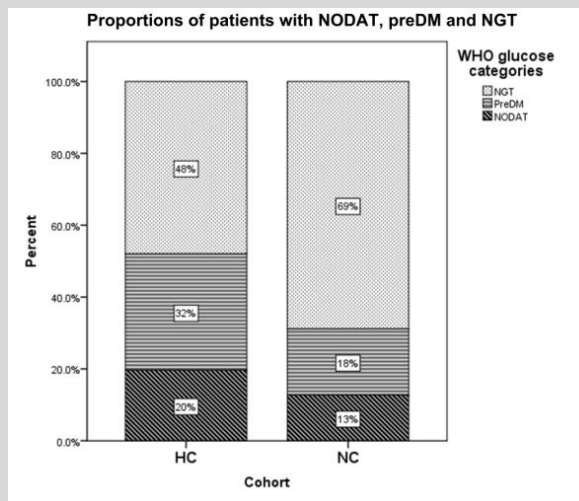




\section{Paper 3 - Association of post-transplant glycaemia with mortality}

We followed a number of 1,471 renal transplant recipients transplanted between 1995 and 2006 with no previous diagnosis of DM for a median of 6.7 (range 0.3-13.8) years. At ten weeks posttransplant 242 (17\%) had developed NODAT, 313 (22\%) IGT, 217 (16\%) IFG, and 638 (45\%) NGT.

Using ADA glucose categories as independent variables, patients with NODAT and IGT had significantly higher all cause mortality than recipients with NGT (reference category) (HR 1.54 [95\% CI 1.09-2-17] and 1.39 [1.01-1.91]). In contrast, IFG was not associated with increased mortality risk $(0.79$ [0.52-1.23]). The results were largely unchanged using WHO diagnostic criteria for diabetes (Figure 5).

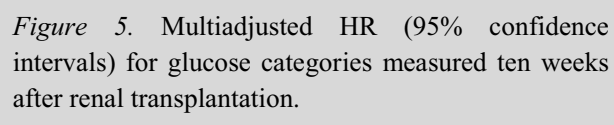
intervals) for glucose categories measured ten weeks after renal transplantation.

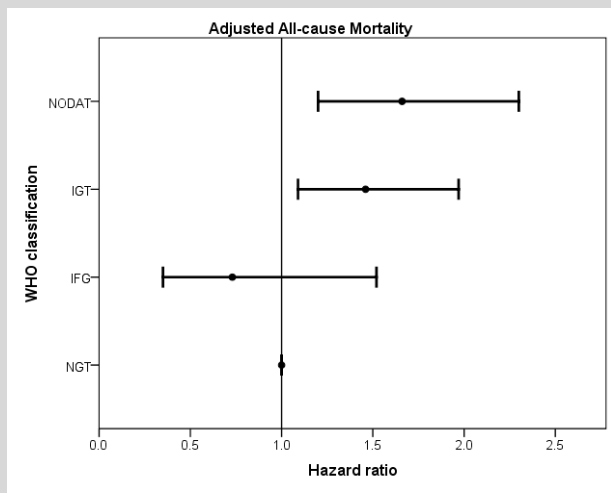

The $2 \mathrm{hPG}$, but not the fPG, measured ten weeks after transplantation was associated with allcause mortality. In the multiadjusted analysis, each $1 \mathrm{mmol} / 1$ increase in $2 \mathrm{hPG}$ was associated with HR 5\% (95\% CI 1\%-9\%) risk of dying.

Subgroup analysis showed that NODAT was associated with $80 \%$ (10\%-96\%) increased risk of $\mathrm{CV}$-death compared to NGT, whereas each mmol/1 increase in $\mathrm{PPG}$ and $2 \mathrm{hPG}$ were associated with 19\% (1\%-39\%) and 6\% (1\%-12\%) increased risk of CV-death. Post-challenge hyperglycemia $(2 \mathrm{hPG} \geq 7.8 \mathrm{mmol} / \mathrm{l})$ was associated with increased death from infectious disease (1.91 [1.09-3.33]). 


\section{DISCUSSION}

\section{Recommendations for diagnosing new-onset diabetes after renal transplantation}

The preferred diagnostic test for new-onset diabetes after renal transplantation

Our study supported the finding of a previous study that a $2 \mathrm{hPG}$ is superior to fPG for the identification of patients with NODAT in a renal transplant population (26). The use of fPG would have identified only half of the recipients with NODAT, whereas more than $80 \%$ of the recipients would have been identified from the $2 \mathrm{hPG} \geq 11.1 \mathrm{mmol} / \mathrm{l}$. The lack of a standardized of methods to diagnose NODAT, various time intervals between transplantation and diagnostic procedures, and different immunosuppressive regimens have contributed to the diversity of the NODAT incidence (167). A major strength of the studies discussed in this thesis is the large cohorts of consecutively included non-diabetic renal transplant recipients who underwent an OGTT with the same time interval between transplantation and diagnosis (70 [9] days). We have used $2 \mathrm{hPG} \geq 11.1 \mathrm{mmol} / \mathrm{l}$ as the reference for diagnosing NODAT and our results cohere with other studies examining patients with an OGTT at various time intervals post-transplant (Table 9). Accordingly, we have strengthened the evidence of early diagnosed NODAT the incidence among Caucasian transplant recipients.

The optimal time to diagnose new-onset diabetes after renal transplantation

The optimal time post-transplant to test for NODAT is unclear. In the immediate post-transplant period, the immunosuppressive therapy consists of high doses of immunosuppressive therapy which places the glucose metabolism under increased stress. Since most of the cases of NODAT develop within three months after transplantation, the testing period would seem reasonable at three to four months post-transplant (19). Furthermore, partial reversibility of NODAT in parallel with lower immunosuppressive doses is well acknowledged. In a recent study of 555 renal 
transplant recipients, $18 \%$ of recipients developed NODAT within an average of 242 (SD 640) days and 31 out of the 102 NODAT cases resolved within three months post-transplant (168). This study however, defined NODAT as an $\mathrm{fPG} \geq 7.8 \mathrm{mmol} / \mathrm{l}$ on at least two consecutive measurements or requirements of oral antidiabetic treatment and may thus have underestimated the true NODAT incidence. Another study showed that $16 \%$ of the recipients who develop NODAT within the first post-transplant year recovered to have NGT after 7 years, whereas some developed late NODAT beyond one year post-transplantation (32). Another study showed that five out of 12 recipients (42\%) with NODAT at ten weeks post-transplant regressed to NGT $(n=4)$ or IGT $(n=1)$ after 6 years (69). On the other hand, a normal OGTT at day 5 post-transplant was associated with reduced risk of NODAT during the first post-transplant year in a prospective study of 359 renal transplant recipients (68). At ten weeks post-transplant, testing for diabetes might be too early and consequently, we might have overestimated the incidence of NODAT.

Table 9. Overall incidences of New-onset diabetes after renal transplantation defined by an oral glucose tolerance test and at various time intervals between transplantation and diagnostic procedures

\begin{tabular}{|c|c|c|c|c|c|c|}
\hline \multirow[b]{2}{*}{ Study } & \multicolumn{5}{|c|}{ NODAT incidence (\%) } & \multirow{2}{*}{$\begin{array}{c}\text { Immunosuppressive } \\
\text { regimens }\end{array}$} \\
\hline & 3 & 6 & 12 & 48 & 84 & \\
\hline Hagen et. al, 2003, Norway, $n=63(84)$ & 19 & & & 22 & & Pred/CsA/Aza \\
\hline David-Neto et al. 2007, Brazil, $n=84$ (36) & 12 & 8 & 8 & & & Pred/Tac/MMF \\
\hline Hur et al, 2007, Korea, n=77 (32) & & & 39 & & 35 & Pred/CsA/MMF \\
\hline Porrini et al., 2008, Spain, $n=154$ (74) & 19 & & 20 & & & Pred/Tac/MMF \\
\hline
\end{tabular}

Pred; prednisolone, CsA; cyclosporine, Tac; tacrolimus, A, Aza; azathioprine, MMF; mycophenolate mofetil. 
The ideal time to perform the first post-transplant OGTT might be further postponed to 4-12 months post-transplantation, concurrently with the time most patients would have reached a maintenance dosage for immunosuppressive medications and the risk of opportunistic viral infections would have been reduced. Furthermore, after 4 months the erythrocyte turnover would have normalized and thus HbA1c might better concur with the glucose concentration in serum (142). However, at our center ten weeks time post-transplant is a feasible approach because at this time the patients leave the hospital after being closely monitored during the early posttransplant period. Performing an OGTT as early as ten weeks post-transplantation contributed to a more comprehensive patient inclusion and reduced the risk of selection bias in the study population.

\section{Paper 1 - Screening and diagnostic considerations for new-onset diabetes after renal transplantation}

\section{Screening for new-onset diabetes after renal transplantation}

Our study shows that the HbAlc have comparable diagnostic accuracy with fPG in the early post-transplant period using a $2 \mathrm{hPG} \geq 11.1 \mathrm{mmol} / 1$ as the reference. Although $2 \mathrm{hPG}$ is superior to fPG in the identification of NODAT, an OGTT may not be feasible in clinical practice. On the other hand, HbA1c may be useful in a two-step screening approach using a lower test-threshold to prompt a further diagnostic test for diabetes. In this sense, it would provide an additional tool for the identification
Figure 6. Diagnostic accuracy of HbAlc explored by receiver operating characteristic analysis ten weeks after renal transplantation.

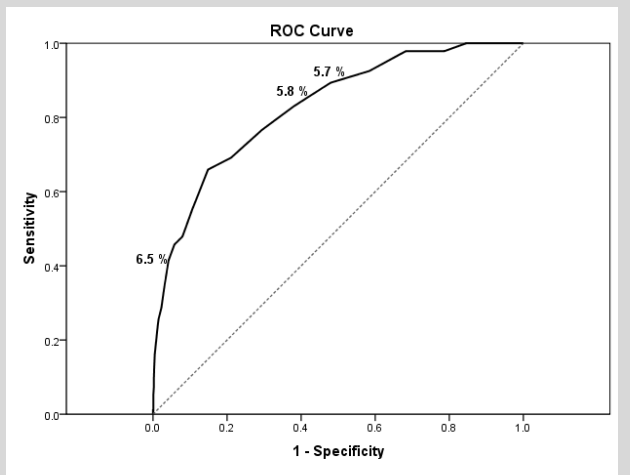

Diagonal segments are produced by ties. 
of patients at increased risk of CVD and mortality. We suggest that renal transplant recipients with an $\mathrm{HbA} 1 \mathrm{c} \geq 5.8 \%$ ten weeks post-transplant are referred to an OGTT for verification of NODAT. Alternatively, recipients with an $\mathrm{fPG} \geq 5.3 \mathrm{mmol} / \mathrm{l}$ may be referred to an OGTT. By these two algorithms $80 \%$ of the NODAT patients would be identified and $40 \%$ and $50 \%$ of the population would have to undergo an OGTT. The combined criterion of $\mathrm{fPG} \geq 5.0 \mathrm{mmol} / 1$ and HbAlc $\geq 5.7 \%$ would provide additional cost benefit and a comparable sensitivity, however, the screening algorithm may not be feasible to implement in a clinical setting. Accordingly, the usage of $\mathrm{fPG}$ and/or HbA1c as the primary screening tool for NODAT would require fewer patients to undergo an OGTT and thus provide a cost-benefit to the identification of NODAT.

\section{Choosing optimal cut-points}

The choice of a cut-off value should be based on expert opinions in addition to the ROC analysis. In this decision, an evaluation on how important it is to minimize the occurrence of false negative or positive results should be included. Clinical conditions such as the prevalence and gravity of a disease in addition to the purpose of the test should be taken into account. Increasing the sensitivity of a test will always be at the expense of decreased specificity and vice versa. Armstrong et al. examined 188 renal transplant recipients with an OGTT on average 6.6 years post-transplant and suggested that $\mathrm{fPG}$ of $5.6 \mathrm{mmol} / \mathrm{l}$ was the optimal threshold for referral to a subsequent diagnostic OGTT, predicting a diabetic $2 \mathrm{hPG} \geq 11.1 \mathrm{mmol} / 1$ with a sensitivity of $64 \%$. In this study, an fPG of $5.3 \mathrm{mmol} / 1$ and $5.0 \mathrm{mmol} / 1$ showed a sensitivity of $77 \%$ and $86 \%$, which is comparable with the findings in our study ( $81 \%$ and $91 \%$, respectively) (26). However, given the serious consequences of NODAT, we would argue for a lower cutoff to incite a subsequent diagnostic OGTT for the verification of the diagnosis. 


\section{Pre-transplant risk assessment of new-onset diabetes after renal transplantation}

Some studies have reported abnormalities in the glucose metabolism before renal transplantation as predictors for the development of NODAT $(64 ; 65 ; 116)$. In addition, a recent study showed that a simple pre-transplant risk score calculated from pre-transplant age, family history of type 2 diabetes, BMI, fPG, TG, use of goat medicine and predicted use of corticosteroids post-transplant predicted the onset of diabetes within the first year after transplantation (169). This study, however, used an $\mathrm{fPG}<7.0 \mathrm{mmol} / 1$ and $\mathrm{HbA} 1 \mathrm{c}<6.5 \%$ for the exclusion of the diagnosis of diabetes mellitus pre-transplant and might have underestimated the true prevalence of diabetes

mellitus before transplantation. In a study of 889 non-diabetic renal transplant candidates on the waiting list, pre-transplant levels of $\mathrm{fPG} \geq 7.0 \mathrm{mmol} / \mathrm{l}$ predicted a $2 \mathrm{hPG} \geq 11.1 \mathrm{mmol} / \mathrm{l}$ in only $22 \%$ of the cases. This study also showed that the diagnostic accuracy for HbAlc in detecting a $2 \mathrm{hPG} \geq 11.1 \mathrm{mmol} / 1$ was poor, predicting a $2 \mathrm{hPG} \geq 11.1 \mathrm{mmol} / 1$ in only $58 \%$ of cases $(50)$. One small study found that pre-transplant glucose abnormalities identified by an OGTT were highly specific (96\%), but had low sensitivity (23\%) in predicting NODAT at six months after transplantation, whereas random blood glucose was associated with a higher diagnostic accuracy than fPG or 2hPG (170). Also, only half of the renal transplant recipients with NODAT 12 months post-transplant had IGT before transplantation in a recent prospective study of 97 nondiabetic uremic patients on the waiting list (56). Furthermore, one study demonstrated that home glucometer monitoring improved the diagnosis of NODAT compared to an fPG in clinical visits (171). Nonetheless, since a major concern of transplant clinicians is the prevention of long-term complications, early identification of recipients with increased risk of premature death is crucial for the implementation of risk reducing strategies. Accordingly, the identification of renal transplant recipients at risk of developing NODAT should be addressed both before and after renal transplantation. 
Validation of $\mathrm{HbAlc} \geq 6.5 \%$ for the diagnosis of new-onset diabetes after renal transplantation.

A post hoc analysis of 976 recipients with $\mathrm{HbAlc}$ available (including patients with $\mathrm{fPG} \geq 7.0$ $\mathrm{mmol} / \mathrm{l}$ ) showed that 76 patients had an $\mathrm{HbAlc} \geq 6.5 \%$. and 94 recipients had NODAT defined by either an $\mathrm{fPG} \geq 7.0 \mathrm{mmol} / \mathrm{l}$ or a $2 \mathrm{hPG} \geq 11.1 \mathrm{mmol} / \mathrm{l}$. The AUC for HbAlc for identifying NODAT by either a $2 \mathrm{hPG} \geq 11.1 \mathrm{mmol} / 1$ or an $\mathrm{PPG} \geq 7.0 \mathrm{mmol} / 1$ was 0.828 (95\% CI $0.785-0.872$ ). The ROC curve is presented in Figure 6 . The sensitivity, specificity, predictive values and likelihood ratios for $\mathrm{HbA} 1 \mathrm{c} \geq 6.5 \%$ are presented in Table 10 . A sensitivity of $42 \%$ would leave 55 out of 94 with undetected NODAT. A positive diagnostic likelihood ratio of 9.9 indicates that $\mathrm{HbA} 1 \mathrm{c}$ is strongly associated with the presence of NODAT. On the other hand, although an $\mathrm{HbA} 1 \mathrm{c}<6.5 \%$ indicated the absence of NODAT, a negative likelihood ratio of 0.611 is not small enough to rule out the disease with confidence. Nevertheless, the majority of the recipients with NODAT had an $\mathrm{HbA1c}<6.5 \%$ and would remain undetected by this diagnostic approach and consequently, we argue that a diagnostic threshold for $\mathrm{HbA} 1 \mathrm{c} \geq 6.5 \%$ might be too high in a renal transplant population early post-transplant.

Table 10. Validation of the diagnostic cut-point of $H b A 1 c \geq 6.5 \%$ for the diagnosis of new-onset diabetes mellitus in a renal transplant population ten weeks after renal transplantation.

\section{Renal transplant recipients}

$(\mathbf{n}=976)$

Sensitivity

Specificity

Positive predictive value

Negative predictive value

Positive likelihood ratio

Negative likelihood ratio
0.415

0.958

0.513

0.939

9.890

0.611 
Our results showed that as early as ten weeks post-transplant, $\mathrm{HbA} 1 \mathrm{c}$ correlated with a $2 \mathrm{hPG}$ $\geq 11.1 \mathrm{mmol} / 1$ in $83 \%$ of the NODAT cases. In a study of patients with ESRD, HbA1c correlated poorly with $2 \mathrm{hPG} \geq 11.1 \mathrm{mmol} / 1$ in patients with ESRD (50). These studies add practical clinical evidence to the identification of patients with undetected diabetes before and early after renal transplantation and suggest that the diagnostic value of HbAlc may differ between ESRD and kidney transplant recipients. Different mechanisms may be involved in the development of diabetes before and after transplantation and a distinction should be made between these two groups of patients in the interpretation of $\mathrm{HbA} 1 \mathrm{c}$ values.

\section{Paper 2 - Reduced incidence of new-onset diabetes after renal transplantation}

This thesis has shown that, although the NODAT incidence has been reduced in a cohort of recipients transplanted in 1995-96 compared to a cohort of patients transplanted in 2004-05, NODAT is a common complication after renal transplantation. The NODAT incidence was lower in the new cohort than the historical cohort in spite of a higher average age and BMI, both known to increase the risk of NODAT. Accordingly, the reduced NODAT incidence might be explained by non-traditional risk factors such as a change in the immunosuppressive medication from azathioprine to MMF and consequently lower rejection rates and steroid doses. Increasing recipient age was associated with lower rates of rejections in a large study of more than 100,000 renal transplant recipients registered in the United Network for Organ Sharing database (172). Furthermore, lower CsA doses and a switch from deferred to pre-emptive treatment of CMV infection might have contributed to the lower NODAT incidence.

Our findings cohere with other studies of early incident NODAT as diagnosed by a $2 \mathrm{hPG} \geq 11.1$ $\mathrm{mmol} / \mathrm{l}$ after an OGTT including different immunosuppressive regimens (Table 9). Although a $2 \mathrm{hPG} \geq 11.1 \mathrm{mmol} / 1$ may identify a higher proportion of renal transplant patients with NODAT than $\mathrm{PPG} \geq 7.0 \mathrm{mmol} / 1$, the findings in our study also concur with studies not using the recommended diagnostic criteria for NODAT. A meta-analysis of 16 studies including more than 
3,000 patients receiving a calcineurin based immunosuppressive regimen showed that $13 \%$ of the recipients developed NODAT as defined by "insulin dependence" (i.e. treatment with insulin in previous non-diabetic subjects) during the first year after transplantation (102). A U.S. population based study showed a cumulative incidence of NODAT defined by using data from Medicare claims increasing from $9 \%$ at 3 months after transplantation, to $16 \%$ at 12 months and $24 \%$ at 36 months post-transplant (19).

\section{Type of immunosuppressive regimens}

Corticosteroids are the most consistently reported determinant of glucose intolerance in a renal transplant population $(21 ; 94 ; 173)$. Considering that a 2hPG after and OGTT identifies more patients with NODAT, a link between $2 \mathrm{hPG}$ and corticosteroid might explain this relationship. When the $2 \mathrm{hPG} 2$-hr serum glucose was considered a continuous variable, multivariate linear regression analysis showed that the association between prednisolone dose and glucose intolerance was strengthened (28). Each $1 \mathrm{mg}$ reduction of prednisolone was further associated with a $0.12 \mathrm{mmol} / 1$ decline in $2 \mathrm{hPG}$ during the first year after renal transplantation (173).

The choice of CNI may also contribute to the diversity of NODAT incidence. In a large prospective study a total of 682 de novo renal transplant recipients were randomized to either tacrolimus or CsA in addition to corticosteroids, mycophenolate mofetil and basiliximab. After six months, the incidence of the composite endpoint of IFG or NODAT was higher in the tacrolimus group than the CsA group (34\% vs. $26 \%, \mathrm{P}=0.046)$ (35).

Notably, one study found that after a successful renal transplantation, a CsA based
Figure 7. Serum insulin concentrations during hyperglycemic glucose clamp procedures before (filled squares) and after (open circles) CsA treatment. Reprinted with kind permission of the authors and Nephrology, Dialysis and Transplantation (176).

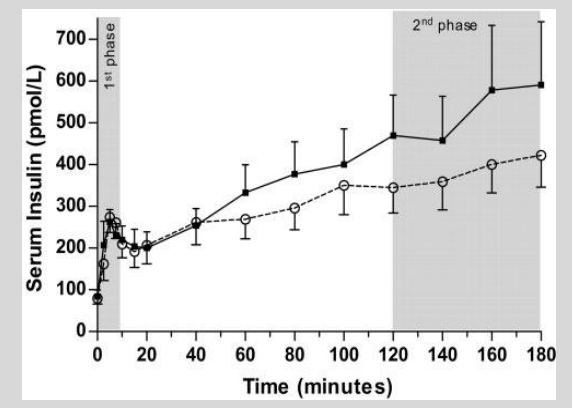


immunosuppressive regimen maintained normal insulin-secreting ability in high risk patients, whereas a tacrolimus based regimen did not (65). On the other hand, a study of non-diabetic patients in hemodialysis showed that short-term treatment with CsA decreased the second phase insulin secretion, whereas no significant change was observed in the average first phase of insulin secretion (Figure 7) (174). In our study the majority of subjects used a CsA based immunosuppressive regimen. Interestingly, we found a lower NODAT incidence in the new cohort than the historical cohort in spite of a higher proportion of recipients treated with tacrolimus (65 [21\%] versus 4 [2\%], $\mathrm{P}<0.001)$. However, the overall number of renal transplant recipients receiving tacrolimus was small, and the results should be interpreted with care.

Recent studies indicate that the mTOR sirolimus is highly diabetogenic $(99 ; 105)$. One study of 395 renal transplant recipients showed that the recipients on sirolimus had a 3.5 times increased risk of developing NODAT compared to recipients with no sirolimus (HR 3.5 [95\% CI 1.5-8.3]) (105). In a small study of 41 renal transplant recipients, both insulin release and insulin sensitivity were impaired after conversion to sirolimus and the increased insulin sensitivity correlated with the change of serum triglycerides (101). Whether the mTOR, everolimus, has a comparable effect on the glucose metabolism is not known. Impaired glucose homeostasis in renal transplant recipients receiving induction therapy with basiliximab was observed in a single center retrospective study of 264 patients (108). This finding has, however, not been verified in other studies. Furthermore, alemtuzumab induction therapy was associated with a decreased risk of NODAT, as reported in the Organ Procurement Transplant Network/United Network of Organ Sharing database (30). Our study participants were predominantly treated with a CsA based regiment, and induction therapy was not included in the immunosuppressive protocols for either the historical cohort or the new cohort.

\section{Steroid free protocols, withdrawal or tapering}

Given the close relationship between corticosteroids doses and impaired glucose metabolism, a reduction in the incidence of NODAT is consistent with the introduction of newer and more 
potent immunosuppressive medication and subsequent reduced rejection rates and lower steroid doses. Steroid free protocols would potentially reduce the risk of NODAT without an increased risk of acute rejections, and lower rates of NODAT have been reported in renal transplant recipients on prednisolone-free maintenance immunosuppression therapy (91). Furthermore, de novo use of antihyperglycemic medication was significantly lower in a steroid free group compared to patients receiving standard steroid therapy in a randomized multicenter study (175). However, conflicting evidence exists on the occurrence of acute rejections rates and long-term outcomes after early steroid withdrawal or tapering. Some studies have suggested that avoiding steroid therapy increased the risk of acute allograft rejection without adversely affecting patients and graft survival (96;175-177). By contrast, a meta-analysis of immunosuppression withdrawal trials showed an increased proportion of patients with acute rejection (mean difference 0.14 [95\%c CI 0.10-0.17]) and an increased risk of graft failure (RR 1.38 [1.08-1.67]) after steroid withdrawal (97). A large US data register showed that renal transplant recipients discharged without steroids who were restarted on corticosteroids after 6-12 months had a $20 \%$ (95\% CI $11 \%-32 \%$ ) increased risk of graft failure (93). Nevertheless, withdrawal of $5 \mathrm{mg}$ prednisolone may not influence insulin sensitivity significantly (95).

\section{Dosage and blood levels of immunosuppressive drugs}

The diabetogenic risk associated with prednisolone is probably dose related (28;173). In keeping with another study, we found a positive continuous relationship between steroid dosage and NODAT (28). In our study, each $1 \mathrm{mg}$ increased prednisolone dose was associated with $11 \%$ increased multiadjusted odds of developing NODAT. Nevertheless, tapering off prednisolone has beneficial effects on insulin action and glucose tolerance after renal transplantation, but a reduction below $5 \mathrm{mg} /$ day may not influence insulin sensitivity significantly $(95 ; 173)$.

Targeting CNI concentrations levels in order to minimize risk factors for CVD or nephrotoxicity, while maintaining adequate immunosuppressive effect such as to avoid acute rejection, is of clinical interest. Studies have suggested that C2 levels of CsA are superior to the C0 levels in 
predicting early post-transplant CsA exposure and acute rejection after renal transplantation $(178 ; 179)$. On the other hand, a recent study of 225 renal transplant recipients reported that both $\mathrm{C} 2$ and $\mathrm{C} 0$ were useful to predict CsA side effects (180). In our study the dosages of CsA were adjusted according to $\mathrm{C} 0$ levels in the historical cohort and according to $\mathrm{C} 2$ levels in the new cohort. However, for comparison, mean C0 levels were reported in the study. Both the C0 levels and the CsA doses were significantly lower in the new cohort compared to the historical cohort ( 216 vs. $242 \mu \mathrm{g} / 1$ and 312 vs. $342 \mathrm{mg} /$ day, both $\mathrm{P}<0.001$ ). Given that the impact of CNI on glucose intolerance may be dose related, a lower CsA dose might have contributed to the reduced NODAT incidence observed in the new cohort (181). A CNI minimizing strategy may be advantageous in terms of renal function by reduced rejection rates as well as for adverse effects such as NODAT in the short-term. However, although the CNI minimization strategies may reduce short-term outcome after renal transplantation, recent studies have reported that the most common cause of late graft failure is immunologic, indicating that inappropriate low exposure to immunosuppressive therapy may result in chronic allograft rejection (182).

\section{Cytomegalovirus infection: in or out?}

A tendency towards lower CMV infection was seen in the new cohort compared to the historical cohort $(54 \%$ vs. $63 \%, \mathrm{P}=0.071)$. Although both the CMV pp65 antigen positive cell detection and the CMV DNA PCR detection are able to detect CMV in blood before the onset of CMV disease, the usage of a PCR technique for the detection of CMV DNA is reported to be more sensitive for the prediction of future CMV disease (144). Thus, the reduced incidence of CMV infection in the new cohort compared to the historical cohort might have been underestimated in this study. However, the reduced incidence of NODAT during the past few decades is more likely to be explained by a change from deferred to pre-emptive treatment of CMV infection. In the historical cohort, patients were treated with ganciclovir when they experienced clinical symptoms of CMV infection, whereas in the new cohort, patients with asymptomatic CMV infection as defined by a positive screening test for CMV were treated orally with valganciclovir. Accordingly, this change in CMV treatment might have contributed to a lower peak and duration 
of viral load in addition to a tendency towards lower CMV infection rate. Thus, given the link between CMV infection and the development of NODAT, the change from deferred to preemptive CMV treatment might have contributed to the reduced incidence seen in the new cohort.

\section{Paper 3 - Association of post-transplant glycemia with mortality}

Our data indicate that a $2 \mathrm{hPG}$ is superior to and independent of fPG in predicting long-term mortality outcome. In our study each $1 \mathrm{mmol} / 1$ increased $2 \mathrm{hPG}$ was associated with $5 \%$ increased risk of death from any cause and a $6 \%$ increased risk of death from CV disease. Similar riskestimates ( $6 \%$ increased risk of all-cause mortality per $1 \mathrm{mmol} / 1$ increment in $2 \mathrm{hPG}$ ) for all cause mortality were recently presented in a study of 505 type 2 diabetic patients (183). In this study self-monitored postprandial blood glucose and $\mathrm{HbA} 1 \mathrm{c}$ independently predicted $\mathrm{CV}$ events and all-cause mortality whereas PPG did not. These risk-estimates support the results of our study and extend the validity to a non-transplant population. Large epidemiological studies have shown that renal transplant recipients with NODAT diagnosed by Medicare claims or by the need of glucose lowering treatment, have a two-fold increased all cause mortality risk compared to recipients without NODAT $(18 ; 19)$. One study investigated the mortality risk in a renal transplant population by comparing both patients with pre-existing diabetes before transplantation and patients with NODAT with non-diabetic patients (18). A survival plot starting at the time of NODAT diagnosis was superimposable with the survival plots for recipients with pre-existing diabetes and it was significantly different from the survival of patients without diabetes (18). This finding indicates that the development of NODAT may be associated with an accelerated progression of diabetes related complications affecting patient survival. The results of our study partly cohere with the findings of these two studies and extend the validity of the results to NODAT defined by a $2 \mathrm{hPG} \geq 11.1 \mathrm{mmol} / 1$. 


\section{Causes of death after renal transplantation}

The main cause of death among renal transplant patients with NODAT is CVD, accounting for nearly half the deaths after renal transplantation $(18 ; 119 ; 184)$. The prevalence of CVD among recipients with pre-existing diabetes and NODAT is reported to be higher than in recipients without diabetes which might explain the higher prevalence of $\mathrm{CV}$ deaths among recipients with NODAT compared to NGT (119). However, a significant reduction in the CV death rate has been demonstrated from the early 1980's to the modern times (adjusted RR 0.61 [95\% CI 0.36-0.96]), suggesting improvements in CV risk management and patients outcome after renal transplantation (8). However, although the number of $\mathrm{CV}$-deaths was reduced, the proportion of deaths attributable to $\mathrm{CV}$ disease has remained unchanged during the last decades, whereas the reduction of death rates may have been caused by a decline in death by infectious disease (8). The proportion of CV deaths (42\%) found in our study cohere with these other studies, whereas the proportion of deaths from malignant disease and infectious disease differed $(8 ; 184)$. Our results included only $5 \%$ deaths from unknown causes which indicate a higher proportion of death from any of the other known causes.

\section{Impact of categorization of continuous glucose measurement}

Assessments of glucose consist of values measured on a continuous scale and categorizing the glucose measurements into glucose categories may contribute to loss of variation within each category. For instance, the mortality risk of a patient with a $2 \mathrm{hPG}$ of $7.7 \mathrm{mmol} / 1$ may not be significantly different from a patient with a $2 \mathrm{hPG}$ of $7.9 \mathrm{~mol} / \mathrm{l}$ although by categorization, they represent different categories (NGT and IGT, respectively).

Although the relationship between continuously measured fPG and all-cause mortality was not statistically significant in our study, a trend of reduced patient survival was shown. In addition, a J-shaped relationship between PPG and cause-specific death has been reported in a general population (127). A possible J-shaped relationship between the dependent and independent variable in a proportional Cox regression analysis might contribute to an underestimation of the 
risk associated with fPG by a false assumption of proportionality. In our study, however, we were unable to confirm a non-linear relationship using multivariable fractional polynomials and no non-linear models of either fPG or 2hPG outperformed the linear model in our sets of data.

\section{The risk of cardiovascular disease with transient diabetes after renal transplantation}

We assessed the association between OGTT derived blood glucose levels measured ten weeks after renal transplantation and long-term mortality outcome without a repeated diagnostic test. By three months post-transplant the immunosuppressive treatment is lowered to a maintenance levels and consequently the impact of immunosuppressive drugs on glycemia may have been reduced. As is shown in Table 9, the incidence of NODAT is lower beyond the first three months posttransplant and consequently, the CV risk of patients with transient NODAT might be reduced in this subgroup of patients. Cosio et al. found that the incidence of $\mathrm{CV}$ events in recipients with persistent NODAT, NODAT that resolved within one month and euglycemia was $23 \%, 10 \%$ and $11 \%$, respectively (31). A post hoc analysis of 23 patients showed that a major cardiac event occurred more frequently in patients with persistent NODAT $(n=11)$ compared to recipients with transient NODAT $(\mathrm{n}=12)$ (none vs. $36 \%, \mathrm{P}=0.037$ ) (119). These findings underline the importance of early identification and repeated assessment of glucose abnormalities to help attenuate or regress the development of NODAT and to prevent CV events.

Is pre-diabetes after renal transplantation a predictor for mortality?

In the general population, it is well established that persons with preDM, either IFG or IGT are associated with increased mortality risk $(123 ; 131 ; 185)$. However, no previous studies have assessed the impact of preDM on long-term mortality outcome in a renal transplant population. Using fPG 5.0-5.5 mmol/l as the reference, one study of renal transplant recipients reported a two-fold increased risk of CV events at five years of patients with fPG 6.1-6.9 mmol/1 (IFG by WHO), but not for patients with fPG levels between 5.6-6.0 mmol/1 (IFG by ADA) (31). We 63 
found no association between IFG and mortality using either ADA or WHO criteria for IFG. The Emerging Risk Factors Collaboration (ERFC) recently demonstrated an association between increasing fasting glucose levels $\geq 5.6 \mathrm{mmol} / 1$ and non-vascular, non-malignant mortality in a general population (127). In this study, post-challenge hyperglycemia, was neither addressed nor discussed as a possible limitation. Individuals with IFG might also have IGT, and thus, the ERFC-study did not address the effect of isolated IFG on non-vascular, non-malignant mortality. In our study, death from infectious disease accounted for the majority (69\%) of non-vascular, non-malignant deaths. Furthermore, no association was found between PPG and malignant or infectious death. Post-challenge glucose $\geq 140 \mathrm{mg} / \mathrm{dl}(7.8 \mathrm{mmol} / \mathrm{l})$ was associated with a $50 \%$ increased risk of infectious death. Nonetheless, our study is the first to indicate both that IGT is associated with increased risk of death from any cause and that post-challenge hyperglycemia correlates to increased risk of death from infectious diseases after renal transplantation. These finding, however, require verification from other populations.

\section{Isolated non-diabetic hyperglycemia: a predictor for mortality after renal transplantation?}

The isolated clinical contribution of post-transplant hyperglycemia to all-cause and CV mortality is unknown. Hyperglycemia is associated with other risk factors for all-cause mortality such as components of the metabolic syndrome. Consequently measurements of hyperglycemia may be a biomarker of increased mortality risk of causes other than abnormal glucose metabolism. Assessments of the impact of post-transplant hyperglycemia on long-term outcome are limited by variations of immunosuppressive therapy, relatively short-term follow-up, and the multifactorial risk management of the high risk population of renal transplant recipients. To clarify the contribution of hyperglycemia on patient survival, prospective studies addressing the impact of glucose lowering therapy on patient outcome are needed. One recent study of the general population aimed to assess the impact of post-prandial glucose lowering treatment with nateglinide in addition to lifestyle modification on incident diabetes or CV events (186). In this study, persons with IGT treated with nateglinide over a five year period did not show reduced incidence of diabetes or the composite cardiovascular endpoints. Furthermore, early intensive 
multifactorial management of 3,057 patients with screen detected type 2 diabetes did not show a significant reduction in the five year incidence of $\mathrm{CV}$ events and death in the general population (187). In this study, the lack of differences between the intervention groups and the control group may be attributed to the quality of care delivered to both groups as the CV-risk factors were assessed, indicating that the screening process itself may be beneficial for patients unaware of the increased risk of morbidity and mortality. 


\section{LIMITATIONS}

In this thesis, less than $10 \%$ of the participants were unable to perform an OGTT and since the non-eligible patients were older and more likely to receive a kidney from a deceased donor, they might have contributed to a sample selection bias. On the other hand, since the patients not included in these studies were older, they might have had a higher risk of developing NODAT and consequently the NODAT incidence may have been underestimated.

The participants in these studies were almost exclusively Caucasians and hepatitis $\mathrm{C}$ negative. Consequently, the results reported may neither apply to populations of other ethnicities nor to populations with a higher prevalence of hepatitis C. On the other hand, comparable results on NODAT incidence and evidence about the association between NODAT and patient survival have been reported in studies including multiple races and ethnicities $(18 ; 19)$. Furthermore, hepatitis $\mathrm{C}$ infection can be excluded as a potentially confounding variable in the interpretation of our results.

Although a higher proportion of the recipients used tacrolimus in the new cohort than in the historical cohort, the majority of patients were maintained on a CsA based immunosuppressive regimen. Many transplant centers are currently using tacrolimus as the immunosuppressive drug of choice. Furthermore, less than 5\% used a non CNI based immunosuppressive regimen (data not shown). The results of our study are thus constricted to a Norwegian renal transplant population using CsA and may not be valid in populations using other immunosuppressive therapy.

Finally, we used a $2 \mathrm{hPG} \geq 11.1 \mathrm{mmol} / 1$ as the "gold standard" for diagnosing NODAT. However, since different diagnostic criteria for diabetes (fPG, $2 \mathrm{hPG}$ and $\mathrm{HbA1c}$ ) identify patients with different glucose metabolism, subgroups of patients may be diagnosed by an $\mathrm{fPG} \geq 7.0 \mathrm{mmol} / \mathrm{l}$ alone or an $\mathrm{HbA} 1 \mathrm{c} \geq 6.5 \%$ alone. Consequently, by defining a $2 \mathrm{hPG}$ after an OGTT as the reference for diagnosing NODAT, some patients with NODAT may remain undetected. 


\section{CONCLUSIONS}

Our findings support the continued usage of a $2 \mathrm{hPG} \geq 11.1 \mathrm{mmol} / 1$ as the more sensitive test for the identification of Norwegian subjects with unknown NODAT. Based on our results, we suggest that two screening algorithms may be feasible in a renal transplant population ten weeks post-transplant. An $\mathrm{HbAlc} \geq 5.8 \%$ or an $\mathrm{fPG} \geq 5.3 \mathrm{mmol} / 1$ may both be used as a primary screening test to select patients to a subsequent OGTT. By these screening algorithms $80 \%$ of the NODAT cases would have been identified and $40 \%$ and $50 \%$ of the renal transplant population would require an OGTT for the verification of NODAT.

We have demonstrated that the incidence of NODAT among Norwegian renal transplant recipients in the early post-transplant period has declined during the last decade. Possible explanations for this improvement are more effective immunosuppressive therapy resulting in a lower frequency of acute rejection and consequently lower steroid doses and a change in the treatment strategy of CMV infection.

We have also shown that early measured glycemia among Norwegian renal transplant recipients predicted long-term survival after renal transplantation and that postprandial hyperglycemia as expressed by $2 \mathrm{hPG}$ may be superior to $\mathrm{PPG}$ in predicting long-term overall mortality and CV mortality. Furthermore, we have demonstrated that the prediabetic glucose category; IGT, but not IFG, is associated with reduced long-term patient survival after renal transplantation. 


\section{IMPLICATIONS AND FUTURE PERSPECTIVES}

The prospective studies in this thesis included a large cohort of renal transplant recipients and may be said to have broadened the level of current understanding surrounding the association between early post-transplant hyperglycemia and patient mortality. The studies further support the continued usage of an OGTT for both diagnosing NODAT and predicting long-term mortality after renal transplantation. We have presented updated incidence figures of early NODAT in line with the recommendations for diagnosing diabetes. However, the incidence of NODAT will probably increase in line with the growing number of obese and older renal transplant recipients (188).

\section{The optimal test and time for diagnosing of new-onset diabetes after renal transplantation}

By performing a routine OGTT ten weeks after renal transplantation we have verified the superior diagnostic sensitivity of an OGTT. Most patients with NODAT have an elevated 2hPG after an OGTT, whereas PPG is often within the normal range. More than half the NODAT cases were identified from a $2 \mathrm{hPG} \geq 11.1 \mathrm{mmol} / 1$ alone whereas $17 \%$ were identified from an $\mathrm{fPG} \geq 7.0$ $\mathrm{mmol} / \mathrm{l}$ and $32 \%$ fulfilled both the criteria. We argue therefore against the current guidelines which suggest that fPG should be the preferred diagnostic test. Nonetheless, performing an OGTT is time consuming and may be difficult to implement as a routine procedure in clinical practice. An alternate screening algorithm may therefore help clinicians to select a subgroup of patients in need of an OGTT for the verification of NODAT.

In the general population, new diagnostic criteria suggest that three diagnostic tests are valid for the diagnosis of DM: fPG, $2 \mathrm{hPG}$ or HbA1c (37). Whether any single diagnostic test should be preferred in a renal transplantation population remains, however, unclear. Although the usage of 
HbA1c as a diagnostic test may be welcomed in the general population, the usage of $\mathrm{HbA1c}$ in the screening and diagnosis of early NODAT has several limitations.

The identification of the optimal time to test for NODAT needs further investigation. Whether a pre-transplant OGTT should guide the choice of immunosuppressive drug regimen is unclear. The rationale for most clinicians in selecting an optimal immunosuppressive therapy is to prevent acute rejection, whereas the predominant cause of graft loss is death with a functioning graft (184). Although pre-transplant testing for NODAT is reported to have low sensitivity for detecting post-transplant hyperglycemia, early identification of both pre-transplant hyperglycemia and NODAT is necessary in order to maintain vigilance regards risk reducing strategies after renal transplantation. To prevent NODAT risk assessment should be performed while patients are still on the waiting list. Future studies should therefore focus on pre-transplant examination of the glucose metabolism in order to tailor immunosuppressive therapy such that it further reduces the risk of NODAT. In patients with increased risk of NODAT, lower doses of prednisolone or tacrolimus should be considered after surgery.

\section{Immunosuppressive therapy: impact on incident diabetes and long-term post- transplant complications}

Newer immunosuppressive drugs may have contributed to the lower NODAT incidence during the last decade, possibly by mechanisms such as lower rejection rates and steroid doses. Current trends in immunosuppression focus on the development of novel agents, and further investigation will hopefully show whether new immunosuppressive drugs will contribute to a further reduction of NODAT incidence. The CNIs have been largely responsible for the low rates of rejections and thus improved short-time outcomes; however they have had little impact on long-term outcome after renal transplantation. Although CNI minimizing strategies may benefit renal transplant patients short-term, recent studies have shown that the most common cause of late allograft failure is immunologic $(181 ; 182)$. Thus, low exposure to immunosuppression in the long-term may result in recurrent disease or chronic alloimmune rejection. The nephrotoxicity and the 69 
unfavorable metabolic side effects associated with current immunosuppressive therapy may be the predominant obstacle in securing improvements in long-term allograft outcomes. Further progress may depend upon new immunosuppressive agents with novel mechanisms of action and a minimum of toxic adverse effects. Agents, targeting humoral immune system have shown improved metabolic risk profile although the acute rejection rates have been higher than for CNIs $(189 ; 190)$. In parallel with the development of newer immunologic agents with minimal nephrotoxic adverse effects and impact on the recipients' CV risk profile; we must continue to monitor risk factors for post-transplant morbidity and mortality.

\section{The role of isolated post-transplantation hyperglycemia in long-term morbidity and mortality}

Although a 2hPG after an OGTT may help select a sub-population with increased risk of premature death after renal transplantation, the specific contribution of post-transplant hyperglycemia is unclear. Epidemiological studies of the general population suggest that postprandial hyperglycemia positively affect the development of CVD, but randomized prospective studies targeting postprandial hyperglycemia have failed to provide evidence of reduced hard CV end points (191). Thus, post-prandial hyperglycemia may represent a marker rather than a risk factor of long-term complications. Future randomized studies addressing the impact of glucose lowering treatment on long-term mortality outcome should investigate in a renal transplant population whether glucose lowering treatment reduces the risk of death. Also, in the context of limited organs there is a tendency of increased acceptance of donors which previously would have been considered unsuitable which may affect patient outcome after renal transplantation (192).

Furthermore, the associations between NODAT and microvascular complications among renal transplant recipients are unknown. The evidence linking NODAT to microvascular complications is limited and the recommendations for screening and management of microvascular complications are in line with the recommendations of the non-transplant population. 
Considering that NODAT may have accelerated progression of diabetes related complication, microvascular complications are likely to be prevalent in transplant population. In parallel with the implementation of risk reducing strategies in renal transplant populations, future studies should address the impact of NODAT on microvascular complications.

\section{Management of new-onset diabetes after renal transplantation}

Intensified lifestyle modifications should be encouraged to prevent and reduce $\mathrm{CV}$ risk after renal transplantation. Active lifestyle intervention has been reported to improve $2 \mathrm{hPG}$ in patients with IGT and NODAT and a regression of IGT to NGT in a renal transplant population followed for six months (74).

There is a paucity of data concerning the usage of hypoglycemic agents after renal transplantation with guidelines predominantly derived from data of non-transplant populations. However, in a renal transplant population, the choice of hypoglycemic agents may not comply with the guidelines for treating type 2 diabetes. First, immunosuppressive drugs are associated with serious drug-interactions. Second, many renal transplant recipient have reduced GFR which may influence the choice of hypoglycemic drug. Metformin is established as the first line agent for type 2 diabetes. However, though it has been suggested that metformin is safe down to a minimum estimated GFR of $30 \mathrm{ml} / \mathrm{min}$ (193), clinicians are reluctant to prescribe metformin due to renal insufficiency. Third, renal transplant recipients often have advanced atherosclerosis and the choice of hypoglycemic treatment should aim to improve rather than increase their risk of progressive CVD. Accordingly, the drug of choice in a renal transplant population may include short-acting insulin secretagogues and possibly metformin in the context of an adequate kidney function (i.e. GFR above $50 \mathrm{ml} / \mathrm{min}$ ). In any case, insulin should be administered in cases of persistent hyperglycemia. Future studies are needed in order to assess the efficacy and safety of hypoglycemic agents for the treatment of NODAT. 


\section{REFERENCES}

(1) Merrill JP, Murray JE, Harrison JH, Guild WR. Successful Homotransplantation of the Human Kidney Between Identical Twins. JAMA: The Journal of the American Medical Association 1984 May 18;251(19):2566-71.

(2) Cash MP, Dente CJ, Feliciano DV. Joseph E. Murray (1919- ). Arch Surg 2005 Mar;140(3):270-2.

(3) Reisaeter AV. Kidney transplantation in Norway - a historical perspective. Tidsskr Nor Laegeforen 1999 Sep 10;119(21):3163-6.

(4) Thorsby E. Transplantation medicine in Norway through 50 years. Tidsskr Nor Laegeforen 2006 Dec 14;126(24):3305-10.

(5) Briggs JD. Causes of death after renal transplantation. Nephrol Dial Transplant 2001 Aug;16(8):1545-9.

(6) Wolfe RA, Ashby VB, Milford EL, Ojo AO, Ettenger RE, Agodoa LY, et al. Comparison of mortality in all patients on dialysis, patients on dialysis awaiting transplantation, and recipients of a first cadaveric transplant. N Engl J Med 1999 Dec 2;341(23):1725-30.

(7) Kasiske BL, Maclean JR, Snyder JJ. Acute myocardial infarction and kidney transplantation. J Am Soc Nephrol 2006 Mar;17(3):900-7.

(8) Pilmore H, Dent H, Chang S, McDonald SP, Chadban SJ. Reduction in cardiovascular death after kidney transplantation. Transplantation 2010 Apr 15;89(7):851-7.

(9) Meier-Kriesche HU, Schold JD, Kaplan B. Long-term renal allograft survival: have we made significant progress or is it time to rethink our analytic and therapeutic strategies? Am J Transplant 2004 Aug;4(8):1289-95.

(10) Brennan DC. Long-term trends in allograft survival. Adv Chronic Kidney Dis 2006 Jan;13(1):11-7.

(11) Miller LW. Cardiovascular Toxicities of Immunosuppressive Agents. Am J Transplant 2002;2(9):807-18.

(12) Nankivell BJ, Borrows RJ, Fung CL, O'Connell PJ, Allen RD, Chapman JR. The natural history of chronic allograft nephropathy. N Engl J Med 2003 Dec 11;349(24):2326-33.

(13) Becker B, Kronenberg F, Kielstein JT, Haller H, Morath C, Ritz E, et al. Renal insulin resistance syndrome, adiponectin and cardiovascular events in patients with kidney 
disease: the mild and moderate kidney disease study. J Am Soc Nephrol 2005 Apr;16(4):1091-8.

(14) Nam JH, Mun JI, Kim SI, Kang SW, Choi KH, Park K, et al. beta-Cell dysfunction rather than insulin resistance is the main contributing factor for the development of postrenal transplantation diabetes mellitus. Transplantation 2001 May 27;71(10):141723.

(15) RIFKIND D, MARCHIORO TL, WADDELL WR, STARZL TE. Infectious diseases associated with renal homotransplantation. JAMA 1964 Aug 10;189:397-407.

(16) Arner P, Gunnarsson R, Blomdahl S, Groth CG. Some characteristics of steroid diabetes: a study in renal-transplant recipients receiving high-dose corticosteroid therapy. Diabetes Care 1983 Jan;6(1):23-5.

(17) Isoniemi HM, Ahonen J, Tikkanen MJ, von Willebrand EO, Krogerus L, Eklund BH, et al. Long-term consequences of different immunosuppressive regimens for renal allografts. Transplantation 1993 Mar;55(3):494-9.

(18) Cosio FG, Pesavento TE, Kim S, Osei K, Henry M, Ferguson RM. Patient survival after renal transplantation: IV. Impact of post-transplant diabetes. Kidney Int 2002 Oct;62(4):1440-6.

(19) Kasiske BL, Snyder JJ, Gilbertson D, Matas AJ. Diabetes mellitus after kidney transplantation in the United States. Am J Transplant 2003 Feb;3(2):178-85.

(20) First MR, Gerber DA, Hariharan S, Kaufman DB, Shapiro R. Posttransplant diabetes mellitus in kidney allograft recipients: incidence, risk factors, and management. Transplantation 2002 Feb 15;73(3):379-86.

(21) Montori VM, Basu A, Erwin PJ, Velosa JA, Gabriel SE, Kudva YC. Posttransplantation diabetes: a systematic review of the literature. Diabetes Care 2002 Mar;25(3):583-92.

(22) Davidson J, Wilkinson A, Dantal J, Dotta F, Haller H, Hernandez D, et al. New-onset diabetes after transplantation: 2003 International consensus guidelines. Proceedings of an international expert panel meeting. Barcelona, Spain, 19 February 2003. Transplantation 2003 May 27;75(10 Suppl):SS3-24.

(23) Report of the Expert Committee on the Diagnosis and Classification of Diabetes Mellitus. Diabetes Care 1997 Jul;20(7):1183-97.

(24) Department of Noncommunicable Disease Surveillance WHO. Definition, diagnosis and classification of diabetes mellitus and its complications: Report of a WHO consultation. Part 1: Diagnosis and classification of diabetes Mellitus. Geneva: World Health Organization. 1999. http://whqlibdoc.who.int/hq/1999/WHO NCD NCS 99.2.pdf 
(25) Hjelmesaeth J, Jenssen T, Hartmann A. Diagnosing PTDM. Transplantation 2003 May 27;75(10):1761.

(26) Armstrong KA, Prins JB, Beller EM, Campbell SB, Hawley CM, Johnson DW, et al. Should an oral glucose tolerance test be performed routinely in all renal transplant recipients? Clin J Am Soc Nephrol 2006 Jan;1(1):100-8.

(27) Delgado P, Diaz JM, Silva I, Osorio JM, Osuna A, Bayes B, et al. Unmasking glucose metabolism alterations in stable renal transplant recipients: a multicenter study. Clin J Am Soc Nephrol 2008 May;3(3):808-13.

(28) Hjelmesaeth J, Hartmann A, Kofstad J, Stenstrom J, Leivestad T, Egeland T, et al. Glucose intolerance after renal transplantation depends upon prednisolone dose and recipient age. Transplantation 1997 Oct 15;64(7):979-83.

(29) Cosio FG, Pesavento TE, Osei K, Henry ML, Ferguson RM. Post-transplant diabetes mellitus: increasing incidence in renal allograft recipients transplanted in recent years. Kidney Int $2001 \mathrm{Feb} ; 59(2): 732-7$.

(30) Shah T, Kasravi A, Huang E, Hayashi R, Young B, Cho YW, et al. Risk factors for development of new-onset diabetes mellitus after kidney transplantation.

Transplantation 2006 Dec 27;82(12):1673-6.

(31) Cosio FG, Kudva Y, van d, V, Larson TS, Textor SC, Griffin MD, et al. New onset hyperglycemia and diabetes are associated with increased cardiovascular risk after kidney transplantation. Kidney Int 2005 Jun;67(6):2415-21.

(32) Hur KY, Kim MS, Kim YS, Kang ES, Nam JH, Kim SH, et al. Risk factors associated with the onset and progression of posttransplantation diabetes in renal allograft recipients. Diabetes Care 2007 Mar;30(3):609-15.

(33) Luan FL, Stuckey LJ, Ojo AO. Abnormal glucose metabolism and metabolic syndrome in non-diabetic kidney transplant recipients early after transplantation. Transplantation 2010 Apr 27;89(8):1034-9.

(34) Mathew JT, Rao M, Job V, Ratnaswamy S, Jacob CK. Post-transplant hyperglycaemia: a study of risk factors. Nephrol Dial Transplant 2003 Jan;18(1):164-71.

(35) Vincenti F, Friman S, Scheuermann E, Rostaing L, Jenssen T, Campistol JM, et al. Results of an international, randomized trial comparing glucose metabolism disorders and outcome with cyclosporine versus tacrolimus. Am J Transplant 2007 Jun;7(6):150614.

(36) David-Neto E, Lemos FC, Fadel LM, Agena F, Sato MY, Coccuza C, et al. The dynamics of glucose metabolism under calcineurin inhibitors in the first year after renal transplantation in nonobese patients. Transplantation 2007 Jul 15;84(1):50-5. 
(37) Standards of Medical Care in Diabetes-2010. Diabetes Care 2010 Jan;33(Supplement 1):S11-S61.

(38) Rodrigo E, Fernandez-Fresnedo G, Valero R, Ruiz JC, Pinera C, Palomar R, et al. Newonset diabetes after kidney transplantation: risk factors. J Am Soc Nephrol 2006 Dec;17(12 Suppl 3):S291-S295.

(39) Fishman JA, Rubin RH. Infection in organ-transplant recipients. N Engl J Med 1998 Jun 11;338(24):1741-51.

(40) Hjelmesaeth J, Sagedal S, Hartmann A, Rollag H, Egeland T, Hagen M, et al. Asymptomatic cytomegalovirus infection is associated with increased risk of new-onset diabetes mellitus and impaired insulin release after renal transplantation. Diabetologia 2004 Sep;47(9):1550-6.

(41) Bloom RD, Rao V, Weng F, Grossman RA, Cohen D, Mange KC. Association of hepatitis $\mathrm{C}$ with posttransplant diabetes in renal transplant patients on tacrolimus. J Am Soc Nephrol 2002 May;13(5):1374-80.

(42) Andermann A, Blancquaert I, Beauchamp S, Dery V. Revisiting Wilson and Jungner in the genomic age: a review of screening criteria over the past 40 years. Bull World Health Organ 2008 Apr;86(4):317-9.

(43) Wilson, J. M. G and Jungner, G. Principles and practice of screening for disease. 1968. http://whqlibdoc.who.int/php/WHO_PHP_34.pdf

(44) Glumer C, Yuyun M, Griffin S, Farewell D, Spiegelhalter D, Kinmonth AL, et al. What determines the cost-effectiveness of diabetes screening? Diabetologia 2006 Jul;49(7):1536-44.

(45) Borch-Johnsen K, Lauritzen T, Glumer C, Sandbaek A. Screening for Type 2 diabetes-should it be now? Diabet Med 2003 Mar;20(3):175-81.

(46) Wareham NJ, Griffin SJ. Should we screen for type 2 diabetes? Evaluation against National Screening Committee criteria. BMJ 2001 Apr 21;322(7292):986-8.

(47) Ziemer DC, Kolm P, Weintraub WS, Vaccarino V, Rhee MK, Caudle JM, et al. Age, $\mathrm{BMI}$, and race are less important than random plasma glucose in identifying risk of glucose intolerance: the Screening for Impaired Glucose Tolerance Study (SIGT 5). Diabetes Care 2008 May;31(5):884-6.

(48) Is fasting glucose sufficient to define diabetes? Epidemiological data from 20 European studies. The DECODE-study group. European Diabetes Epidemiology Group. Diabetes Epidemiology: Collaborative analysis of Diagnostic Criteria in Europe. Diabetologia 1999 Jun;42(6):647-54. 
(49) Buell C, Kermah D, Davidson MB. Utility of A1C for diabetes screening in the 1999 2004 NHANES population. Diabetes Care 2007 Sep;30(9):2233-5.

(50) Bergrem HA, Valderhaug TG, Hartmann A, Hjelmesaeth J, Leivestad T, Bergrem H, et al. Undiagnosed diabetes in kidney transplant candidates: a case-finding strategy. Clin J Am Soc Nephrol 2010 Apr;5(4):616-22.

(51) Bloom RD, Crutchlow MF. New-onset diabetes mellitus in the kidney recipient: diagnosis and management strategies. Clin J Am Soc Nephrol 2008 Mar;3 Suppl 2:S38S48.

(52) Sharif A, Baboolal K. Diagnostic application of the A(1c) assay in renal disease. J Am Soc Nephrol 2010 Mar;21(3):383-5.

(53) Hoban R, Gielda B, Temkit M, Saha C, Book BK, Baker E, et al. Utility of HbA1c in the detection of subclinical post renal transplant diabetes. Transplantation $2006 \mathrm{Feb}$ $15 ; 81(3): 379-83$.

(54) Hjelmesaeth J, Midtvedt K, Jenssen T, Hartmann A. Insulin resistance after renal transplantation: impact of immunosuppressive and antihypertensive therapy. Diabetes Care 2001 Dec;24(12):2121-6.

(55) Ekstrand A, Schalin-Jantti C, Lofman M, Parkkonen M, Widen E, Franssila-Kallunki A, et al. The effect of (steroid) immunosuppression on skeletal muscle glycogen metabolism in patients after kidney transplantation. Transplantation $1996 \mathrm{Mar}$ 27;61(6):889-93.

(56) Hornum M, Jorgensen KA, Hansen JM, Nielsen FT, Christensen KB, Mathiesen ER, et al. New-onset diabetes mellitus after kidney transplantation in Denmark. Clin J Am Soc Nephrol 2010 Apr;5(4):709-16.

(57) Balagopal PB, de Ferranti SD, Cook S, Daniels SR, Gidding SS, Hayman LL, et al. Nontraditional risk factors and biomarkers for cardiovascular disease: mechanistic, research, and clinical considerations for youth: a scientific statement from the American Heart Association. Circulation 2011 Jun 14;123(23):2749-69.

(58) Vasan RS. Biomarkers of cardiovascular disease: molecular basis and practical considerations. Circulation 2006 May 16;113(19):2335-62.

(59) Froslie KF, Roislien J, Laake P, Henriksen T, Qvigstad E, Veierod MB. Categorisation of continuous exposure variables revisited. A response to the Hyperglycaemia and Adverse Pregnancy Outcome (HAPO) Study. BMC Med Res Methodol 2010;10:103.

(60) Altman DG, Royston P. The cost of dichotomising continuous variables. BMJ 2006 May 6;332(7549):1080. 
(61) Kang ES, Kim MS, Kim YS, Hur KY, Han SJ, Nam CM, et al. A variant of the transcription factor 7-like 2 (TCF7L2) gene and the risk of posttransplantation diabetes mellitus in renal allograft recipients. Diabetes Care 2008 Jan;31(1):63-8.

(62) Bamoulid J, Courivaud C, Deschamps M, Mercier P, Ferrand C, Penfornis A, et al. IL-6 promoter polymorphism -174 is associated with new-onset diabetes after transplantation. J Am Soc Nephrol 2006 Aug;17(8):2333-40.

(63) Porrini E, Moreno JM, Osuna A, Benitez R, Lampreabe I, Diaz JM, et al. Prediabetes in patients receiving tacrolimus in the first year after kidney transplantation: a prospective and multicenter study. Transplantation 2008 Apr 27;85(8):1133-8.

(64) Bergrem HA, Valderhaug TG, Hartmann A, Bergrem H, Hjelmesaeth J, Jenssen T. Glucose tolerance before and after renal transplantation. Nephrol Dial Transplant 2010 Mar;25(3):985-92.

(65) Sato T, Inagaki A, Uchida K, Ueki T, Goto N, Matsuoka S, et al. Diabetes mellitus after transplant: relationship to pretransplant glucose metabolism and tacrolimus or cyclosporine A-based therapy. Transplantation 2003 Nov 15;76(9):1320-6.

(66) Hjelmesaeth J, Hartmann A, Midtvedt K, Aakhus S, Stenstrom J, Morkrid L, et al. Metabolic cardiovascular syndrome after renal transplantation. Nephrol Dial Transplant 2001 May;16(5):1047-52.

(67) Ramesh Prasad GV, Kim SJ, Huang M, Nash MM, Zaltzman JS, Fenton SS, et al. Reduced incidence of new-onset diabetes mellitus after renal transplantation with 3hydroxy-3-methylglutaryl-coenzyme a reductase inhibitors (statins). Am J Transplant 2004 Nov;4(11):1897-903.

(68) Kuypers DR, Claes K, Bammens B, Evenepoel P, Vanrenterghem Y. Early clinical assessment of glucose metabolism in renal allograft recipients: diagnosis and prediction of post-transplant diabetes mellitus (PTDM). Nephrol Dial Transplant 2008 Jun;23(6):2033-42.

(69) Hagen M, Hjelmesaeth J, Jenssen T, Morkrid L, Hartmann A. A 6-year prospective study on new onset diabetes mellitus, insulin release and insulin sensitivity in renal transplant recipients. Nephrol Dial Transplant 2003 Oct;18(10):2154-9.

(70) Rodrigo E, Santos L, Pinera C, Quintanar JA, Ruiz JC, Fernandez-Fresnedo G, et al. Early prediction of new-onset diabetes mellitus by fifth-day fasting plasma glucose, pulse pressure, and proteinuria. Transplant Proc 2011 Jul;43(6):2208-10.

(71) Kelley DE, Goodpaster BH. Skeletal muscle triglyceride. An aspect of regional adiposity and insulin resistance. Diabetes Care 2001 May;24(5):933-41.

(72) Hjelmesaeth J, Asberg A, Muller F, Hartmann A, Jenssen T. New-onset posttransplantation diabetes mellitus: insulin resistance or insulinopenia? Impact of 
immunosuppressive drugs, cytomegalovirus and hepatitis $\mathrm{C}$ virus infection. Curr Diabetes Rev 2005 Feb;1(1):1-10.

(73) Bruce CR, Hawley JA. Improvements in insulin resistance with aerobic exercise training: a lipocentric approach. Med Sci Sports Exerc 2004 Jul;36(7):1196-201.

(74) Sharif A, Moore R, Baboolal K. Influence of lifestyle modification in renal transplant recipients with postprandial hyperglycemia. Transplantation 2008 Feb 15;85(3):353-8.

(75) Gustafsson PE, Persson M, Hammarstrom A. Life course origins of the metabolic syndrome in middle-aged women and men: the role of socioeconomic status and metabolic risk factors in adolescence and early adulthood. Ann Epidemiol 2011 Feb;21(2):103-10.

(76) Langenberg C, Kuh D, Wadsworth ME, Brunner E, Hardy R. Social circumstances and education: life course origins of social inequalities in metabolic risk in a prospective national birth cohort. Am J Public Health 2006 Dec;96(12):2216-21.

(77) Hjelmesaeth J, Muller F, Jenssen T, Rollag H, Sagedal S, Hartmann A. Is there a link between cytomegalovirus infection and new-onset posttransplantation diabetes mellitus? Potential mechanisms of virus induced beta-cell damage. Nephrol Dial Transplant 2005 Nov;20(11):2311-5.

(78) Baid S, Tolkoff-Rubin N, Farrell ML, Delmonico F, Williams WW, Hayden D, et al. Tacrolimus-associated posttransplant diabetes mellitus in renal transplant recipients: role of hepatitis C infection. Transplant Proc 2002 Aug;34(5):1771-3.

(79) Gourishankar S, Jhangri GS, Tonelli M, Wales LH, Cockfield SM. Development of diabetes mellitus following kidney transplantation: a Canadian experience. Am J Transplant 2004 Nov;4(11):1876-82.

(80) Sharif A, Baboolal K. Risk factors for new-onset diabetes after kidney transplantation. Nat Rev Nephrol 2010 Jul;6(7):415-23.

(81) Ibernon M, Moreso F, Moreno JM, Bestard O, Cruzado JM, Grinyo JM, et al. Low serum mannose-binding lectin as a risk factor for new onset diabetes mellitus after renal transplantation. Transplantation 2009 Jul 27;88(2):272-8.

(82) Murray JE, Merrill JP, DAMMIN GJ, DEALY JB, Jr., WALTER CW, BROOKE MS, et al. Study on transplantation immunity after total body irradiation: clinical and experimental investigation. Surgery $1960 \mathrm{Jul} ; 48: 272-84$.

(83) Citterio F. Steroid side effects and their impact on transplantation outcome. Transplantation 2001 Dec 27;72(12 Suppl):S75-S80. 
(84) Vanrenterghem YF, Claes K, Montagnino G, Fieuws S, Maes B, Villa M, et al. Risk factors for cardiovascular events after successful renal transplantation. Transplantation 2008 Jan 27;85(2):209-16.

(85) Oterdoom LH, de Vries AP, Gansevoort RT, van Son WJ, van der Heide JJ, Ploeg RJ, et al. Determinants of insulin resistance in renal transplant recipients. Transplantation 2007 Jan 15;83(1):29-35.

(86) van Raalte DH, Nofrate V, Bunck MC, van IT, Elassaiss SJ, Nassander UK, et al. Acute and 2-week exposure to prednisolone impair different aspects of beta-cell function in healthy men. Eur J Endocrinol 2010 Apr;162(4):729-35.

(87) Yki-Jarvinen H. Pathogenesis of non-insulin-dependent diabetes mellitus. Lancet 1994 Jan 8;343(8889):91-5.

(88) Weyer C, Bogardus C, Mott DM, Pratley RE. The natural history of insulin secretory dysfunction and insulin resistance in the pathogenesis of type 2 diabetes mellitus. J Clin Invest 1999 Sep;104(6):787-94.

(89) Clunk JM, Lin CY, Curtis JJ. Variables affecting weight gain in renal transplant recipients. Am J Kidney Dis 2001 Aug;38(2):349-53.

(90) El Haggan W., Vendrely B, Chauveau P, Barthe N, Castaing F, Berger F, et al. Early evolution of nutritional status and body composition after kidney transplantation. Am $\mathrm{J}$ Kidney Dis 2002 Sep;40(3):629-37.

(91) Matas AJ, Kandaswamy R, Gillingham KJ, McHugh L, Ibrahim H, Kasiske B, et al. Prednisone-free maintenance immunosuppression-a 5-year experience. Am J Transplant 2005 Oct;5(10):2473-8.

(92) Grinyo JM. Steroid sparing strategies in renal transplantation. Nephrol Dial Transplant 2005 Oct;20(10):2028-31.

(93) Schold JD, Santos A, Rehman S, Magliocca J, Meier-Kriesche HU. The success of continued steroid avoidance after kidney transplantation in the US. Am J Transplant 2009 Dec;9(12):2768-76.

(94) Boots JM, van Duijnhoven EM, Christiaans MH, Wolffenbuttel BH, van Hooff JP. Glucose metabolism in renal transplant recipients on tacrolimus: the effect of steroid withdrawal and tacrolimus trough level reduction. J Am Soc Nephrol 2002 Jan;13(1):221-7.

(95) Midtvedt K, Hjelmesaeth J, Hartmann A, Lund K, Paulsen D, Egeland T, et al. Insulin resistance after renal transplantation: the effect of steroid dose reduction and withdrawal. J Am Soc Nephrol 2004 Dec;15(12):3233-9. 
(96) Hricik DE, O'Toole MA, Schulak JA, Herson J. Steroid-free immunosuppression in cyclosporine-treated renal transplant recipients: a meta-analysis. J Am Soc Nephrol 1993 Dec;4(6):1300-5.

(97) Kasiske BL, Chakkera HA, Louis TA, Ma JZ. A meta-analysis of immunosuppression withdrawal trials in renal transplantation. J Am Soc Nephrol 2000 Oct;11(10):1910-7.

(98) Weir MR, Fink JC. Risk for posttransplant Diabetes mellitus with current immunosuppressive medications. Am J Kidney Dis 1999 Jul;34(1):1-13.

(99) Johnston O, Rose CL, Webster AC, Gill JS. Sirolimus is associated with new-onset diabetes in kidney transplant recipients. J Am Soc Nephrol 2008 Jul;19(7):1411-8.

(100) Roland M, Gatault P, Doute C, Buchler M, Al-Najjar A, Barbet C, et al. Immunosuppressive medications, clinical and metabolic parameters in new-onset diabetes mellitus after kidney transplantation. Transpl Int 2008 Jun;21(6):523-30.

(101) Teutonico A, Schena PF, Di PS. Glucose metabolism in renal transplant recipients: effect of calcineurin inhibitor withdrawal and conversion to sirolimus. J Am Soc Nephrol 2005 Oct;16(10):3128-35.

(102) Heisel O, Heisel R, Balshaw R, Keown P. New onset diabetes mellitus in patients receiving calcineurin inhibitors: a systematic review and meta-analysis. Am J Transplant 2004 Apr;4(4):583-95.

(103) Knoll GA, Bell RC. Tacrolimus versus cyclosporin for immunosuppression in renal transplantation: meta-analysis of randomised trials. BMJ 1999 Apr 24;318(7191):11047.

(104) Webster AC, Woodroffe RC, Taylor RS, Chapman JR, Craig JC. Tacrolimus versus ciclosporin as primary immunosuppression for kidney transplant recipients: metaanalysis and meta-regression of randomised trial data. BMJ 2005 Oct 8;331(7520):810.

(105) Gyurus E, Kaposztas Z, Kahan BD. Sirolimus therapy predisposes to new-onset diabetes mellitus after renal transplantation: a long-term analysis of various treatment regimens. Transplant Proc 2011 Jun;43(5):1583-92.

(106) Mathis AS, Dave N, Knipp GT, Friedman GS. Drug-related dyslipidemia after renal transplantation. Am J Health Syst Pharm 2004 Mar 15;61(6):565-85.

(107) Chueh SC, Kahan BD. Dyslipidemia in renal transplant recipients treated with a sirolimus and cyclosporine-based immunosuppressive regimen: incidence, risk factors, progression, and prognosis. Transplantation $2003 \mathrm{Jul}$ 27;76(2):375-82.

(108) Aasebo W, Midtvedt K, Valderhaug TG, Leivestad T, Hartmann A, Reisaeter AV, et al. Impaired glucose homeostasis in renal transplant recipients receiving basiliximab.

Nephrol Dial Transplant 2010 Apr;25(4):1289-93. 
(109) Sagedal S, Hartmann A, Nordal KP, Osnes K, Leivestad T, Foss A, et al. Impact of early cytomegalovirus infection and disease on long-term recipient and kidney graft survival. Kidney Int 2004 Jul;66(1):329-37.

(110) Hartmann A, Sagedal S, Hjelmesaeth J. The natural course of cytomegalovirus infection and disease in renal transplant recipients. Transplantation 2006 Jul 27;82(2 Suppl):S15S17.

(111) Leung Ki EL, Venetz JP, Meylan P, Lamoth F, Ruiz J, Pascual M. Cytomegalovirus infection and new-onset post-transplant diabetes mellitus. Clin Transplant 2008 Mar;22(2):245-9.

(112) Sharma RK, Prakash R, Jeloka T, Gupta A, Gulati S, Sharma AP, et al. Posttransplant diabetes mellitus in renal transplant recipients-a single-center experience. Transplant Proc 2003 Feb;35(1):266-7.

(113) Domsgen E, Paroni F, Kerr-Conte A, Dotzauer A, and Maedler K. Endosomal TLR3 activation by Coxachievirus initiates stron immune response and death of beta cells. Diabetologia 2011 (54), Supplement 1, 184.

(114) Mehta SH, Brancati FL, Sulkowski MS, Strathdee SA, Szklo M, Thomas DL. Prevalence of type 2 diabetes mellitus among persons with hepatitis $\mathrm{C}$ virus infection in the United States. Ann Intern Med 2000 Oct 17;133(8):592-9.

(115) Finni PE, Souza ER, Rioja S, Ventura S, Starling P, Almeida JR, et al. Is hepatitis C a risk factor to posttransplant diabetes mellitus after renal transplantation in patients using tacrolimus? Transplant Proc 2004 May;36(4):884-5.

(116) Kamar N, Mariat C, Delahousse M, Dantal J, Al NA, Cassuto E, et al. Diabetes mellitus after kidney transplantation: a French multicentre observational study. Nephrol Dial Transplant 2007 Jul;22(7):1986-93.

(117) Sens YA, Silva VD, Malafronte P, Souza JF, Miorin LA, Jabur P. Posttransplant diabetes mellitus in renal transplant patients with hepatitis $C$ virus. Transplant Proc 2004 May;36(4):886-8.

(118) Revanur VK, Jardine AG, Kingsmore DB, Jaques BC, Hamilton DH, Jindal RM. Influence of diabetes mellitus on patient and graft survival in recipients of kidney transplantation. Clin Transplant 2001 Apr;15(2):89-94.

(119) Hjelmesaeth J, Hartmann A, Leivestad T, Holdaas H, Sagedal S, Olstad M, et al. The impact of early-diagnosed new-onset post-transplantation diabetes mellitus on survival and major cardiac events. Kidney Int 2006 Feb;69(3):588-95.

(120) Kuo HT, Sampaio MS, Vincenti F, Bunnapradist S. Associations of pretransplant diabetes mellitus, new-onset diabetes after transplant, and acute rejection with transplant outcomes: an analysis of the Organ Procurement and Transplant Network/United 
Network for Organ Sharing (OPTN/UNOS) database. Am J Kidney Dis 2010 Dec;56(6):1127-39.

(121) Cole EH, Johnston O, Rose CL, Gill JS. Impact of Acute Rejection and New-Onset Diabetes on Long-Term Transplant Graft and Patient Survival. Clinical Journal of the American Society of Nephrology 2008 May;3(3):814-21.

(122) Matas AJ, Gillingham KJ, Humar A, Ibrahim HN, Payne WD, Gruessner RW, et al. Posttransplant diabetes mellitus and acute rejection: impact on kidney transplant outcome. Transplantation 2008 Feb 15;85(3):338-43.

(123) Glucose tolerance and mortality: comparison of WHO and American Diabetes Association diagnostic criteria. The DECODE study group. European Diabetes Epidemiology Group. Diabetes Epidemiology: Collaborative analysis Of Diagnostic criteria in Europe. Lancet 1999 Aug 21;354(9179):617-21.

(124) deVegt F, Dekker JM, Ruhe HG, Stehouwer CD, Nijpels G, Bouter LM, et al. Hyperglycaemia is associated with all-cause and cardiovascular mortality in the Hoorn population: the Hoorn Study. Diabetologia 1999 Aug;42(8):926-31.

(125) Ceriello A. The post-prandial state and cardiovascular disease: relevance to diabetes mellitus. Diabetes Metab Res Rev 2000 Mar;16(2):125-32.

(126) Barr EL, Boyko EJ, Zimmet PZ, Wolfe R, Tonkin AM, Shaw JE. Continuous relationships between non-diabetic hyperglycaemia and both cardiovascular disease and all-cause mortality: the Australian Diabetes, Obesity, and Lifestyle (AusDiab) study. Diabetologia 2009 Mar;52(3):415-24.

(127) Seshasai SR, Kaptoge S, Thompson A, Di AE, Gao P, Sarwar N, et al. Diabetes mellitus, fasting glucose, and risk of cause-specific death. N Engl J Med 2011 Mar 3;364(9):829-41.

(128) Sarwar N, Gao P, Seshasai SR, Gobin R, Kaptoge S, Di AE, et al. Diabetes mellitus, fasting blood glucose concentration, and risk of vascular disease: a collaborative metaanalysis of 102 prospective studies. Lancet 2010 Jun 26;375(9733):2215-22.

(129) The DECODE Study Group. Is the Current Definition for Diabetes Relevant to Mortality Risk From All Causes and Cardiovascular and Noncardiovascular Diseases? Diabetes Care 2003 Mar 1;26(3):688-96.

(130) Barr EL, Zimmet PZ, Welborn TA, Jolley D, Magliano DJ, Dunstan DW, et al. Risk of cardiovascular and all-cause mortality in individuals with diabetes mellitus, impaired fasting glucose, and impaired glucose tolerance: the Australian Diabetes, Obesity, and Lifestyle Study (AusDiab). Circulation 2007 Jul 10;116(2):151-7. 
(131) Meisinger C, Wolke G, Brasche S, Strube G, Heinrich J. Postload plasma glucose and 30 -year mortality among nondiabetic middle-aged men from the general population: the ERFORT Study. Ann Epidemiol 2006 Jul;16(7):534-9.

(132) Ford ES, Zhao G, Li C. Pre-diabetes and the risk for cardiovascular disease: a systematic review of the evidence. J Am Coll Cardiol 2010 Mar 30;55(13):1310-7.

(133) Rustad P, Felding P, Franzson L, Kairisto V, Lahti A, Martensson A, et al. The Nordic Reference Interval Project 2000: recommended reference intervals for 25 common biochemical properties. Scand J Clin Lab Invest 2004;64(4):271-84.

(134) D'Orazio P, Burnett RW, Fogh-Andersen N, Jacobs E, Kuwa K, Kulpmann WR, et al. Approved IFCC recommendation on reporting results for blood glucose: International Federation of Clinical Chemistry and Laboratory Medicine Scientific Division, Working Group on Selective Electrodes and Point-of-Care Testing (IFCC-SD-WGSEPOCT). Clin Chem Lab Med 2006;44(12):1486-90.

(135) Department of Noncommunicable Disease Management WHO. Screening for Type 2 Diabetes. Report of a World Health Organisation and International Diabetes Federation meeting. Geneva, World Health Organisation. 2003. http://whqlibdoc.who.int/hq/2003/WHO NMH_MNC 03.1.pdf

(136) Mooy JM, Grootenhuis PA, de VH, Kostense PJ, Popp-Snijders C, Bouter LM, et al. Intra-individual variation of glucose, specific insulin and proinsulin concentrations measured by two oral glucose tolerance tests in a general Caucasian population: the Hoorn Study. Diabetologia 1996 Mar;39(3):298-305.

(137) Berg JP, Hanssen KF, Bjerve KS, Claudi T, Dahl-Jorgensen K, Rustad P, et al. [Standardized hemoglobin A1C for diagnostic use?]. Tidsskr Nor Laegeforen $2011 \mathrm{Mar}$ 18;131(6):565-6.

(138) Chang J, Hoke C, Ettinger B, Penerian G. Evaluation and interference study of hemoglobin A1c measured by turbidimetric inhibition immunoassay. Am J Clin Pathol 1998 Mar;109(3):274-8.

(139) Bry L, Chen PC, Sacks DB. Effects of hemoglobin variants and chemically modified derivatives on assays for glycohemoglobin. Clin Chem 2001 Feb;47(2):153-63.

(140) Graesdal JS, Gundersen K, Holm B, Waage A. [Thalassemia and sickle-cell disease in Norway]. Tidsskr Nor Laegeforen 2001 Feb 28;121(6):678-80.

(141) Weykamp CW, Penders TJ, Siebelder CW, Muskiet FA, van der Slik W. Interference of carbamylated and acetylated hemoglobins in assays of glycohemoglobin by HPLC, electrophoresis, affinity chromatography, and enzyme immunoassay. Clin Chem 1993 Jan;39(1):138-42. 
(142) Winkelmayer WC, Chandraker A. Pottransplantation anemia: management and rationale. Clin J Am Soc Nephrol 2008 Mar;3 Suppl 2:S49-S55.

(143) Rollag H, Sagedal S, Holter E, Degre M, Ariansen S, Nordal KP. Diagnosis of cytomegalovirus infection in kidney transplant recipients by a quantitative RNA-DNA hybrid capture assay for cytomegalovirus DNA in leukocytes. Eur J Clin Microbiol Infect Dis 1998 Feb;17(2):124-7.

(144) Rollag H, Sagedal S, Kristiansen KI, Kvale D, Holter E, Degre M, et al. Cytomegalovirus DNA concentration in plasma predicts development of cytomegalovirus disease in kidney transplant recipients. Clin Microbiol Infect 2002 Jul;8(7):431-4.

(145) Report of the expert committee on the diagnosis and classification of diabetes mellitus. Diabetes Care 2003 Jan;26 Suppl 1:S5-20.

(146) The Norwegian Renal Registry. The Norwegian Renal Registry. Annual report 2009. 2009. www.nephro.no/nnr/AARSM2009.pdf

(147) Turner EL, Dobson JE, Pocock SJ. Categorisation of continuous risk factors in epidemiological publications: a survey of current practice. Epidemiol Perspect Innov 2010;7:9.

(148) Lusted LB. Signal detectability and medical decision-making. Science 1971 Mar 26;171(977):1217-9.

(149) Zou KH, O'Malley AJ, Mauri L. Receiver-operating characteristic analysis for evaluating diagnostic tests and predictive models. Circulation 2007 Feb 6;115(5):654-7.

(150) Akobeng AK. Understanding diagnostic tests 3: Receiver operating characteristic curves. Acta Paediatr 2007 May;96(5):644-7.

(151) Altman DG, Bland JM. Diagnostic tests. 1: Sensitivity and specificity. BMJ 1994 Jun $11 ; 308(6943): 1552$.

(152) Altman DG, Bland JM. Diagnostic tests 2: Predictive values. BMJ 1994 Jul 9;309(6947):102.

(153) Deeks JJ, Altman DG. Diagnostic tests 4: likelihood ratios. BMJ 2004 Jul 17;329(7458):168-9.

(154) Peat J, Barton B. Medical statistics. A guide to data analysis and critical appraisal. London, Blackwell Publishing, BMJ Books. 2005.

(155) Perkins NJ, Schisterman EF. The inconsistency of "optimal" cutpoints obtained using two criteria based on the receiver operating characteristic curve. Am J Epidemiol 2006 Apr 1;163(7):670-5. 
(156) Soreide K. Receiver-operating characteristic curve analysis in diagnostic, prognostic and predictive biomarker research. J Clin Pathol 2009 Jan;62(1):1-5.

(157) Haukoos JS, Newgard CD. Advanced statistics: missing data in clinical research--part 1: an introduction and conceptual framework. Acad Emerg Med 2007 Jul;14(7):662-8.

(158) Newgard CD, Haukoos JS. Advanced statistics: missing data in clinical research--part 2: multiple imputation. Acad Emerg Med 2007 Jul;14(7):669-78.

(159) Sinharay S, Stern HS, Russell D. The use of multiple imputation for the analysis of missing data. Psychol Methods 2001 Dec;6(4):317-29.

(160) van Buuren S, Boshuizen HC, Knook DL. Multiple imputation of missing blood pressure covariates in survival analysis. Stat Med 1999 Mar 30;18(6):681-94.

(161) Barzi F, Woodward M. Imputations of missing values in practice: results from imputations of serum cholesterol in 28 cohort studies. Am J Epidemiol $2004 \mathrm{Jul}$ $1 ; 160(1): 34-45$.

(162) Concato J, Peduzzi P, Holford TR, Feinstein AR. Importance of events per independent variable in proportional hazards analysis. I. Background, goals, and general strategy. J Clin Epidemiol 1995 Dec;48(12):1495-501.

(163) Peduzzi P, Concato J, Feinstein AR, Holford TR. Importance of events per independent variable in proportional hazards regression analysis. II. Accuracy and precision of regression estimates. J Clin Epidemiol 1995 Dec;48(12):1503-10.

(164) Peduzzi P, Concato J, Kemper E, Holford TR, Feinstein AR. A simulation study of the number of events per variable in logistic regression analysis. J Clin Epidemiol 1996 Dec;49(12):1373-9.

(165) Vittinghoff E, McCulloch CE. Relaxing the rule of ten events per variable in logistic and Cox regression. Am J Epidemiol 2007 Mar 15;165(6):710-8.

(166) Royston P, Ambler G, Sauerbrei W. The use of fractional polynomials to model continuous risk variables in epidemiology. Int J Epidemiol 1999 Oct;28(5):964-74.

(167) Yates CJ, Fourlanos S, Hjelmesaeth J, Colman PG, Cohney SJ. New-Onset Diabetes After Kidney Transplantation-Changes and Challenges. Am J Transplant 2011 Nov 28.

(168) Demirci MS, Toz H, Yilmaz F, Ertilav M, Asci G, Ozkahya M, et al. Risk factors and consequences of post-transplant diabetes mellitus. Clin Transplant 2010 Sep;24(5):E170-E177.

(169) Chakkera HA, Weil EJ, Swanson CM, Dueck AC, Heilman RL, Reddy KS, et al. Pretransplant risk score for new-onset diabetes after kidney transplantation. Diabetes Care 2011 Oct;34(10):2141-5. 
(170) Ramesh Prasad GV, Huang M, Bandukwala F, Nash MM, Rapi L, Montada-Atin T, et al. Pre-transplantation glucose testing for predicting new-onset diabetes mellitus after renal transplantation. Clin Nephrol 2009 Feb;71(2):140-6.

(171) Shah A, Kendall G, Demme RA, Taylor J, Bozorgzadeh A, Orloff M, et al. Home glucometer monitoring markedly improves diagnosis of post renal transplant diabetes mellitus in renal transplant recipients. Transplantation 2005 Sep 27;80(6):775-81.

(172) Tullius SG, Tran H, Guleria I, Malek SK, Tilney NL, Milford E. The combination of donor and recipient age is critical in determining host immunoresponsiveness and renal transplant outcome. Ann Surg 2010 Oct;252(4):662-74.

(173) Hjelmesaeth J, Hartmann A, Kofstad J, Egeland T, Stenstrom J, Fauchald P. Tapering off prednisolone and cyclosporin the first year after renal transplantation: the effect on glucose tolerance. Nephrol Dial Transplant 2001 Apr;16(4):829-35.

(174) Hjelmesaeth J, Hagen LT, Asberg A, Midtvedt K, Storset O, Halvorsen CE, et al. The impact of short-term ciclosporin A treatment on insulin secretion and insulin sensitivity in man. Nephrol Dial Transplant 2007 Jun;22(6):1743-9.

(175) Vincenti F, Schena FP, Paraskevas S, Hauser IA, Walker RG, Grinyo J. A randomized, multicenter study of steroid avoidance, early steroid withdrawal or standard steroid therapy in kidney transplant recipients. Am J Transplant 2008 Feb;8(2):307-16.

(176) Rama I, Cruzado JM, Gil-Vernet S, Torras J, Seron D, Castelao AM, et al. Steroids can be safely withdrawn from cyclosporine and mycophenolate mofetil-treated renal allograft recipients: long-term results. Transplantation 2005 Jul 27;80(2):164-8.

(177) Woodle ES, First MR, Pirsch J, Shihab F, Gaber AO, Van VP. A prospective, randomized, double-blind, placebo-controlled multicenter trial comparing early (7 day) corticosteroid cessation versus long-term, low-dose corticosteroid therapy. Ann Surg 2008 Oct;248(4):564-77.

(178) Pescovitz MD, Barbeito R. Two-hour post-dose cyclosporine level is a better predictor than trough level of acute rejection of renal allografts. Clin Transplant 2002 Oct;16(5):378-82.

(179) Canadian Neoral Renal Transplantation Study Group. Absorption profiling of cyclosporine microemulsion (neoral) during the first 2 weeks after renal transplantation. Transplantation 2001 Sep 27;72(6):1024-32.

(180) Rodrigo E, Ruiz JC, Angeles de CM, Ruiz J, Gago M, Pinera C, et al. Correlation of C0 and $\mathrm{C} 2$ levels with cyclosporine side effects in kidney transplantation. Transplant Proc $2009 \mathrm{Jul} ; 41(6): 2328-31$. 
(181) Ekberg H, Tedesco-Silva H, Demirbas A, Vitko S, Nashan B, Gurkan A, et al. Reduced exposure to calcineurin inhibitors in renal transplantation. N Engl J Med 2007 Dec 20;357(25):2562-75.

(182) Gaston RS, Cecka JM, Kasiske BL, Fieberg AM, Leduc R, Cosio FC, et al. Evidence for antibody-mediated injury as a major determinant of late kidney allograft failure. Transplantation 2010 Jul 15;90(1):68-74.

(183) Cavalot F, Pagliarino A, Valle M, Di ML, Bonomo K, Massucco P, et al. Postprandial blood glucose predicts cardiovascular events and all-cause mortality in type 2 diabetes in a 14-year follow-up: lessons from the san luigi gonzaga diabetes study. Diabetes Care 2011 Oct;34(10):2237-43.

(184) Ojo AO, Hanson JA, Wolfe RA, Leichtman AB, Agodoa LY, Port FK. Long-term survival in renal transplant recipients with graft function. Kidney Int 2000 Jan;57(1):307-13.

(185) Sorkin JD, Muller DC, Fleg JL, Andres R. The relation of fasting and 2-h postchallenge plasma glucose concentrations to mortality: data from the Baltimore Longitudinal Study of Aging with a critical review of the literature. Diabetes Care 2005 Nov;28(11):262632.

(186) Holman RR, Haffner SM, McMurray JJ, Bethel MA, Holzhauer B, Hua TA, et al. Effect of nateglinide on the incidence of diabetes and cardiovascular events. N Engl J Med 2010 Apr 22;362(16):1463-76.

(187) Griffin SJ, Borch-Johnsen K, Davies MJ, Khunti K, Rutten GE, Sandbaek A, et al. Effect of early intensive multifactorial therapy on 5-year cardiovascular outcomes in individuals with type 2 diabetes detected by screening (ADDITION-Europe): a clusterrandomised trial. Lancet $2011 \mathrm{Jul}$ 9;378(9786):156-67.

(188) Friedman AN, Miskulin DC, Rosenberg IH, Levey AS. Demographics and trends in overweight and obesity in patients at time of kidney transplantation. Am J Kidney Dis $2003 \mathrm{Feb} ; 41(2): 480-7$.

(189) Webber A, Hirose R, Vincenti F. Novel strategies in immunosuppression: issues in perspective. Transplantation 2011 May 27;91(10):1057-64.

(190) Vanrenterghem Y, Bresnahan B, Campistol J, Durrbach A, Grinyo J, Neumayer HH, et al. Belatacept-Based Regimens Are Associated With Improved Cardiovascular and Metabolic Risk Factors Compared With Cyclosporine in Kidney Transplant Recipients (BENEFIT and BENEFIT-EXT Studies). Transplantation 2011 May 15;91(9):976-83.

(191) Standl E, Schnell O, Ceriello A. Postprandial hyperglycemia and glycemic variability: should we care? Diabetes Care 2011 May;34 Suppl 2:S120-S127. 
(192) Audard V, Matignon M, Dahan K, Lang P, Grimbert P. Renal transplantation from extended criteria cadaveric donors: problems and perspectives overview. Transpl Int 2008 Jan;21(1):11-7.

(193) Shaw JS, Wilmot RL, Kilpatrick ES. Establishing pragmatic estimated GFR thresholds to guide metformin prescribing. Diabet Med 2007 Oct;24(10):1160-3. 


\section{PUBLICATIONS}



[ 

[ 

[] 



\title{
The association of early post-transplant glucose levels with long-term mortality
}

\author{
T. G. Valderhaug • J. Hjelmesæth • A. Hartmann • \\ J. Røislien • H. A. Bergrem • T. Leivestad • P. D. Line • \\ T. Jenssen
}

Received: 18 October 2010 / Accepted: 7 February 2011 / Published online: 16 March 2011

(C) The Author(s) 2011. This article is published with open access at Springerlink.com

\begin{abstract}
Aims/objective We aimed to assess the long-term effects of post-transplant glycaemia on long-term survival after renal transplantation.

Methods Study participants were 1,410 consecutive transplant recipients without known diabetes who underwent an OGTT 10 weeks post-transplant and were observed for a median of 6.7 years (range $0.3-13.8$ years). The HRs adjusted for age, sex, traditional risk factors and transplant-related risk factors were estimated.

Results Each $1 \mathrm{mmol} / \mathrm{l}$ increase in fasting plasma glucose (fPG) or $2 \mathrm{~h}$ plasma glucose ( $2 \mathrm{hPG}$ ) was associated with $11 \%$ (95\% CI $-1 \%, 24 \%)$ and $5 \%(1 \%, 9 \%)$ increments in all-cause mortality risk and $19 \%(1 \%, 39 \%)$ and $6 \%(1 \%, 12 \%)$ increments in cardiovascular (CV) mortality risk, respectively. Including both
\end{abstract}

T. G. Valderhaug and J. Hjelmesæth contributed equally to this study.

T. G. Valderhaug · A. Hartmann · H. A. Bergrem · T. Jenssen

Section for Nephrology, Department for Organ Transplantation,

Gastroenterology and Nephrology,

Division for Specialized Medicine and Surgery,

Oslo University Hospital, Rikshospitalet,

Oslo, Norway

T. G. Valderhaug · A. Hartmann

Institute of Clinical Medicine,

Faculty Division Rikshospitalet,

University of Oslo,

Oslo, Norway

T. G. Valderhaug $(\bowtie)$

Department of Thoracic and Cardiovascular Surgery,

Oslo University Hospital, Rikshospitalet,

Sognsvannsveien 20 ,

0027 Oslo, Norway

e-mail: t.g.valderhaug@medisin.uio.no

J. Hjelmesæth · J. Røislien

Morbid Obesity Centre,

Vestfold Hospital Trust,

Tønsberg, Norway
fPG and 2hPG in the multi-adjusted model the HR for $2 \mathrm{hPG}$ remained unchanged, while the HR for $\mathrm{PPG}$ was attenuated $(1.05[1.00,1.11]$ and $0.97[0.84,1.14])$. Compared with recipients with normal glucose tolerance, patients with posttransplant diabetes mellitus had higher all-cause and $\mathrm{CV}$ mortality $(1.54[1.09,2.17]$ and $1.80[1.10,2.96])$, while patients with impaired glucose tolerance (IGT) had higher all-cause, but not CV mortality $(1.39$ [1.01, 1.91] and 1.04 [0.62, 1.74]). Conversely, impaired fasting glucose was not associated with increased all-cause or CV mortality $(0.79[0.52,1.23]$ and 0.76 $[0.39,1.49])$. Post-challenge hyperglycaemia predicted death from any cause and infectious disease in the multivariable analyses (1.49 [1.15, 1.95] and 1.91 [1.09, 3.33]).

Conclusions/interpretation For predicting all-cause and CV mortality, $2 \mathrm{hPG}$ is superior to $\mathrm{PPG}$ after renal transplanta-

J. Røislien

Department of Biostatistics,

Institute of Basic Medical Science,

University of Oslo,

Oslo, Norway

\section{T. Leivestad}

Institute of Immunology,

Oslo University Hospital, Rikshospitalet,

Oslo, Norway

P. D. Line

Section for Transplantation Surgery,

Department for Organ Transplantation,

Gastroenterology and Nephrology,

Division for Specialized Medicine and Surgery,

Oslo University Hospital, Rikshospitalet,

Oslo, Norway

T. Jenssen

Institute of Clinical Medicine,

University of Tromsø,

Tromsø, Norway 
tion. Also, early post-transplant diabetes, IGT and postchallenge hyperglycaemia were significant predictors of death. Future studies should determine whether an OGTT helps identify renal transplant recipients at increased risk of premature death.

Keywords Mortality after renal transplantation $\cdot$ New-onset post-transplant diabetes mellitus - Oral glucose tolerance test $\cdot$ Post-transplant complications

\section{Abbreviations}

$\begin{array}{ll}\text { 2hPG } & 2 \mathrm{~h} \text { plasma glucose after an OGTT } \\ \text { CV } & \text { Cardiovascular } \\ \text { CMV } & \text { Cytomegalovirus } \\ \text { fPG } & \text { Plasma glucose after an overnight fast } \\ \text { IFG } & \text { Impaired fasting glucose } \\ \text { IGT } & \text { Impaired glucose tolerance } \\ \text { NGT } & \text { Normal glucose tolerance } \\ \text { PTDM } & \text { Post-transplant diabetes mellitus }\end{array}$

\section{Introduction}

Renal transplant recipients have an increased risk of premature death, with cardiovascular disease (CVD), malignancy and infectious disease being the predominant causes of mortality [1]. Immunosuppressive therapy may potentiate traditional pre-transplant risk factors [2], but cannot fully explain the increased long-term mortality after renal transplantation [3].

Hyperglycaemia is reported to be a risk marker for CVD and cancer among healthy individuals without diabetes [4, 5]. Post-challenge hyperglycaemia is particularly associated with increased all-cause, cardiovascular (CV) and cancer mortality in the general population [5-7]. The impact of hyperglycaemia on patient survival after renal transplantation is, however, unknown. Some studies indicate an association between post-transplant diabetes mellitus (PTDM) and mortality [8-10], whereas others do not [11, 12]. Renal transplant recipients may have normal fasting plasma glucose (fPG) but at the same time elevated $2 \mathrm{~h}$ plasma glucose ( $2 \mathrm{hPG})$. Only half of individuals with newonset diabetes after renal transplantation are identified from an $\mathrm{fPG} \geq 7.0 \mathrm{mmol} / 1$ [13], as compared with $70 \%$ in the general population [14] and $80 \%$ in morbidly obese persons [15]. In addition, approximately one out of five recipients has impaired glucose tolerance (IGT) or impaired fasting glucose (IFG) 10 weeks after renal transplantation [16]. Thus, performing an OGTT in the early post-transplant period may be important for the identification of renal transplant patients with hyperglycaemia.
The aim of this study was to assess the long-term effects of early post-transplant glycaemia on overall and causespecific mortality after renal transplantation.

\section{Methods}

Design and study population A total of 2,458 consecutive patients received a renal transplant at our centre between 2 February 1995 and 19 October 2006. After the exclusion of 1,048 patients because of re-transplantation, age $<18$ years, early death, early graft loss, pre-existing diabetes mellitus or failure to perform an OGTT, 1,410 patients were included in this prospective cohort study (Fig. 1). The participants were observed until either the primary endpoint (death) was reached or 31 December 2008 (median [range] 6.7 [0.3-13.8] years). Patients who developed PTDM (manifest PTDM, $n=58$ ) before the scheduled OGTT did not complete the test, while the remaining 1,352 first-time renal transplant recipients underwent an OGTT 10 weeks (mean [SD] 71 [9]

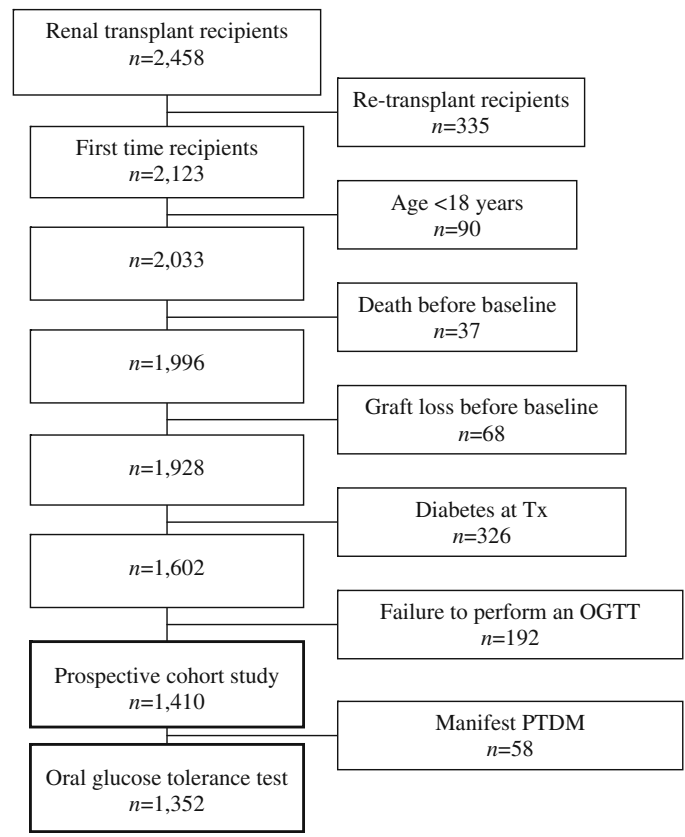

Fig. 1 The number of patients receiving their first kidney transplant without pre-existing diabetes mellitus at the time of transplantation (Tx). Re-transplant recipients were excluded. Failure to perform an OGTT denotes patients who were transferred to local hospitals before the scheduled OGTT at baseline 10 weeks after renal transplantation. Patients who developed manifest diabetes during the first 10 weeks after transplantation (Manifest PTDM) did not undergo an OGTT. A total of 1,410 patients were included in the prospective cohort study and 1,352 patients underwent an OGGT 
days) after renal transplantation. The participants gave informed consent and the study was approved by the regional ethics committee and was performed in accordance with the Declaration of Helsinki [17].

Glucose measurements The OGTT was performed after an overnight fast with patients instructed not to eat or drink, to refrain from smoking and not to take any medication less than $8 \mathrm{~h}$ before the test. Each patient drank $75 \mathrm{~g}$ of anhydrous glucose dissolved in $250 \mathrm{ml}$ of water. Blood samples were drawn at 0 and $120 \mathrm{~min}$. From May 1995 to August 1996, glucose was measured in serum using a glucose dehydrogenase method (Cobas Mira, Roche, Basel, Switzerland). From September 1996 until December 2006 venous whole blood glucose was measured using the Hemocue AB B-glucose Analyzer, Angelholm, Sweden. The glucose measurements are presented as plasma (serum) glucose [18]. Plasma glucose was calculated by multiplying whole blood glucose with the constant factor of 1.11 [19].

Assessment of diabetes and glycaemia The current ADA criteria were used to classify patients into the following glucose categories: PTDM, fPG $\geq 7.0 \mathrm{mmol} / 1$ or $2 \mathrm{hPG}$ $\geq 11.1 \mathrm{mmol} / 1$; IFG, fPG 5.6-6.9 $\mathrm{mmol} / 1$ and $2 \mathrm{hPG}$ $<7.8 \mathrm{mmol} / \mathrm{l}$; IGT, fPG $<7.0 \mathrm{mmol} / 1$ and $2 \mathrm{hPG} 7.8$ $11.0 \mathrm{mmol} / \mathrm{l}$; and normal glucose tolerance (NGT), fPG $<5.6 \mathrm{mmol} / \mathrm{l}$ and $2 \mathrm{hPG}<7.8 \mathrm{mmol} / 1$ [20]. Patients were also categorised as either post-challenge hyperglycaemia defined as a $2 \mathrm{hPG} \geq 7.8 \mathrm{mmol} / \mathrm{l}$ or normoglycaemia defined as a $2 \mathrm{hPG}<7.8 \mathrm{mmol} / 1$ [20].

Immunosuppressive therapy Our immunosuppressive protocol has been described previously [13]. In summary, the standard protocol from February 1995 to January 2000 consisted of prednisolone, ciclosporin A, azathioprine, and thereafter the protocol included prednisolone, ciclosporin A and mycophenolate. In most instances, tacrolimus was given if ciclosporin A was withdrawn because of rejection, toxicity or side effects.

Data registration and endpoints The following baseline data were collected 10 weeks after renal transplantation: recipient age, sex, $\mathrm{BMI}$, fPG, $2 \mathrm{hPG}, \mathrm{HbA}_{1 \mathrm{c}}$, serum creatinine, Cr-EDTA-measured glomerular filtration rate, serum lipids and immunosuppressive medication. Friedewald's equation was used to calculate LDL-cholesterol. We searched the Norwegian Renal Registry [21] and the DataCor database [22] to identify patients with pre-transplant CVD. Patients were classified as having pre-transplant CVD if they had: suffered a CV event (myocardial infarction, angina pectoris, stroke/transient ischaemic attack or claudication); or had undergone a revascularisation procedure (percutaneous coronary intervention or coronary artery bypass graft surgery) or surgery on pre-cerebral arteries or for peripheral vascular disease. Data on smoking habits, pre-transplant renal status and hypertension were collected from the Norwegian Renal Registry [21]. According to National Kidney Foundation Disease Outcome Quality guidelines, hypertension was defined if patients were using anti-hypertensive therapy within the first posttransplant year or had a systolic blood pressure $\geq 140 \mathrm{mmHg}$ or a diastolic blood pressure $\geq 90 \mathrm{mmHg}$. Patients who did not receive pre-transplant dialysis were encoded as pre-emptive transplantation. Early cytomegalovirus (CMV) infection was diagnosed in patients with at least one positive test for either CMV-pp65 antigen in leucocytes or CMV-PCR in plasma before baseline [23].

The study outcomes were all-cause and cause-specific mortality after renal transplantation as defined by the European Renal Association-European Dialysis and Transplant Association causes of death codes: CV 11-18 and 2129; infection 31-43; malignancy 66-67; other diagnoses (43-46, 51-53, 61-64, 69-73, 81-82); and unknown (0) [24]. Nephrologists at 24 centres annually report data on all Norwegian patients undergoing renal replacement therapy to the Norwegian Renal Registry [21], from which numbers and causes of deaths were retrieved. The numbers of death were cross-checked with the official Norwegian National Registry and the causes of death were encoded by experienced local nephrologists.

Missing data Some variables in the data set had missing data: hypertension (32\%), smoking status (27\%), total cholesterol $(10 \%)$, height $(3 \%)$, weight $(3 \%)$, creatinine $(3 \%)$ and CMV infection (1\%). To compensate for missing data, multiple imputation was used to generate ten iterations for the variables with missing data, each containing 1,410 complete cases [25]. Both complete and incomplete variables were used as predictors during the imputation process. The variables used for multiple imputation included: age, sex, donor age, donor status (living or deceased), height, weight, creatinine, use of ciclosporin A, early CMV infection, early hepatitis $\mathrm{C}$ virus infection, total cholesterol, fPG, $2 \mathrm{hPG}, \mathrm{HbA}_{1 \mathrm{c}}$, early rejection, hypertension, primary diagnosis of renal disease (glomerulonephritis, pyelonephritis, polycystic kidney disease, nephrosclerosis, other diagnoses), pre-transplant renal status (haemodialysis, peritoneal dialysis, pre-emptive transplantation), human leucocyte antigen (HLA)-DR mismatch (none, one, two), smoking status (never, former or current), cause of death (CVD, malignancy, infection, other, unknown), survival time (months). Variables not normally distributed were logarithmically transformed (fPG, $2 \mathrm{hPG}$ and creatinine). Statistical analyses were first performed on each imputed data set, and thereafter pooled to achieve a single variable estimate. 
Statistical analyses Non-imputed descriptive data are presented as mean (SD) or frequency (\%). The 1,352 patients who underwent the OGTT were dichotomised to have postchallenge hyperglycaemia $(2 \mathrm{hPG} \geq 7.8 \mathrm{mmol} / \mathrm{l})$ or normoglycaemia. Differences between groups were analysed using independent samples $t$ test for continuous data and Fisher's exact test for categorical data. Associations between $\mathrm{fPG}$ and $2 \mathrm{hPG}$ were analysed using nonparametric correlations (Spearman's $\rho$ ). Kaplan-Meier plots and logrank test were used to analyse crude cumulative survival for the various ADA categories.

Hazard ratios and corresponding 95\% CIs were estimated using Cox proportional hazard regression models. Glycaemia was included as either a continuous explanatory variable or a categorical variable. Continuous explanatory variables were fPG and $2 \mathrm{hPG}$. Categorical variables were: NGT=reference; IFG; IGT; PTDM; and post-challenge hyperglycaemia, yes/no. Patients with manifest PTDM $(n=58)$ before the scheduled OGTT were included only in the analyses with glucose categories as explanatory variables. Also, an interaction term between $\mathrm{PPG}$ and $2 \mathrm{hPG}$ was included.

We fitted three multiple Cox regression models. In model 1 we adjusted for age and sex. In model 2 we further adjusted for traditional risk factors: BMI; creatinine; pre-transplant CVD; total cholesterol; hypertension; and smoking status [1-3, 10]. In model 3 we included additional adjustments for transplant-related risk factors: donor status; pre-emptive transplantation; CMV infection; early rejection; and usage of ciclosporin $\mathrm{A}[2,3,11]$. The assumption of linearity was assessed by fitting multifractional models, which allows for several types of nonlinearity, and testing for the best fit [26].

Model discrimination between predicted and estimated risk was assessed using Harrell's concordance index (c-statistic) [27, 28]. A result was considered to be statistically significant when $p<0.05$. Statistical analyses were conducted with the use of Stata 11.0 (StataCorp, College Station, TX, USA) and PASW 18.0 (Chicago, IL, USA).

\section{Results}

Out of 1,410 recipients included in the prospective study, a total of $638(45 \%)$ had NGT, $217(16 \%)$ had IFG, 313 (22\%) had IGT and 242 (17\%) had PTDM.

Demographic and clinical characteristics of the patients who underwent an OGTT $(n=1,352)$ according to the presence or absence of post-challenge hyperglycaemia are presented in Table 1 . The recipients with a $2 \mathrm{hPG}$ $\geq 7.8 \mathrm{mmol} / \mathrm{l}$ were significantly older, had less favourable kidney function and were more likely to have a history of smoking, pre-transplant CVD, CMV infection and rejection than those with $2 \mathrm{hPG}<7.8 \mathrm{mmol} / 1$. Unadjusted all-cause and $\mathrm{CV}$ mortality HRs of prevalent risk factors inherent to the transplant population are presented in Table 2 .

A total of $282(20 \%)$ of the 1,410 recipients died during the study period: $79(12 \%)$ of the patients with NGT, $31(14 \%)$ of the patients with isolated IFG, $90(29 \%)$ of the patients with IGT, and $82(34 \%)$ of the patients with PTDM $(p<0.001)$. A total of $120(42 \%)$ patients died from CVD, 65 (23\%) from malignancy, 67 (24\%) from infectious diseases, $17(6 \%)$ from other causes and $13(5 \%)$ from unknown causes. Septicaemia and bacterial pneumonia accounted for $57 \%$ and $31 \%$ of the infectious deaths, respectively.

Mortality according to glucose as a continuous variable Both fPG and 2hPG were associated with increased all-cause and $\mathrm{CV}$ mortality risk in the unadjusted Cox regression analyses (Tables 3 and 4). After adjustments for confounders, the impact of fPG became statistically non-significant, while $2 \mathrm{hPG}$ remained a significant predictor of overall mortality risk (Table 3). In the multivariable cause-specific Cox regression analyses, both $\mathrm{PPG}$ and $2 \mathrm{hPG}$ remained associated with increased risk of $\mathrm{CV}$ death (Table 4). The $\mathrm{fPG}$ and $2 \mathrm{hPG}$ were correlated $(r=0.59, p<0.001)$, but there was no statistically significant interaction between $\mathrm{PPG}$ and $2 \mathrm{hPG}(p=0.527)$. When both $2 \mathrm{hPG}$ and $\mathrm{fPG}$ were included in the multivariable model 3 , only $2 \mathrm{hPG}$ was found to be a predictor of all-cause mortality (2hPG, HR 1.05 [95\% CI 1.00, 1.11] $p=0.038$; fPG, HR 0.97 [95\% CI 0.84, 1.14] $p=0.740$ ). For all the regressions analyses, a linear model was the best fit for the continuous glucose measurements (data not shown).

Mortality and glucose as categorical variables Cumulative mortality according to glucose category is shown in Fig. 2. The logrank test indicated a significant difference in mortality between the subgroups $(p<0.001)$. Recipients with PTDM, IGT or post-challenge hyperglycaemia at baseline had an approximately twofold unadjusted increased death risk compared with those with NGT or postchallenge normoglycaemia (Table 3 ). The overall mortality risk was attenuated after multiple adjustments in Cox models $1-3$, but remained statistically significant in all the multivariable analyses. Conversely, IFG failed to show any association with mortality (Tables 3 and 4).

Table 4 shows that post-challenge hyperglycaemia was associated with an approximately twofold increased risk of death from CV disease, malignancy and infectious disease. PTDM was associated with a nearly threefold increased risk from CVD, while IGT was associated with a twofold increased risk of infectious death. After multivariable adjustments, PTDM remained associated with a twofold increased risk of CV death, whilst post-challenge hyperglycaemia, but not IGT, remained associated with a nearly 
Table 1 Baseline characteristics of the study population according to post-challenge glycaemia
Data are given as mean (SD) or frequency $(\%)$

$p$ values denote differences between groups

LDL-cholesterol was calculated using Friedewald's equation

Pre-emptive transplantation denotes patients who received a kidney transplant before starting dialysis

\begin{tabular}{|c|c|c|c|c|}
\hline Characteristic & Total & $\begin{array}{l}\text { Post-challenge } \\
\text { normoglycaemia } \\
(<7.8 \mathrm{mmol} / \mathrm{l})\end{array}$ & $\begin{array}{l}\text { Post-challenge } \\
\text { hyperglycaemia } \\
(\geq 7.8 \mathrm{mmol} / \mathrm{l})\end{array}$ & $p$ value \\
\hline$n(\%)$ & 1,352 & $863(64)$ & $489(36)$ & - \\
\hline Age (years) & $51(15)$ & $49(15)$ & $55(14)$ & $<0.001$ \\
\hline Male, $n(\%)$ & $892(66)$ & $564(65)$ & $328(67)$ & 0.550 \\
\hline BMI $\left(\mathrm{kg} / \mathrm{m}^{2}\right)$ & $24.3(3.6)$ & $24.2(3.5)$ & $24.6(3.7)$ & 0.062 \\
\hline Obese (BMI $\left.\geq 30 \mathrm{~kg} / \mathrm{m}^{2}\right), n(\%)$ & 87 (7) & $51(6)$ & $36(8)$ & 0.300 \\
\hline Creatinine $(\mu \mathrm{mol} / \mathrm{l})$ & $132(41)$ & $129(36)$ & $137(47)$ & 0.002 \\
\hline GFR $\left(\mathrm{ml} \mathrm{min} \min ^{-1} 1.73 \mathrm{~m}^{-2}\right)$ & $53.7(14.7)$ & $54.5(14.1)$ & $52.0(15.8)$ & 0.006 \\
\hline Pre-transplant CVD, n (\%) & $216(16)$ & $116(13)$ & $100(20)$ & 0.001 \\
\hline Total cholesterol (mmol/l) & $6.53(1.50)$ & $6.51(1.45)$ & $6.57(1.59)$ & 0.519 \\
\hline HDL-cholesterol (mmol/l) & $1.55(0.49)$ & $1.59(0.49)$ & $1.46(0.46)$ & $<0.001$ \\
\hline Triacylglycerol (mmol/l) & $2.14(2.17)$ & $2.03(2.45)$ & $2.38(1.43)$ & 0.008 \\
\hline LDL-cholesterol (mmol/l) & $4.02(1.53)$ & $4.01(1.61)$ & $4.05(1.36)$ & 0.657 \\
\hline Hypertension, $n(\%)$ & $745(83)$ & $487(84)$ & $258(83)$ & 0.925 \\
\hline Active or former smoker, $n(\%)$ & $603(61)$ & $393(57)$ & $210(69)$ & 0.001 \\
\hline Deceased donor, $n(\%)$ & $745(55)$ & $427(50)$ & $318(65)$ & $<0.001$ \\
\hline Months on dialysis & $15(13)$ & $14(14)$ & $15(11)$ & 0.578 \\
\hline Pre-emptive transplantation, $n(\%)$ & $328(24)$ & $214(25)$ & $114(23)$ & 0.553 \\
\hline CMV infection, $n(\%)$ & $740(55)$ & $445(52)$ & $295(61)$ & 0.002 \\
\hline Early rejection, $n(\%)$ & $490(36)$ & $277(32)$ & $213(44)$ & $<0.001$ \\
\hline Prednisolone dose (mg/day) & $13.1(5.2)$ & $12.5(4.6)$ & $14.3(6.0)$ & $<0.001$ \\
\hline Use of ciclosporin A, $n(\%)$ & $1,137(90)$ & $732(90)$ & $405(90)$ & 0.768 \\
\hline Ciclosporin A trough level $(\mu \mathrm{g} / \mathrm{l})$ & $219(76)$ & $212(73)$ & $233(81)$ & $<0.001$ \\
\hline Use of tacrolimus, $n(\%)$ & $124(10)$ & $78(10)$ & $46(10)$ & 0.767 \\
\hline Tacrolimus trough level $(\mu \mathrm{g} / \mathrm{l})$ & $9.7(3.3)$ & $9.4(3.3)$ & $10.2(3.2)$ & 0.194 \\
\hline
\end{tabular}

twofold higher mortality risk from infectious disease (Table 4). Including the various glucose variables into model 3 had minimal effect on overall and CV mortality with an increase in $c$-statistic of less than 0.01 (data not shown).

Table 2 Unadjusted HR risk estimates by Cox proportional regression analyses for all-cause and CV mortality

\begin{tabular}{lll}
\hline Variable & $\begin{array}{l}\text { Overall mortality } \\
\text { HR }(95 \% \mathrm{CI})\end{array}$ & $\begin{array}{l}\text { CV mortality } \\
\text { HR }(95 \% \mathrm{CI})\end{array}$ \\
\hline Age (years) & $1.06(1.05,1.07)$ & $1.07(1.06,1.09)$ \\
Male & $1.31(1.01,1.69)$ & $1.66(1.09,2.52)$ \\
BMI $\left(\mathrm{kg} / \mathrm{m}^{2}\right)$ & $0.97(0.94,1.01)$ & $1.01(0.96,1.06)$ \\
Creatinine $(\mu \mathrm{mol} / \mathrm{l})$ & $1.00(1.00,1.01)$ & $1.01(1.00,1.01)$ \\
Pre-transplant CVD & $2.07(1.59,2.71)$ & $2.56(1.73,3.79)$ \\
Total cholesterol $(\mathrm{mmol} / \mathrm{l})$ & $1.01(0.92,1.10)$ & $0.96(0.84,1.09)$ \\
Hypertension & $0.66(0.48,0.92)$ & $0.88(0.46,1.67)$ \\
Active or former smoker & $1.17(0.79,1.74)$ & $1.28(0.71,2.32)$ \\
Deceased donor & $2.39(1.83,3.12)$ & $2.77(1.82,4.23)$ \\
Pre-emptive transplantation & $0.62(0.46,0.84)$ & $0.58(0.36,0.93)$ \\
CMV infection & $1.62(1.26,2.07)$ & $1.91(1.29,2.84)$ \\
Early rejection & $1.02(0.81,1.30)$ & $1.31(0.92,1.88)$ \\
Use of ciclosporin A & $1.83(1.02,3.27)$ & $1.57(0.69,3.58)$ \\
\hline
\end{tabular}

Of the 184 recipients with new-onset PTDM diagnosed from an OGTT, 92 (50\%) were diagnosed from an $\mathrm{fPG}$ $\geq 7.0 \mathrm{mmol} / \mathrm{l}$ and an equal number of patients were diagnosed from an isolated $2 \mathrm{hPG} \geq 11.1 \mathrm{mmol} / \mathrm{l} \quad(n=92)$, whereas $63(34 \%)$ patients fulfilled both the criteria. Mean $\mathrm{fPG}$ for recipients with an isolated $2 \mathrm{hPG} \geq 11.1 \mathrm{mmol} / 1$ was $5.9(0.69) \mathrm{mmol} / \mathrm{l}$. Compared with recipients without PTDM, the multi-adjusted HRs of recipients diagnosed from $\mathrm{fPG} \geq 7.0 \mathrm{mmol} / 1$ and $2 \mathrm{hPG} \geq 11.1 \mathrm{mmol} / 1$ were $1.49(95 \%$ CI $1.00,2.23)$ and $1.22(0.80,1.86)$.

\section{Discussion}

The main finding of this large single-centre study of renal transplant recipients was that as a predictor of long-term mortality, post-challenge $2 \mathrm{hPG}$ measured early after renal transplantation was superior to, and independent of, fPG, even after adjustments for confounding risk factors. Each $1 \mathrm{mmol} / \mathrm{l}$ increment in $2 \mathrm{hPG}$ was associated with a $5 \%$ $(95 \%$ CI $1 \%, 9 \%)$ increased risk of death from any cause and $6 \%(95 \%$ CI $1 \%, 12 \%)$ increased risk of death from $\mathrm{CV}$ 
Table 3 HRs estimated by Cox regression analyses for all-cause mortality according to plasma glucose (as categorical or continuous variables)

\begin{tabular}{|c|c|c|c|c|}
\hline \multirow[t]{2}{*}{ Variable } & \multirow[t]{2}{*}{ Unadjusted HR ( $95 \%$ CI) } & \multicolumn{3}{|c|}{ Multivariable HR $(95 \% \mathrm{CI})$} \\
\hline & & Model 1 & Model 2 & Model 3 \\
\hline \multicolumn{5}{|l|}{ Glucose category } \\
\hline Normal glucose tolerance & 1.00 & 1.00 & 1.00 & 1.00 \\
\hline Impaired fasting glucose & $0.74(0.49,1.13)$ & $0.77(0.50,1.17)$ & $0.77(0.51,1.18)$ & $0.79(0.52,1.23)$ \\
\hline Impaired glucose tolerance & $1.78(1.32,2.42)^{*}$ & $1.43(1.05,1.94)^{*}$ & $1.42(1.05,1.94)^{*}$ & $1.39(1.01,1.91)^{*}$ \\
\hline Post-transplant diabetes mellitus & $2.03(1.49,2.77)^{*}$ & $1.51(1.10,2.07)^{*}$ & $1.54(1.12,2.13)^{*}$ & $1.54(1.09,2.17)^{*}$ \\
\hline$p$ values for trend & $<0.001$ & 0.001 & 0.002 & 0.006 \\
\hline Harrell's concordance index & 0.597 & 0.738 & 0.759 & 0.757 \\
\hline \multicolumn{5}{|l|}{ Level of $2 \mathrm{hPG}$} \\
\hline Post-challenge normoglycaemia & 1.00 & 1.00 & 1.00 & 1.00 \\
\hline Post-challenge hyperglycaemia & $1.98(1.55,2.54)^{*}$ & $1.53(1.19,1.97)^{*}$ & $1.55(1.21,2.00)^{*}$ & $1.49(1.15,1.95)^{*}$ \\
\hline Harrell's concordance index & 0.583 & 0.737 & 0.755 & 0.759 \\
\hline \multicolumn{5}{|l|}{$\mathrm{fPG}$} \\
\hline $\mathrm{fPG}(\mathrm{mmol} / \mathrm{l})$ & $1.13(1.03,1.24)^{*}$ & $1.10(1.00,1.21)$ & $1.12(1.01,1.24)^{*}$ & $1.11(0.99,1.24)$ \\
\hline Harrell's concordance index & 0.538 & 0.734 & 0.750 & 0.755 \\
\hline \multicolumn{5}{|l|}{$2 \mathrm{hPG}$} \\
\hline 2hPG (mmol/l) & $1.08(1.05,1.12)^{*}$ & $1.04(1.01,1.08)^{*}$ & $1.05(1.01,1.09)^{*}$ & $1.05(1.01,1.09)^{*}$ \\
\hline Harrell's concordance index & 0.594 & 0.742 & 0.754 & 0.757 \\
\hline
\end{tabular}

Model 1 is adjusted for age and sex. Model 2 is additionally adjusted for traditional risk factors: BMI; creatinine; pre-transplant CVD; total cholesterol; hypertension; and smoking status. Model 3 is additionally adjusted for transplant-related risk factors: donor status; pre-emptive transplantation; CMV infection; early rejection; and use of ciclosporin A

$* p<0.05$

Table 4 HR estimated by Cox regression analyses for CV death, death from malignancy and from infectious disease according to plasma glucose (as categorical or continuous variables)

\begin{tabular}{|c|c|c|c|c|c|c|}
\hline \multirow[t]{2}{*}{ Variable } & \multicolumn{3}{|c|}{ Unadjusted HR $(95 \% \mathrm{CI})$} & \multicolumn{3}{|c|}{ Multivariable HR (95\% CI) (model 3) } \\
\hline & CVD & Malignancy & Infection & CVD & Malignancy & Infection \\
\hline \multicolumn{7}{|l|}{ Glucose category } \\
\hline Normal glucose tolerance & 1.00 & 1.00 & 1.00 & 1.00 & 1.00 & 1.00 \\
\hline Impaired fasting glucose & $0.73(0.37,1.41)$ & $0.94(0.42,2.08)$ & $0.44(0.16,1.17)$ & $0.76(0.39,1.49)$ & $0.97(0.42,2.00)$ & $0.50(0.18,1.37)$ \\
\hline Impaired glucose tolerance & $1.52(0.93,2.50)$ & $1.73(0.92,3.25)$ & $1.89(1.05,3.41)^{*}$ & $1.04(0.62,1.74)$ & $1.37(0.71,2.64)$ & $1.75(0.92,3.34)$ \\
\hline Post-transplant diabetes mellitus & $2.72(1.73,4.29)^{*}$ & $1.80(0.93,3.48)$ & $1.45(0.75,2.82)$ & $1.80(1.10,2.96)^{*}$ & $1.36(0.65,2.83)$ & $1.37(0.66,2.86)$ \\
\hline$p$ values for trend & $<0.001$ & 0.138 & 0.011 & 0.023 & 0.687 & 0.055 \\
\hline Harrell's concordance index & 0.627 & 0.572 & 0.595 & 0.782 & 0.736 & 0.816 \\
\hline \multicolumn{7}{|l|}{ Level of $2 \mathrm{hPG}$} \\
\hline Post-challenge normoglycaemia & 1.00 & 1.00 & 1.00 & 1.00 & 1.00 & 1.00 \\
\hline Post-challenge hyperglycaemia & $2.00(1.36,2.93)^{*}$ & $1.79(1.07,2.97)^{*}$ & $2.07(1.24,3.46)^{*}$ & $1.34(0.89,2.00)$ & $1.34(0.78,2.30)$ & $1.91(1.09,3.33)^{*}$ \\
\hline Harrell's concordance index & 0.593 & 0.572 & 0.568 & 0.779 & 0.738 & 0.817 \\
\hline \multicolumn{7}{|l|}{$\mathrm{fPG}$} \\
\hline fPG (mmol/l) & $1.21(1.06,1.37)^{*}$ & $1.17(0.98,1.40)$ & $0.95(0.75,1.20)$ & $1.19(1.01,1.39)^{*}$ & $1.16(0.94,1.44)$ & $0.95(0.73,1.24)$ \\
\hline Harrell's concordance index & 0.562 & 0.557 & 0.512 & 0.777 & 0.732 & 0.810 \\
\hline \multicolumn{7}{|l|}{$2 \mathrm{hPG}$} \\
\hline 2hPG (mmol/l) & $1.11(1.06,1.16)^{*}$ & $1.05(0.98,1.13)$ & $1.06(1.00,1.14)$ & $1.06(1.01,1.12)^{*}$ & $1.01(0.93,1.09)$ & $1.05(0.97,1.14)$ \\
\hline Harrell's concordance index & 0.626 & 0.573 & 0.556 & 0.780 & 0.734 & 0.813 \\
\hline
\end{tabular}

Model 3 is adjusted for age, sex, BMI, creatinine, pre-transplant CVD, total cholesterol, hypertension, smoking status, donor status, pre-emptive transplantation, CMV infection, early rejection and use of ciclosporin A

$* p<0.05$ 


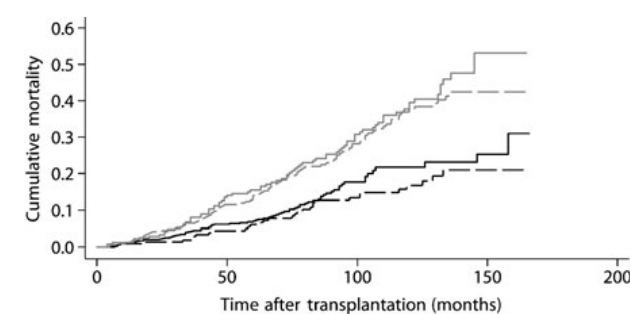

Number at risk

$\begin{array}{rllll}\text { NGT } 638 & 466 & 117 & 35 & 0 \\ \text { IFG } 217 & 183 & 127 & 15 & 0 \\ \text { IGT } 313 & 237 & 125 & 27 & 0 \\ \text { PTDM } 242 & 183 & 111 & 13 & 0\end{array}$

Fig. 2 Cumulative mortality for recipients with NGT (solid black line), IFG (dashed black line), IGT (dashed grey line) and PTDM (solid grey line)

disease. In addition, our findings are the first to indicate that renal transplant recipients with IGT have lower long-term chance of survival than those with NGT.

Glucose measurements as continuous variables This study demonstrates an independent continuous relationship between $2 \mathrm{hPG}$ and long-term mortality in a renal transplant population without known diabetes. These findings are in accordance with two previous community-based cohort studies of non-diabetic persons of comparable age [6, 29]. Our results also partly support the findings from a population-based prospective cohort of more than 10,000 adult men and women demonstrating a continuous positive relationship between non-diabetic hyperglycaemia and mortality [30]. In our study the association between $\mathrm{fPG}$ and mortality became statistically non-significant after adjustments for transplant-related risk factors. Some studies have reported a J-shaped relationship between $\mathrm{PPG}$ as a continuous variable and both overall and CV mortality, whereas a linear relationship best described the association between $2 \mathrm{hPG}$ and overall and CV mortality [30, 31]. We cannot completely rule out the possibility that a non-linear relationship between PPG and mortality might have influenced the Cox proportional hazard risk. However, by fitting our models using multifractional models, no non-linear model outperformed a standard linear model in our sets of data.

Post-challenge hyperglycaemia and glucose categories Recipients with post-challenge hyperglycaemia, PTDM and IGT had an increased overall mortality risk. Our findings confirm the results of two large cohort studies that demonstrated that PTDM, diagnosed by Medicare claims or required treatment for hyperglycaemia, is associated with reduced patient survival $[8,10]$. We now extend this conclusion to PTDM diagnosed by fasting glucose as well as to PTDM and IGT diagnosed by an OGTT.
Our findings also concur with those from two large metaanalyses addressing the impact of IFG and IGT on mortality in non-transplant European populations that found that IGT is superior to IFG in predicting all-cause and CV mortality and from five Asian populations that found that IGT but not IFG was associated with all-cause and CV mortality [7, 32]. In contrast to the latter analysis, we diagnosed patients with isolated IFG (fPG of 5.6-6.9 mmol/l) (excluding concomitant IGT), which might have reduced the mortality risk in this group. Nevertheless, IFG was not associated with death after the inclusion of all recipients with an fPG of 5.6$6.9 \mathrm{mmol} / 1$ in the present study (data not shown).

In further contrast with our study, the previous studies implemented the criteria of the WHO for IFG (fPG 6.1$6.9 \mathrm{mmol} / \mathrm{l})$ [33]. However, our results were largely unchanged when we reclassified the glucose categories according to the WHO criteria (data not shown). Partly in contrast with our findings, one large Australian prospective study showed that both isolated IFG (WHO criteria) and IGT were independent predictors of all-cause and CV mortality [34]. Our findings indicate persons with increased risk of death, but do not necessarily imply that lowering of glucose excursions would reduce this risk. In a recently published study of non-transplanted persons with IGT and either established CVD or known risk factors for CVD, a 5-year period of treatment with nateglinide did not influence the incidence of CVD. In this study, however, the participants had a lower mortality risk as compared with a transplant population.

Whether glucose-lowering therapy in renal transplant recipients with either IGT or PTDM is associated with lower long-term morbidity or mortality remains to be shown.

In the cause-specific analysis, PTDM was associated with increased mortality from CVD whilst post-challenge hyperglycaemia predicted increased mortality from infectious disease. The reduction in deaths from infectious disease is considered one of the major improvements in short-term mortality outcome after renal transplantation during the recent decades, and the predominant cause of infection beyond 6 months post-transplant is bacterial rather than viral [1]. In the present study, $90 \%$ of the infectious deaths were caused by either bacterial pneumonia or septicaemia. However, our finding of a possible relationship between post-challenge hyperglycaemia and long-term mortality from infectious diseases needs verification and should be interpreted with care.

Strengths and limitations The inclusion of a large number of consecutively included non-diabetic renal transplant recipients at the single transplant centre in Norway reduced the possibility of sample selection bias and increased the internal validity of the study. Only $10 \%$ of the eligible patients were unable to participate. The study population 
consisted predominantly of white individuals, and thus the results cannot be extended to populations of other ethnicities. However, comparable results for PTDM have been reported in two other studies that included individuals of multiple races and ethnicities [8, 10].

The OGTT has poor reproducibility and a repeated test diagnostic of diabetes is recommended by the current guidelines [20]. However, according to the WHO an epidemiological diagnosis of diabetes can be based on a single OGTT or fPG [35]. Furthermore, although the OGTT is more time consuming and has a higher intraindividual coefficient of variance compared with fasting plasma glucose, it is a more sensitive test for diagnosing PTDM and IGT after renal transplantation $[13,36]$.

To account for missing data on hypertension (32\%), smoking status $(27 \%)$ and total cholesterol (10\%), we performed ten iterations of multiple imputations. Also, the prognostic effect of $2 \mathrm{hPG}$ on overall mortality was attenuated after adjustment for age and sex, but was largely unchanged after further adjustments for both traditional and transplant-related risk factors. Thus, the imputed covariates contributed little to the prognostic effect of early posttransplant glucose levels on long-term mortality.

The estimated outcomes coincided with the observed mortality in this study (multi-adjusted $c$-statistics: all-cause $>75 \%$ and $\mathrm{CV}$ mortality $>77 \%$ ). The additional effect of including the various glucose variables in the multiadjusted models was, however, minimal. Nevertheless, early post-transplant glycaemia remained an independent predictor of both all-cause and CV mortality.

We used $\mathrm{fPG}$ and $2 \mathrm{hPG}$ as diagnostic criteria for diabetes without including the recently introduced ADA criteria of $\mathrm{HbA}_{1 \mathrm{c}} \geq 6.5 \%$ [20]. The diagnostic value of $\mathrm{HbA}_{1 \mathrm{c}}$ in patients with end-stage renal disease awaiting renal transplantation is poor, possibly because of uraemia, usage of erythropoietin and dialysis [37]. In the early posttransplant period haemoglobin levels stabilise and normalised levels of erythropoietin and haematocrit have been reported as early as at 2 months post-transplant [38]. However, blood loss related to surgical procedures and subsequent inflammation, immunosuppressant agents causing bone marrow suppression and abrupt cessation of erythropoietin are among the factors that may affect $\mathrm{HbA}_{1 \mathrm{c}}$ levels early after kidney transplantation [38].The usage of $\mathrm{HbA}_{1 \mathrm{c}}$ as a diagnostic criterion might therefore not apply in the early post-transplant period.

\section{Conclusions}

This study indicates that $2 \mathrm{hPG}$, when measured early after renal transplantation, is superior to $\mathrm{PPG}$ in predicting long- term all-cause and CV mortality. It also demonstrates that PTDM predicts both all-cause and CV mortality, whereas IGT predicts all-cause, but not CV mortality and finally that post-challenge hyperglycaemia predicts all-cause mortality and death from infectious disease. Post-challenge hyperglycaemia may be a predictor of long-term outcome in renal transplant patients, and an OGTT might provide a method to identify renal transplant recipients with increased risk of premature death.

Acknowledgements For their contribution to data we acknowledge the efforts of K. Midtvedt, H. Holdaas and A. Varberg Reisæter at Oslo University Hospital, Rikshospitalet, Section of Nephrology. Thanks are also due to K. Lund, J. Narverud, E. Breistein and J. Stenstrøm at the Laboratory of Renal Physiology for their laboratory assistance and to M. McGee (Morbid Obesity Centre, Vestfold Hospital Trust) for proofreading the manuscript. This study was funded by Oslo University Hospital, Rikshospitalet, Section of Nephrology.

Duality of interest The authors declare there to be no duality of interest associated with this manuscript.

Open Access This article is distributed under the terms of the Creative Commons Attribution Noncommercial License which permits any noncommercial use, distribution, and reproduction in any medium, provided the original author(s) and source are credited.

\section{References}

1. Briggs JD (2001) Causes of death after renal transplantation. Nephrol Dial Transplant 16:1545-1549

2. Miller LW (2002) Cardiovascular toxicities of immunosuppressive agents. Am J Transplant 2:807-818

3. Kasiske BL, Chakkera HA, Roel J (2000) Explained and unexplained ischemic heart disease risk after renal transplantation. J Am Soc Nephrol 11:1735-1743

4. Levitan EB, Song Y, Ford ES, Liu S (2004) Is nondiabetic hyperglycemia a risk factor for cardiovascular disease? A metaanalysis of prospective studies. Arch Intern Med 164:2147-2155

5. Stattin P, Bjor O, Ferrari P et al (2007) Prospective study of hyperglycemia and cancer risk. Diab Care 30:561-567

6. deVegt F, Dekker JM, Ruhe HG et al (1999) Hyperglycaemia is associated with all-cause and cardiovascular mortality in the Hoorn population: the Hoorn Study. Diabetologia 42:926-931

7. DECODE study group (1999) Glucose tolerance and mortality: comparison of WHO and American Diabetes Association diagnostic criteria. The DECODE study group. European Diabetes Epidemiology Group. Diabetes Epidemiology: Collaborative analysis Of Diagnostic criteria in Europe. Lancet 354:617-621

8. Kasiske BL, Snyder JJ, Gilbertson D, Matas AJ (2003) Diabetes mellitus after kidney transplantation in the United States. Am J Transplant 3:178-185

9. Revanur VK, Jardine AG, Kingsmore DB, Jaques BC, Hamilton DH, Jindal RM (2001) Influence of diabetes mellitus on patient and graft survival in recipients of kidney transplantation. Clin Transplant 15:89-94

10. Cosio FG, Pesavento TE, Kim S, Osei K, Henry M, Ferguson RM (2002) Patient survival after renal transplantation: IV. Impact of post-transplant diabetes. Kidney Int 62:1440-1446 
11. Hjelmesaeth J, Hartmann A, Leivestad T et al (2006) The impact of early-diagnosed new-onset post-transplantation diabetes mellitus on survival and major cardiac events. Kidney Int 69:588-595

12. Miles AM, Sumrani N, Horowitz R et al (1998) Diabetes mellitus after renal transplantation: as deleterious as non-transplantassociated diabetes? Transplantation 65:380-384

13. Valderhaug TG, Jenssen T, Hartmann A et al (2009) Fasting plasma glucose and glycosylated hemoglobin in the screening for diabetes mellitus after renal transplantation. Transplantation $88: 429-434$

14. DECODE study group (1999) Is fasting glucose sufficient to define diabetes? Epidemiological data from 20 European studies. The DECODE-study group. European Diabetes Epidemiology Group. Diabetes Epidemiology: Collaborative analysis of Diagnostic Criteria in Europe. Diabetologia 42:647-654

15. Hofso D, Jenssen T, Hager H, Roislien J, Hjelmesaeth J (2010) Fasting plasma glucose in the screening for type 2 diabetes in morbidly obese subjects. Obes Surg 20:302-307

16. Valderhaug TG, Hjelmesaeth J, Rollag H et al (2007) Reduced incidence of new-onset posttransplantation diabetes mellitus during the last decade. Transplantation 84:1125-1130

17. World Medical Association (2000) World Medical Association Declaration of Helsinki: ethical principles for medical research involving human subjects. JAMA 284:3043-3045

18. Rustad P, Felding P, Franzson L et al (2004) The Nordic Reference Interval Project 2000: recommended reference intervals for 25 common biochemical properties. Scand J Clin Lab Invest 64:271-284

19. D’Orazio P, Burnett RW, Fogh-Andersen N et al (2006) Approved IFCC recommendation on reporting results for blood glucose: International Federation of Clinical Chemistry and Laboratory Medicine Scientific Division, Working Group on Selective Electrodes and Point-of-Care Testing (IFCC-SD-WG-SEPOCT). Clin Chem Lab Med 44:1486-1490

20. American Diabetes Association (2010) Standards of Medical Care in Diabetes 2010. Diab Care 33:S11-S61

21. The Norwegian Renal Registry (2009) The Norwegian Renal Registry. Annual report 2008. Available from: www.nephro.no/ nnr/AARSM2008.pdf, accessed 17 Dec 2009

22. Svennevig JL, Bech J, Karlsen H, Amlie E, Olsen A (1995) From a registry to a clinical information system. Development of the Datacor system at the surgery department A, Rikshospitalet. Tidsskr Nor Laegeforen 115:1057-1059, article in Norwegian

23. Rollag H, Sagedal S, Kristiansen KI et al (2002) Cytomegalovirus DNA concentration in plasma predicts development of cytomegalovirus disease in kidney transplant recipients. Clin Microbiol Infect 8:431-434

24. van Dijk PCW, Jager KJ, de Charro F et al (2001) Renal replacement therapy in Europe: the results of a collaborative effort by the ERA-EDTA registry and six national or regional registries. Nephrol Dial Transplant 16:1120-1129
25. Newgard CD, Haukoos JS (2007) Advanced statistics: missing data in clinical research-part 2: multiple imputation. Acad Emerg Med 14:669-678

26. Royston P, Ambler G, Sauerbrei W (1999) The use of fractional polynomials to model continuous risk variables in epidemiology. Int J Epidemiol 28:964-974

27. Harrell FE Jr, Lee KL, Mark DB (1996) Multivariable prognostic models: issues in developing models, evaluating assumptions and adequacy, and measuring and reducing errors. Stat Med 15:361-387

28. Pencina MJ, D'Agostino RB (2004) Overall C as a measure of discrimination in survival analysis: model specific population value and confidence interval estimation. Stat Med 23:2109-2123

29. Metter EJ, Windham BG, Maggio M et al (2008) Glucose and insulin measurements from the oral glucose tolerance test and mortality prediction. Diab Care 31:1026-1030

30. Barr EL, Boyko EJ, Zimmet PZ, Wolfe R, Tonkin AM, Shaw JE (2009) Continuous relationships between non-diabetic hyperglycaemia and both cardiovascular disease and all-cause mortality: the Australian Diabetes, Obesity, and Lifestyle (AusDiab) study. Diabetologia 52:415-424

31. Sarwar N, Gao P, Seshasai SR et al (2010) Diabetes mellitus, fasting blood glucose concentration, and risk of vascular disease: a collaborative meta-analysis of 102 prospective studies. Lancet 375:2215-2222

32. Nakagami T (2004) Hyperglycaemia and mortality from all causes and from cardiovascular disease in five populations of Asian origin. Diabetologia 47:385-394

33. Department of Noncommunicable Disease Surveillance WHO (1999) Definition, diagnosis and classification of diabetes mellitus and its complications. Report of a WHO consultation. Part 1. Diagnosis and classification of diabetes mellitus. Geneva, World Health Organization. Available from: http://whqlibdoc.who.int/hq/ 1999/WHO NCD NCS 99.2.pdf. Accessed 13 March 2006

34. Barr EL, Zimmet PZ, Welborn TA et al (2007) Risk of cardiovascular and all-cause mortality in individuals with diabetes mellitus, impaired fasting glucose, and impaired glucose tolerance: the Australian Diabetes, Obesity, and Lifestyle Study (AusDiab). Circulation 116:151-157

35. Department of Noncommunicable Disease Management WHO (2003) Screening for type 2 diabetes. Report of a World Health Organization and International Diabetes Federation meeting. Geneva, World Health Organization. Available from: http://whqlibdoc.who.int/ hq/2003/WHO_NMH_MNC_03.1.pdf. Accessed 23 June 2010

36. Armstrong KA, Prins JB, Bëller EM et al (2006) Should an oral glucose tolerance test be performed routinely in all renal transplant recipients? Clin J Am Soc Nephrol 1:100-108

37. Bergrem HA, Valderhaug TG, Hartmann A et al (2010) Undiagnosed diabetes in kidney transplant candidates: a casefinding strategy. Clin J Am Soc Nephrol 5:616-622

38. Winkelmayer WC, Chandraker A (2008) Pottransplantation anemia: management and rationale. Clin J Am Soc Nephrol 3 (Suppl 2):S49-S55 
